\title{
Investigation on the Coprecipitation of Transuranium Elements from Alkaline Solutions by the Method of Appearing Reagents
}

\author{
N. Krot \\ V. Shilov \\ A. Bessonov \\ N. Budantseva \\ 1. Charushnikova \\ V. Perminov \\ L. Astafurova \\ Institute of Physical Chemistry \\ of the Russian Academy of Sciences \\ Date Published \\ June 1996
}

Prepared for the U.S. Department of Energy

Assistant Secretary for Environmental Management Office of Science and Technology

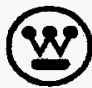

Management and Operations Contractor for the

U.S. Department of Energy under Contract DE-AC06-87RL 10930

Approved for public release; distribution is unlimited 


\section{RELEASE AUTHORIZATION}

Document Number: WHC-EP-0898

Investigation on the Coprecipitation of Transuranium

Document Title: Elements from Alkaline Solutions by the Method of Appearing Reagents

Release Date: $\quad 6 / 6 / 96$

This document was reviewed following the procedures described in WHC-CM-3-4 and is:

APPROVED FOR PUBLIC RELEASE

WHC Information Release Administration Specialist:

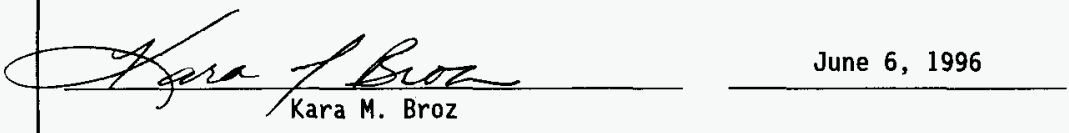




\section{LEQAL DISCLAMER}

This report was prepared as an account of work sponsored by an agency of the United States Govornment. Neither the United States Government nor any agency thereof, nor any of their employees, nor any of their contractors, subcontractors or their employees, makes any warranty, express or implied, or assumes any legal liability or responsibility for the accuracy. complateness, or any third party's use or the results of auch use of any information, apperatus, product, or process disclosed, or represents that its use would not infringe privately owned rights. Reference herein to any specific commercial product, process, or service by trade name, trademark, manufacturer, or otherwise, does not necessarily constitute or imply its endorsement, recommendation, or favoring by the United States Government or any agency thereof or its contractors or subcontractors. The views and opinions of authers expressed herein do not necessarily state or reflect those of the United States Government or any agency thereof.

This report hes been reproduced from the best available copy. Aveilable in paper copy and microfiche.

Aveilable to the U.S. Department of Energy and its contractors from

U.S. Department of Energy

Office of Scientific and Technical Information (OSTI)

P.O. Box 62

Oak Ridge, TN 37831

(615) 576-8401

Avalable to the public from the U.S. Department of Commerce National Technical Information Service (NTIS)

5285 Port Royal Roed

Springfield, VA 22161

(703) 487-4650

Printed in the United States of America

DISCLM-1.CHP (8-95) 


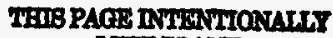

IEFPT BLANK 


\title{
INVESTIGATION ON THE COPRECIPITATION OF TRANSURANIUM ELEMENTS FROM ALKALINE SOLUTIONS BY THE METHOD OF APPEARING REAGENTS
}

\author{
N. Krot \\ V. Shilov \\ A. Bessonov \\ N. Budantseva \\ I. Charushnikova \\ V. Perminov \\ L. Astafurova \\ Institute of Physical Chemistry of \\ Russian Academy of Sciences
}

\begin{abstract}
Highly alkaline radioactive waste solutions originating from production of plutonium for military purposes are stored in underground tanks at the U.S. Department of Energy Hanford Site. The purification of alkaline solutions from neptunium and plutonium is important in the treatment and disposal of these wastes. This report describes scoping tests with sodium hydroxide solutions, where precipitation techniques were investigated to perform the separation. Hydroxides of iron(III), manganese(II), cobalt(II,III), and chromium(III); manganese (IV) oxide; and sodium uranate were investigated as carriers. The report describes the optimum conditions that were identified to precipitate these carriers homogeneously throughout the solution by reductive, hydrolytic, or catalytic decomposition of alkali-soluble precursor compounds (nitroprusside, ferrate, permanganate, cobalt ammine complexes, chromate, chromium(III) acetate, and peroxouranate) by a technique called the Method of Appearing Reagents. The coprecipitation of pentavalent and hexavalent neptunium
\end{abstract}


and plutonium was investigated for the candidate agents under optimum conditions and is described in this report along with the following results. Plutonium coprecipitated well with all tested materials except manganese(IV) oxide. Neptunium only coprecipitated well with uranate. The report presents a hypothesis to explain these behaviors. Further tests with more complex solution matrices must be performed. 


\section{EXECUTIVE SUMMARY}

This report describes the results of transuranium element coprecipitation research completed as a part of an agreement between the U.S. Department of Energy and the Institute of Physical Chemistry of the Russian Academy of Sciences. The work was supported by the Office of Science and Technology under the Office of Environmental Management of the U.S. Department of Energy. The agreement is concerned with solving the problem of decontaminating high-level alkaline radioactive wastes of complex composition accumulated during military plutonium production on the Hanford Site and now stored in underground tanks. The purification of alkaline solutions from long-lived neptunium, plutonium, and americium isotopes is an important stage in treatment and disposal of the alkaline wastes. Coprecipitation of transuranium elements with carriers obtained in alkaline solutions by the Method of Appearing Reagents is a possible method to solve this problem. Scientific substantiation of the method is the subject of this research program.

In the initial part of the research, Mn(IV) oxide; $\mathrm{Mn}$ (II), $\mathrm{Fe}$ (III), $\mathrm{Co}$ (III) and (II), and $\mathrm{Cr}$ (III) hydroxides; and sodium uranates were selected as candidate carriers for the transuraniumelement coprecipitation from alkaline solution. Reduction of $\mathrm{MnO}_{4}^{-}$or $\mathrm{MnO}_{4}^{2-}$ produces the first two carriers in alkalis by the Method of Appearing Reagents. The hydroxides of Fe(III) and $\mathrm{Cr}(\mathrm{III})$ may be prepared in an analogous way using $\mathrm{FeO}_{4}^{2-}$ and $\mathrm{CrO}_{4}^{2-}$ as initial reagents. These carriers also may be obtained by heating nitroprusside or $\mathrm{Cr}(\mathrm{III})$ hydroxo complexes in alkaline solution. The soluble $\left[\mathrm{Co}\left(\mathrm{NH}_{3}\right)_{6}\right]^{3+}$ or $\left[\mathrm{Co}\left(\mathrm{NH}_{3}\right)_{5} \mathrm{Cl}\right]^{2+}$ complexes can be decomposed by heating and hydrolysis to produce Co(III) hydroxide. The hydrolysis of 
cobalt ammine complexes in the presence of strong reductants yields a Co(II) hydroxide precipitate. The preparation of sodium uranates can be easily carried out by the catalytic decomposition of uranyl peroxo complexes directly in alkaline solution. Particular attention was given to deriving optimum conditions for the precipitation of selected carriers from alkaline solutions.

In the second part of the report, results are given of the investigation of the coprecipitation of $\mathrm{Np}(\mathrm{V}, \mathrm{VI})$ and $\mathrm{Pu}(\mathrm{V}, \mathrm{VI})$ from alkaline solutions with the selected carriers [Mn(IV) oxide; hydroxides of $\mathrm{Fe}(\mathrm{III}), \mathrm{Mn}(\mathrm{II}), \mathrm{Co}(\mathrm{II}, \mathrm{III}), \mathrm{Cr}(\mathrm{III})$; and sodium uranates], obtained by the Method of Appearing Reagents. Carriers were isolated from alkaline solutions under the optimum conditions (with respect to kinetics and completeness of precipitate isolation) determined in the first part of this research.

Independent of the initial oxidation state (VI or V), plutonium coprecipitates well from alkaline solution with $\mathrm{Fe}(\mathrm{OH})_{3}$ obtained by reducing $\mathrm{FeO}_{4}^{2-}$ with hydrazine or by the hydrolysis of $\left[\mathrm{Fe}(\mathrm{CN})_{5} \mathrm{NO}\right]^{2-}$, with $\mathrm{Co}(\mathrm{OH})_{3}$ precipitated by thermal decomposition of $\left[\mathrm{Co}\left(\mathrm{NH}_{3}\right)_{6}\right]^{3+}$ or $\left[\mathrm{Co}\left(\mathrm{NH}_{3}\right)_{5} \mathrm{Cl}\right]^{2+}$, with $\mathrm{Cr}(\mathrm{OH})_{3}$ formed by heating $\mathrm{Cr}(\mathrm{III})$ hydroxo complexes, and with sodium uranates formed by catalytic decomposition of $\left[\mathrm{UO}_{2}\left(\mathrm{O}_{2}\right)_{3}\right]^{4-}$. Plutonium can be captured almost completely by precipitates of $\mathrm{Mn}(\mathrm{OH})_{2}$ and $\mathrm{Co}(\mathrm{OH})_{2}$ (obtained by the reduction of $\mathrm{MnO}_{4}$ with hydroxylamine and by hydrolysis of $\left[\mathrm{Co}\left(\mathrm{NH}_{3}\right)_{5} \mathrm{Cl}\right]^{2+}$ in the presence of $\mathrm{N}_{2} \mathrm{H}_{4}$, respectively) but only from solutions with $\mathrm{NaOH}$ concentration lower than $4 \mathrm{M}$. With manganese dioxide, $\mathrm{Pu}(\mathrm{VI})$ and $(\mathrm{V})$ are coprecipitated poorly. 
In contrast with plutonium, neptunium, present in the initial alkaline solution in the hexa- or pentavalent state, coprecipitates only to a small extent with all the previously mentioned carriers except sodium uranates. A hypothesis to explain this phenomenon is offered. 


\section{CONTENTS}

PART 1. SELECTION OF CARRIERS AND DETERMINATION OF THE OPTIMUM CONDITIONS FOR THEIR PRECIPITATION $\ldots \ldots \ldots \ldots 1.1-1$

1.0 INTRODUCTION

2.0 EXPERIMENTAL MATERIALS AND METHODS $\ldots \ldots \ldots \ldots \ldots \ldots$ 1.2-1

2.1 REAGENTS AND EQUIPMENT $\ldots \ldots \ldots \ldots \ldots \ldots \ldots \ldots \ldots \ldots$

2.2 EXPERIMENTAL METHODS $\ldots \ldots \ldots \ldots \ldots \ldots \ldots \ldots \ldots \ldots \ldots . .2-1$

2.3 CHOICE OF INITIAL COMPOUNDS $\ldots \ldots \ldots \ldots \ldots \ldots \ldots \ldots . .2-2$

3.0 RESULTS AND DISCUSSION $\ldots \ldots \ldots \ldots \ldots \ldots \ldots \ldots \ldots \ldots \ldots \ldots \ldots .1 .3-1$

3.1 MANGANESE DIOXIDE ISOLATION FROM

$\mathrm{MnO}_{4}^{-}$AND $\mathrm{MnO}_{4}^{2-}$ ALKALINE SOLUTIONS $\ldots \ldots \ldots \ldots \ldots \ldots$. . . $\ldots \ldots$

3.2 MANGANESE(II) HYDROXIDE ISOLATION FROM

$\mathrm{MnO}_{4}^{-}$AND $\mathrm{MnO}_{4}^{2-}$ ALKALINE SOLUTIONS $\ldots \ldots \ldots \ldots \ldots \ldots$

3.3 IRON(III) HYDROXIDE ISOLATION

FROM FeO ${ }_{4}^{2-}$ ALKALINE SOLUTIONS $\ldots \ldots \ldots \ldots \ldots \ldots \ldots$ 1.3-10

3.4 IRON(III) HYDROXIDE ISOLATION

FROM NITROPRUSSIDE ALKALINE SOLUTIONS $\ldots \ldots \ldots \ldots$. . . . . . .

3.5 SODIUM URANATE ISOLATION FROM

$\left[\mathrm{UO}_{2}\left(\mathrm{O}_{2}\right)_{3}\right]^{4-}$ ALKALINE SOLUTTONS $\ldots \ldots \ldots \ldots \ldots \ldots \ldots \ldots .3 .14$

3.6 COBALT(III) HYDROXIDE ISOLATION FROM $\left[\mathrm{Co}\left(\mathrm{NH}_{3}\right)_{6}\right]^{3+}$

AND $\left[\mathrm{Co}\left(\mathrm{NH}_{3}\right)_{5} \mathrm{Cl}\right]^{2+}$ ALKALINE SOLUTIONS $\ldots \ldots \ldots \ldots \ldots .3 .3 .20$

3.7 COBALT(II) HYDROXIDE ISOLATION FROM $\left[\mathrm{Co}\left(\mathrm{NH}_{3}\right)_{6}\right]^{3+}$

AND $\left[\mathrm{Co}\left(\mathrm{NH}_{3}\right)_{5} \mathrm{Cl}\right]^{2+}$ ALKALINE SOLUTIONS $\ldots \ldots \ldots \ldots \ldots$. . . . $\ldots \ldots$

3.8 CHROMIUM(III) HYDROXIDE ISOLATION FROM

$\mathrm{CrO}_{4}^{2-}$ OR Cr(III) ALKALINE SOLUTIONS $\ldots \ldots \ldots \ldots \ldots \ldots \ldots$ 1.3-27

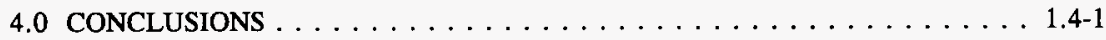

PART 2. COPRECIPITATION OF Np(VI,V) AND Pu(VI,V)

WITH THE SELECTED CARRIERS $\ldots \ldots \ldots \ldots \ldots \ldots \ldots \ldots .1-1$

1.0 INTRODUCTION $\ldots \ldots \ldots \ldots \ldots \ldots \ldots \ldots \ldots \ldots \ldots \ldots \ldots \ldots \ldots \ldots .1-1$

2.0 EXPERIMENTAL MATERIALS AND METHODS $\ldots \ldots \ldots \ldots \ldots \ldots .2 .2-1$

2.1 REAGENTS AND EQUIPMENT $\ldots \ldots \ldots \ldots \ldots \ldots \ldots \ldots \ldots .2 .1$

2.2 EXPERIMENTAL METHODS $\ldots \ldots \ldots \ldots \ldots \ldots \ldots \ldots \ldots \ldots \ldots \ldots .2-2$

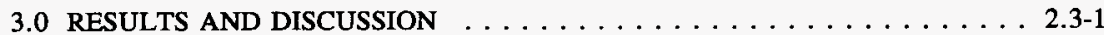

3.1 COPRECIPITATION OF Np(VI,V) AND Pu(VI,V) WITH

COBALT(III) HYDROXIDE . . . . . . . . . . . . . 2.3-1 


\section{CONTENTS (Continued)}

3.2 COPRECIPITATION OF Np(VI,V) AND Pu(VI,V)

WITH COBALT(II) HYDROXIDE

3.3 COPRECIPITATION OF Np(VI,V) AND Pu(VI,V)

WITH CHROMIUM(III) HYDROXIDE . . . . . . . . . . . . . . . . 2.3-9

3.4 COPRECIPITATION OF Np(VI,V) AND Pu(VI,V)

WITH IRON(III) HYDROXIDE $\ldots \ldots \ldots \ldots \ldots \ldots \ldots . . .2 .3 .12$

3.5 COPRECIPITATION OF Np(VI,V) AND Pu(VI,V)

WITH MANGANESE DIOXIDE . . . . . . . . . . . . . . . . 2.3-19

3.6 COPRECIPITATION OF Np(VI,V) AND Pu(VI,V) WITH MANGANESE(II) HYDROXIDE $\ldots \ldots \ldots \ldots \ldots \ldots \ldots .3 .21$

3.7 COPRECIPITATION OF Np(VI,V) AND Pu(VI,V) WITH

SODIUM URANATES $\ldots \ldots \ldots \ldots \ldots \ldots \ldots \ldots \ldots \ldots \ldots \ldots .2 .3 .23$

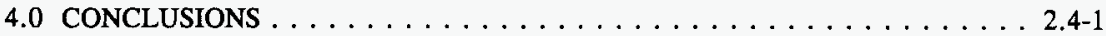

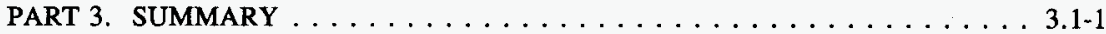

1.0 DISCUSSION OF THE RESULTS $\ldots \ldots \ldots \ldots \ldots \ldots \ldots \ldots \ldots \ldots \ldots$

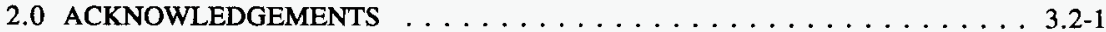

3.0 REFERENCES . . . . . . . . . . . . . . . . . . . 


\section{LIST OF FIGURES}

1.3-1 Solubility of $\mathrm{Mn}(\mathrm{OH})_{2}$ in $\mathrm{NaOH}$ or $\mathrm{KOH}$ Solutions $\ldots \ldots \ldots \ldots \ldots$. . . . . . .

1.3-2 Influence of $\mathrm{NaOH}$ Concentration and Temperature on the Residual Fe(III)

Solution Concentration after Reduction of $2.5 \times 10^{-2} \mathrm{M} \mathrm{FeO}_{4}^{2-}$

by $4 \times 10^{-2} \mathrm{M}$ Hydrazine $\ldots \ldots \ldots \ldots \ldots \ldots \ldots \ldots \ldots \ldots \ldots \ldots \ldots \ldots \ldots \ldots .12$

1.3-3 Kinetic Curves for the Hydrolysis of $2.3 \times 10^{-2} \mathrm{M}\left[\mathrm{Fe}(\mathrm{CN})_{5} \mathrm{NO}\right]^{2-}$ in

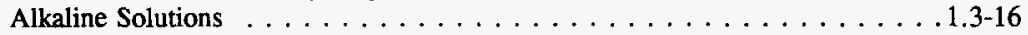

1.3-4 Dependence of $\mathrm{Na}_{4} \mathrm{UO}_{2}\left(\mathrm{O}_{2}\right)_{3} \cdot 9 \mathrm{H}_{2} \mathrm{O}$ Solubility on $\mathrm{NaOH}$

Concentration at $25{ }^{\circ} \mathrm{C} \ldots \ldots \ldots \ldots \ldots \ldots \ldots \ldots \ldots \ldots \ldots \ldots \ldots \ldots .17$

1.3-5 Rate of Sodium Uranate Precipitation from $4 \times 10^{-3} \mathrm{M}\left[\mathrm{UO}_{2}\left(\mathrm{O}_{2}\right)_{3}\right]^{4-}$

Alkaline Solutions in the Presence of $5 \times 10^{-3} \mathrm{M} \mathrm{Cu}$ (II) $\ldots \ldots \ldots \ldots$. . . . . . .

1.3-6 $\mathrm{Co}(\mathrm{III})$ Concentration Decrease on Heating $0.1 \mathrm{M}\left[\mathrm{Co}\left(\mathrm{NH}_{3}\right)_{6}\right]^{3+}$

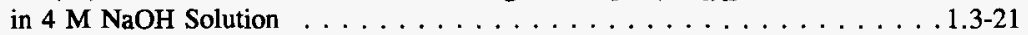

1.3-7 Influence of $\mathrm{NaOH}$ Concentration on $0.1 \mathrm{M}\left[\mathrm{Co}\left(\mathrm{NH}_{3}\right)_{6}\right]^{3+}$

Decomposition at $80{ }^{\circ} \mathrm{C} \ldots \ldots \ldots \ldots \ldots \ldots \ldots \ldots \ldots \ldots \ldots \ldots \ldots \ldots .22$

1.3-8 Co(III) Concentration Decrease on Heating of $0.1 \mathrm{M}\left[\mathrm{Co}\left(\mathrm{NH}_{3}\right)_{5} \mathrm{Cl}\right]^{2+}$

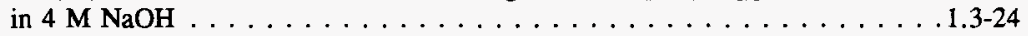

1.3-9 Influence of $\mathrm{NaOH}$ Concentration on $0.1 \mathrm{M}\left[\mathrm{Co}\left(\mathrm{NH}_{3}\right)_{5} \mathrm{Cl}\right]^{2+}$

Decomposition at $60{ }^{\circ} \mathrm{C} \ldots \ldots \ldots \ldots \ldots \ldots \ldots \ldots \ldots \ldots \ldots \ldots \ldots \ldots \ldots .25$

1.3-10 Cobalt Concentration Decrease on Heating of $0.1 \mathrm{M}\left[\mathrm{Co}\left(\mathrm{NH}_{3}\right)_{5} \mathrm{Cl}^{2+}\right.$

in $4 \mathrm{M} \mathrm{NaOH}$ in the Presence of $0.2 \mathrm{M} \mathrm{N}_{2} \mathrm{H}_{4} \ldots \ldots \ldots \ldots \ldots \ldots .3-26$

1.3-11 Kinetic Curves for $0.05 \mathrm{M} \mathrm{CrO}_{4}^{2-}$ Reduction by $0.19 \mathrm{M}$ Hydroxylamine

in Alkaline Solution at $70^{\circ} \mathrm{C} \ldots \ldots \ldots \ldots \ldots \ldots \ldots \ldots \ldots \ldots \ldots \ldots .3 .28$

1.3-12 Kinetic Curves for $0.05 \mathrm{M} \mathrm{CrO}_{4}^{2-}$ Reduction by $0.09 \mathrm{M}$ Hydrazine in Alkaline Solutions at $70^{\circ} \mathrm{C} \ldots \ldots \ldots \ldots \ldots \ldots \ldots \ldots \ldots \ldots \ldots \ldots .3 .29$

1.3-13 Variation of $\mathrm{Cr}(\mathrm{III})$ Concentration with Heating Time for $0.083 \mathrm{M} \mathrm{Cr}\left(\mathrm{CH}_{3} \mathrm{COO}\right)_{3}$ and $4 \mathrm{M} \mathrm{NaOH}$ Solutions $\ldots \ldots \ldots \ldots \ldots .3-31$

1.3-14 $\mathrm{Cr}$ (III) Hydroxide Precipitation at $80^{\circ} \mathrm{C}$ and $0.083 \mathrm{M} \mathrm{Cr}\left(\mathrm{CH}_{3} \mathrm{COO}\right)_{3}$ in Various $\mathrm{NaOH}$ Solutions $\ldots \ldots \ldots \ldots \ldots \ldots .3-32$ 


\section{LIST OF TABLES}

1.3-1 Estimated Time of Coagulation ( $\mathrm{t}$ ) of $\delta-\mathrm{MnO}_{2}$ in Various Conditions by the Reaction of $\mathrm{KMnO}_{4}$ with $0.02 \mathrm{M} \mathrm{H}_{2} \mathrm{O}_{2}$ in $\mathrm{NaOH}$ Solutions . . . . . 1.3-3

1.3-2 The Influence of Conditions on the Time of Reduction ( $t$ ) of $3.6 \times 10^{-3} \mathrm{M}$ $\mathrm{KMnO}_{4}$ to $\delta-\mathrm{MnO}_{2}$ by Sulfite in $\mathrm{NaOH}$ Solutions $\ldots \ldots \ldots$. . . . . . . .

1.3-3 The Influence of Conditions on Time of Reduction $(\mathrm{t})$ of $3.6 \times 10^{-3} \mathrm{M} \mathrm{KMnO}_{4}$ to $\delta-\mathrm{MnO}_{2}$ by Formate in $\mathrm{NaOH}$ Solutions $\ldots \ldots \ldots \ldots \ldots$. . . . . . . . .

1.3-4 Reduction of $\mathrm{KMnO}_{4}$ to $\mathrm{Mn}(\mathrm{OH})_{2}$ by $0.05 \mathrm{M} \mathrm{N}_{2} \mathrm{H}_{4} \ldots \ldots \ldots$

1.3-5 Estimated Time of $\mathrm{Mn}(\mathrm{OH})_{2}$ Coagulation (t) Under Various Conditions by the Reaction of $\mathrm{KMnO}_{4}$ with $0.05 \mathrm{M} \mathrm{NH}_{2} \mathrm{OH}$ in $\mathrm{NaOH}$ Solutions . . . . . . . . . 1.3-9

1.3-6 The Influence of Conditions on Completeness of Fe(III) Hydroxide Separation from $2.5 \times 10^{-2} \mathrm{M} \mathrm{FeO}_{4}^{2-}$ Solutions After Addition of $4 \times 10^{-2} \mathrm{M} \mathrm{N}_{2} \mathrm{H}_{4} \ldots \ldots$. $\ldots$.11

1.3-7 The Influence of Various Parameters on $\left[\mathrm{Fe}(\mathrm{CN})_{5} \mathrm{NO}\right]^{2-}$ Hydrolysis in $\mathrm{NaOH}$ Solutions . . . . . . . . . . . . . .

2.3-1 Decontamination of $\mathrm{NaOH}$ Solutions from Pu(VI) by the Precipitation of $\mathrm{Co}$ (III) Hydroxide from Hydrolysis of $\left[\mathrm{Co}\left(\mathrm{NH}_{3}\right)_{6}\right]^{3+} \ldots \ldots \ldots \ldots$

2.3-2 Decontamination of $\mathrm{NaOH}$ Solutions from $\mathrm{Pu}(\mathrm{VI})$ by the Precipitation of $\mathrm{Co}$ (III) Hydroxide from the Hydrolysis of $\left[\mathrm{Co}\left(\mathrm{NH}_{3}\right)_{5} \mathrm{Cl}\right]^{2+} \ldots \ldots$. . . . . . . . 2-3

2.3-3 Decontamination of $\mathrm{NaOH}$ Solutions from $\mathrm{Pu}(\mathrm{V})$ by the Precipitation of Co(III) Hydroxide from the Hydrolysis of $\left[\mathrm{Co}\left(\mathrm{NH}_{3}\right)_{6}\right]^{3+} \ldots \ldots \ldots$ 2.3-4

2.3-4 Decontamination of $\mathrm{NaOH}$ Solutions from $\mathrm{Pu}(\mathrm{V})$ by the Precipitation of $\mathrm{Co}$ (III) Hydroxide from the Hydrolysis of $\left[\mathrm{Co}\left(\mathrm{NH}_{3}\right)_{5} \mathrm{Cl}\right]^{2+} \ldots \ldots \ldots \ldots$

2.3-5 Decontamination of $\mathrm{NaOH}$ Solutions from $\mathrm{Np}(\mathrm{VI})$ by the Precipitation of $\mathrm{Co}$ (III) Hydroxide from the Hydrolysis of $\left[\mathrm{Co}\left(\mathrm{NH}_{3}\right)_{6}\right]^{3+} \ldots \ldots \ldots \ldots$

2.3-6 Decontamination of $\mathrm{NaOH}$ Solutions from $\mathrm{Np}(\mathrm{V})$ by the Precipitation of $\mathrm{Co}$ (III) Hydroxide from the Hydrolysis of $\left[\mathrm{Co}\left(\mathrm{NH}_{3}\right)_{6}\right]^{3+} \ldots \ldots$. . . . . . . . .

2.3-7 Decontamination of $\mathrm{NaOH}$ Solutions from $\mathrm{Np}(\mathrm{V})$ by the Precipitation of $\mathrm{Co}$ (III) Hydroxide from the Hydrolysis of $\left[\mathrm{Co}\left(\mathrm{NH}_{3}\right)_{5} \mathrm{Cl}\right]^{2+} \ldots \ldots \ldots \ldots$ 


\section{LIST OF TABLES (Continued)}

2.3-8 Decontamination of $\mathrm{NaOH}$ Solutions from Pu(VI) by the Precipitation of $\mathrm{Co}(\mathrm{OH})_{2}$ from the Hydrolysis of $\left[\mathrm{Co}\left(\mathrm{NH}_{3}\right)_{5} \mathrm{Cl}\right]^{2+}$ in the Presence of $0.1 \mathrm{M} \mathrm{N}_{2} \mathrm{H}_{4}$ 2.3-7

2.3-9 Decontamination of $\mathrm{NaOH}$ Solutions from $\mathrm{Np}(\mathrm{V})$ by the Precipitation of $\mathrm{Co}(\mathrm{OH})_{2}$ from the Hydrolysis of $\left[\mathrm{Co}\left(\mathrm{NH}_{3}\right)_{5} \mathrm{Cl}\right]^{2+}$ in the Presence of $0.1 \mathrm{M} \mathrm{N}_{2} \mathrm{H}_{4}$ 2.3-8

2.3-10 Decontamination of $\mathrm{NaOH}$ Solutions from $\mathrm{Pu}(\mathrm{VI})$ by the Precipitation of Cr(III) Hydroxide from $\mathrm{Cr}\left(\mathrm{OOCCH}_{3}\right)_{3}$ Hydrolysis . . . . . . . . . . . . . 2.3-10

2.3-11 Decontamination of $\mathrm{NaOH}$ Solutions from $\mathrm{Pu}(\mathrm{V})$ by the Precipitation of

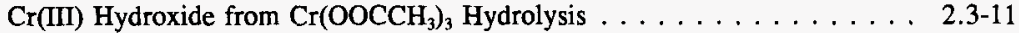

2.3-12 Decontamination of $\mathrm{NaOH}$ Solutions from $\mathrm{Np}(\mathrm{V})$ by the Precipitation of $\mathrm{Cr}(\mathrm{III}) \mathrm{Hydroxide}$ from $\mathrm{Cr}\left(\mathrm{OOCCH}_{3}\right)_{3}$ Hydrolysis . . . . . . . . . . . . 2.3-12

2.3-13 Decontamination of $\mathrm{NaOH}$ Solutions from Pu(VI) by the Precipitation of $\mathrm{Fe}(\mathrm{III}) \mathrm{Hydroxide}$ from $\mathrm{FeO}_{4}^{2-}$ Reduction with $0.02 \mathrm{M}$ Excess $\mathrm{N}_{2} \mathrm{H}_{4} \ldots \ldots$ 2.3-13

2.3-14 Decontamination of $\mathrm{NaOH}$ Solutions from $\mathrm{Pu}(\mathrm{VI})$ by the Precipitation of Fe(III) Hydroxide from $\left[\mathrm{Fe}(\mathrm{CN})_{5} \mathrm{NO}^{2-}\right.$ Hydrolysis $\ldots \ldots \ldots \ldots$. . . . . . . . . . . .

2.3-15 Decontamination of $\mathrm{NaOH}$ Solutions from $\mathrm{Pu}(\mathrm{V})$ by the Precipitation of $\mathrm{Fe}(\mathrm{III}) \mathrm{Hydroxide}$ from $\left[\mathrm{Fe}(\mathrm{CN})_{5} \mathrm{NO}^{2-}\right.$ Hydrolysis $\ldots \ldots \ldots$. . . . . . . . . . . . .

2.3-16 Decontamination of $\mathrm{NaOH}$ Solutions from $\mathrm{Np}(\mathrm{VI})$ by the Precipitation of Fe(III) Hydroxide from $\mathrm{FeO}_{4}^{2-}$ Reduction with $0.02 \mathrm{M}$ Excess $\mathrm{N}_{2} \mathrm{H}_{4} \ldots \ldots$ 2.3-17

2.3-17 Decontamination of $\mathrm{NaOH}$ Solutions from $\mathrm{Np}(\mathrm{VI})$ by the Precipitation of $\mathrm{Fe}(\mathrm{III}) \mathrm{Hydroxide}$ from $\left[\mathrm{Fe}(\mathrm{CN})_{5} \mathrm{NO}^{2-}\right.$ Hydrolysis $\ldots \ldots \ldots \ldots$. . . . . . . . . . .

2.3-18 Decontamination of $\mathrm{NaOH}$ Solutions from $\mathrm{Np}(\mathrm{V})$ by the Precipitation of

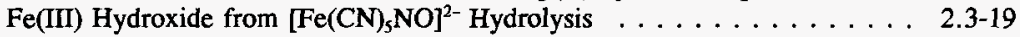

2.3-19 Decontamination of $\mathrm{NaOH}$ Solutions from $\mathrm{Pu}(\mathrm{VI})$ by the Precipitation of $\mathrm{MnO}_{2}$ from $\mathrm{MnO}_{4}^{-}$Reduction with $0.05 \mathrm{M} \mathrm{H}_{2} \mathrm{O}_{2} \ldots \ldots \ldots \ldots$ 2.3-20

2.3-20 Decontamination of $\mathrm{NaOH}$ Solutions from $\mathrm{Np}(\mathrm{VI})$ by the Precipitation of $\mathrm{MnO}_{2}$ from $\mathrm{MnO}_{4}^{-}$Reduction with $0.05 \mathrm{M} \mathrm{H}_{2} \mathrm{O}_{2} \ldots \ldots \ldots$ 2.3-21

2.3-21 Decontamination of $\mathrm{NaOH}$ Solutions from $\mathrm{Pu}(\mathrm{VI})$ by the Precipitation of $\mathrm{Mn}(\mathrm{OH})_{2}$ from $\mathrm{MnO}_{4}^{-}$Reduction with $0.05 \mathrm{M} \mathrm{NH}_{2} \mathrm{OH} \ldots \ldots \ldots$ 2.3-22 


\section{LIST OF TABLES (Continued)}

2.3-22 Decontamination of $\mathrm{NaOH}$ Solutions from $\mathrm{Np}(\mathrm{VI})$ by the Precipitation of $\mathrm{Mn}(\mathrm{OH})_{2}$ by $\mathrm{MnO}_{4}^{-}$Reduction with $0.05 \mathrm{M} \mathrm{NH}_{2} \mathrm{OH} \ldots \ldots$ 2.3-23

2.3-23 Decontamination of $\mathrm{NaOH}$ Solutions from $\mathrm{Pu}(\mathrm{VI})$ by Sodium Uranate Precipitation from the Catalytic Decomposition of

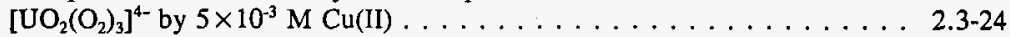

2.3-24 Decontamination of $\mathrm{NaOH}$ Solutions from $\mathrm{Pu}(\mathrm{V})$ by Sodium Uranate Precipitation from the Catalytic Decomposition of

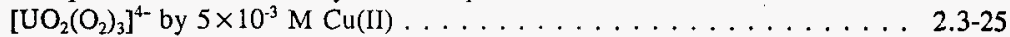

2.3-25 Decontamination of $\mathrm{NaOH}$ Solutions from $\mathrm{Np}$ (VI) by Sodium Uranate Precipitation from the Catalytic Decomposition of

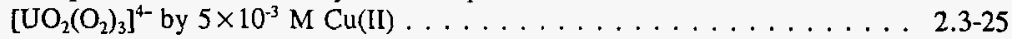

2.3-26 Decontamination of $\mathrm{NaOH}$ Solutions from $\mathrm{Np}(\mathrm{V})$ by Sodium Uranate Precipitation from the Catalytic Decomposition of $\left[\mathrm{UO}_{2}\left(\mathrm{O}_{2}\right)_{3}\right]^{4-}$ by $5 \times 10^{-3} \mathrm{M} \mathrm{Cu}(\mathrm{II}) \ldots \ldots \ldots \ldots \ldots \ldots \ldots \ldots . . \ldots \ldots$ 


\section{LIST OF TERMS}

HLW

LLW

MAR

TUE high-level waste

low-level waste

Method of Appearing Reagents

transuranium elements 


\title{
INVESTIGATION ON THE COPRECIPITATION OF TRANSURANIUM ELEMENTS FROM ALKALINE SOLUTIONS BY THE METHOD OF APPEARING REAGENTS
}

\author{
PART 1: SELECTION OF CARRIERS AND DETERMINATION OF THE \\ OPTIMUM CONDITIONS FOR THEIR PRECIPITATION
}

\subsection{INTRODUCTION}

Decontamination and treatment of radioactive waste accumulated during industrial production of plutonium for military use in both the United States and Russia is an important subject of investigation and research (Walton 1979, Harmon 1994, Delegard et al. 1994). Processing and disposing of Hanford Site high-level waste (HLW) is part of the problem. This waste is made up of about 329,000 tons of alkaline solutions, salt cakes, and sludges that contain considerable quantities of hazardous long-lived plutonium, neptunium, and americium isotopes (Delegard et al. 1994). However, the waste is not homogenous; rather its chemical composition is complex and varies greatly from tank to tank.

Most of the transuranium radionuclides likely will report to the solid phase following processing of Hanford HLW. However, even small quantities of these radionuclides remaining in the product supernate solutions may be enough to keep the alkaline solutions from being classified as low-level waste (LLW). Additional purification of alkaline solutions to remove transuranium elements (TUE) likely will be required. Special methods, based on the coprecipitation of TUE with convenient carriers, could be used to solve this problem. The precipitates obtained by coprecipitation may be suitable for vitrification or other subsequent treatments to isolate the TUE.

Coprecipitation of TUE with various carriers has been the subject of numerous investigations. It is widely used in analytical practice, as part of certain radiochemical technologies, and as a treatment method in ecological settings. Metal hydroxides are potential carriers to purify alkaline solutions of TUE. Certain types of compounds with low solubility at high hydroxide $\left(\mathrm{OH}^{-}\right)$concentrations can be used for the coprecipitation. However, application of these carriers in the ordinary way (i.e., by the introduction of low acid or neutral aqueous solutions of the compound directly into the alkaline medium) is complicated by the rapid formation of the precipitate at the boundary surface between the mixed liquids. As a result, TUE isolation occurs mainly by adsorption on the surface of freshly formed precipitates and the effectiveness of TUE capture is low. 
Compounds that are soluble in alkaline solution, but can be readily precipitated homogeneously throughout the solution by hydrolysis or redox reactions, avoid these difficulties. The Method of Appearing Reagents (MAR) is such a method. Using the MAR would accomplish uniform formation of the precipitate throughout the entire solution volume and, therefore, more effective capture of TUE by the precipitating solid phase.

To achieve TUE coprecipitation from alkaline media by the MAR, it is first necessary to select soluble starting compounds and find optimum conditions for transforming these soluble ingredients into the corresponding precipitates. The performance of these carriers in the coprecipitation of the TUE in various oxidation states then must be determined. 


\subsection{EXPERIMENTAL MATERIALS AND METHODS}

\subsection{REAGENTS AND EQUIPMENT}

Standardized sodium hydroxide solutions $(0.5$ to $14.0 \mathrm{M})$ were used in the experiments. The solutions were prepared by diluting $17.7 \mathrm{M} \mathrm{NaOH}$ pro analysis grade solution with distilled water. The distilled water had been acidified to $\mathrm{pH} 3$ to 4 by $\mathrm{HNO}_{3}$ and boiled to remove dissolved $\mathrm{CO}_{2}$. The alkaline solutions were kept in closed polyethylene flasks. Potassium ferrate(VI) was prepared by the chlorine oxidation of $\mathrm{FeCl}_{3}$ in concentrated alkali (Brauer 1981). Only freshly prepared $\mathrm{K}_{2} \mathrm{FeO}_{4}$ solutions, obtained by the dissolution of calculated quantities of the compound in $4 \mathrm{M} \mathrm{NaOH}$, were used.

Initial solutions of lithium peroxouranate were obtained by the reaction:

$$
\mathrm{UO}_{2}\left(\mathrm{NO}_{3}\right)_{2}+3 \mathrm{H}_{2} \mathrm{O}_{2}+6 \mathrm{LiOH} \rightarrow \mathrm{Li}_{4} \mathrm{UO}_{2}\left(\mathrm{O}_{2}\right)_{3}+2 \mathrm{LiNO}_{3}+6 \mathrm{H}_{2} \mathrm{O}
$$

To obtain the lithium peroxouranate, excess hydrogen peroxide was added to a measured volume of titrated uranyl nitrate solution at the molar ratio $U: \mathrm{H}_{2} \mathrm{O}_{2}$ of $1: 3.2$. The precipitate was dissolved in $\mathrm{LiOH}$ solution. The concentrations of uranium and free alkali in the final solution were 0.4 and $0.1 \mathrm{M}$, respectively.

To obtain $1 \mathrm{M} \mathrm{UCl}_{4}$ solutions, electrolysis of $1 \mathrm{M}$ uranyl chloride solution was carried out on a mercury-pool cathode in an electrochemical cell with separate cathode/anode compartments. Uranium(IV) concentrations in the product solutions were determined by complexometric titration in $0.02 \mathrm{M} \mathrm{HCl}$ using xylenol orange as an indicator. Other solutions of reagents used in the work were prepared from reagent chemical compounds and distilled water.

\subsection{EXPERIMENTAL METHODS}

All experiments were conducted in centrifuge test tubes made of glass (polyethylene for hot alkaline solutions). Medical centrifuges (model CLK-1, $36 \mathrm{~cm}$ diameter, 3,000 revolutions/minute, separation factor 1,750 ) were used to separate precipitates from supernatant solutions. Constant solution temperatures (within $0.2^{\circ} \mathrm{C}$ ) were maintained by a thermostat (model U-5, Germany). Absorption spectra were recorded using SFD-2 (Russia) or UV-3101PC (Shimadzu Instruments, Japan) spectrophotometers. Powder $\mathrm{x}$-ray diffraction patterns were obtained by a 100 -mm Guinier camera, model XDC-700, using $\mathrm{CuK}_{\alpha 1}$-radiation (x-ray generator PW 1140/90/96, Philips, Holland). 


\subsection{CHOICE OF INITIAL COMPOUNDS}

Initial compounds that can be used for the coprecipitation of TUE by MAR from alkaline solutions must meet the following requirements:

- Moderately soluble in water and $\mathrm{NaOH}$ solutions up to $14 \mathrm{M}$ concentration

- Sufficient stability in alkaline media to disperse uniformly throughout the entire solution phase

- Able to react to form insoluble precipitates that capture TUE contaminants

- Nonflammable and nonexplosive and have low toxicity for use in radiochemical plants

- Readily available and inexpensive on an industrial scale.

Numerous literature data were surveyed to find compounds that met these criteria. The following compounds were chosen for further examination as precipitate precursors:

$\mathrm{KMnO}_{4}, \mathrm{~K}_{2} \mathrm{MnO}_{4}, \mathrm{~K}_{2} \mathrm{FeO}_{4}, \mathrm{Na}_{2}\left[\mathrm{Fe}(\mathrm{CN})_{5} \mathrm{NO}\right] \cdot 2 \mathrm{H}_{2} \mathrm{O}, \mathrm{K}_{2} \mathrm{CrO}_{4}, \mathrm{Cr}\left(\mathrm{NO}_{3}\right)_{3} \cdot 9 \mathrm{H}_{2} \mathrm{O}, \mathrm{Cr}\left(\mathrm{CH}_{3} \mathrm{COO}\right)_{3}$, $\left[\mathrm{Co}\left(\mathrm{NH}_{3}\right)_{6}\right] \mathrm{Cl}_{3},\left[\mathrm{Co}\left(\mathrm{NH}_{3}\right)_{5} \mathrm{Cl}\right] \mathrm{Cl}_{2}$, and $\mathrm{Li}_{4} \mathrm{UO}_{2}\left(\mathrm{O}_{2}\right)_{3}$. The following precipitates, potential carriers for the TUE coprecipitation, may be obtained from the precursor compounds in alkaline solutions using the MAR: manganese dioxide; hydroxides of $\mathrm{Mn}$ (II), Fe(III), $\mathrm{Cr}(\mathrm{III}), \mathrm{Co}(\mathrm{III}), \mathrm{Co}(\mathrm{II})$; and sodium uranates. Optimum conditions for the precipitation of the enumerated carriers are presented in Section 3. 


\subsection{RESULTS AND DISCUSSION}

Experiments were conducted to determine the optimum conditions for the formation of TUE carriers using the MAR. Experimental parameters included carrier precursor concentration, alkali concentration, temperature, and time.

\subsection{MANGANESE DIOXIDE ISOLATION FROM $\mathrm{MnO}_{4}^{-}$AND $\mathrm{MnO}_{4}^{2-}$ ALKALINE SOLUTIONS}

Manganese dioxide is a well-known compound widely used as a catalyst, sorbent, depolarizer in electric batteries, and oxidant. Many works have investigated its preparation, structure, and properties. Most of the earlier works are summarized (Gmelin 1973a). It is especially important to note that the series of oxides of stoichiometry $\mathrm{MnO}_{1.7}$ to $\mathrm{MnO}_{2}$ can be designated as manganese dioxide. Depending on how it is prepared, the manganese dioxide compounds also can contain hydroxide ions, molecules of water, and various (mainly alkaline) cations. Many modifications of manganese dioxide $(\alpha, \beta, \gamma, \delta, \varepsilon)$, distinct in composition and structure, are known. In the case of $\mathrm{KMnO}_{4}$ reduction in alkaline media, $\delta-\mathrm{MnO}_{2}$ generally is formed (Glemser et al. 1961, Regner et al. 1963, Sterr et al. 1969, Giovanoli et al. 1970, and Yamamoto et al. 1980). The chemical composition of this practically amorphous product varies between (I) $-\mathrm{Na}_{4} \mathrm{Mn}_{14} \mathrm{O}_{27} \cdot 9 \mathrm{H}_{2} \mathrm{O}$ and (II) $\mathrm{Mn}_{7} \mathrm{O}_{13} \cdot 5 \mathrm{H}_{2} \mathrm{O}$ (Gmelin 1973a and Giovanoli et al. 1973). The $\delta-\mathrm{MnO}_{2}$ isolated from $\mathrm{NaOH}$ solutions as a mixture of modifications (I) and (II) differ somewhat in their consequent reactions (Yamamoto et al. 1980). For example, the first modification can be found precipitated from $\mathrm{KOH}$ solutions.

The presence of cations and $\mathrm{OH}^{-}$groups in $\mathrm{MnO}_{2}$ make it able to sorb both anions (from acid media) and cations (from neutral and alkaline solutions) by ion exchange mechanisms (Gmelin 1973a). This compound also can act as a molecular sorbent. Therefore manganese dioxide, obtained from $\mathrm{MnO}_{4}^{-}$or $\mathrm{MnO}_{4}^{2-}$ alkaline solutions, may be proposed as a prospective carrier for coprecipitation using the MAR under certain conditions for at least some chemical forms of TUE.

The transformation of $\mathrm{MnO}_{4}^{-}$to $\mathrm{MnO}_{2}$ can be carried out using different reductants (Gmelin 1973a, Glemser et al. 1961, Regner et al. 1963, Sterr et al. 1969, and Giovanoli et al. 1970). In most cases, hydrogen peroxide $\left(\mathrm{H}_{2} \mathrm{O}_{2}\right)$ is used for this process. In all cases, the reduction reactions go through some intermediate products, the first of which is $\mathrm{MnO}_{4}^{2-}$ (Gmelin 1966). Therefore, the behaviors of $\mathrm{MnO}_{4}^{-}$and $\mathrm{MnO}_{4}^{2-}$ in forming $\mathrm{MnO}_{2}$ are the same. When $\mathrm{H}_{2} \mathrm{O}_{2}$ is added to manganate and permanganate solutions, $\mathrm{O}_{2}$ bubbles evolve because of the oxidation of the reductant and its catalytic decomposition on the $\delta-\mathrm{MnO}_{2}$ precipitate. 
Neutral or weakly alkaline solutions of permanganate generally were used in the cited studies. Information in the technical literature is limited concerning $\mathrm{MnO}_{4}^{-}$and $\mathrm{MnO}_{4}^{2-}$ reduction to form $\delta-\mathrm{MnO}_{2}$ over a wide range of $\mathrm{NaOH}$ concentration. Therefore, additional experiments were conducted to estimate the rate of the isolation of $\delta-\mathrm{MnO}_{2}$ from dilute $\mathrm{KMnO}_{4}$ solutions in 0.5 to $14.0 \mathrm{M} \mathrm{NaOH}$ in the presence of $\mathrm{SO}_{3}^{2-}$ (sulfite), $\mathrm{HCOO}^{-}$ (formate), and $\mathrm{H}_{2} \mathrm{O}_{2}$ reductants.

The experimental techniques used for all three reductants were the same. Measured volumes of titrated $\mathrm{NaOH}$ and $\mathrm{KMnO}_{4}$ solutions were added to centrifuge test tubes; water was added up to $5 \mathrm{~mL}$. The test tubes were kept in a thermostat for 15 minutes to reach a chosen temperature and then a reductant was added. The solution color changes were checked visually or by spectrophotometry after the precipitate separated. The manganese dioxide precipitates were coagulated by periodically mixing the suspensions. The precipitation process was assumed to be complete if the supernatant solution, produced after four minutes' centrifugation, was colorless and transparent.

The experiments showed that all steps of $\mathrm{KMnO}_{4}$ reduction to dioxide are very fast at room temperature over a wide range of $\mathrm{NaOH}$ concentrations $(0.5$ to $14.0 \mathrm{M})$. The reactions essentially are complete in the time required to mix the reagents and are accompanied by intense oxygen gas evolution (bubbling). Gas evolution leads to emulsion formation if the alkali concentration exceeds $8 \mathrm{M}$. The stability of such emulsions increases with increased viscosity of the alkaline solution. About 30 minutes are required to destroy the emulsion in $14 \mathrm{M} \mathrm{NaOH}$ at $20^{\circ} \mathrm{C}$.

Manganese dioxide precipitate forms in alkaline media after $\mathrm{KMnO}_{4}$ reduction by hydrogen peroxide by the following steps:

1. Colloid solution

2. Fine dispersed suspension

3. Coagulated precipitate.

The time required for precipitate coagulation increases considerably with increasing alkali concentration (Table 1.3-1). The time required depends to a lesser extent on temperature and initial permanganate concentration.

The $\delta-\mathrm{MnO}_{2}$ precipitate settles slowly and incompletely. Therefore, filtration or centrifugation is necessary; decantation is not sufficient to separate the precipitate from the mother solution.

In contrast with $\mathrm{H}_{2} \mathrm{O}_{2}$, reduction of $\mathrm{MnO}_{4}^{-}$in alkaline solutions by sulfite or formate proceeds rapidly only to $\mathrm{MnO}_{4}^{2-}$. Subsequent formation of manganese dioxide proceeds at a moderate rate and depends on temperature and solution composition. The influence of test conditions on the time to complete the $\mathrm{MnO}_{4}^{2-} \rightarrow \delta-\mathrm{MnO}_{2}$ reduction is shown in Tables 1.3-2 and 1.3-3. 
Table 1.3-1. Estimated Time of Coagulation ( $\mathrm{t}$ ) of $\delta-\mathrm{MnO}_{2}$ in Various Conditions by the Reaction of $\mathrm{KMnO}_{4}$ with $0.02 \mathrm{M} \mathrm{H}_{2} \mathrm{O}_{2}$ in $\mathrm{NaOH}$ Solutions.

\begin{tabular}{|c|c|c|c|c|}
\hline No. & Grom, $Y$ & Gaino. $\mathrm{M}$ & T. $\mathrm{C}=$ & I. minutes \\
\hline 1 & 0.5 & $3.6 \times 10^{-3}$ & 22 & 15 \\
\hline 2 & 2.0 & $3.6 \times 10^{-3}$ & 22 & 30 \\
\hline 3 & 3.6 & $3.6 \times 10^{-3}$ & 22 & 50 \\
\hline 4 & 6.5 & $3.6 \times 10^{-3}$ & 22 & 80 \\
\hline 5 & 10.0 & $3.6 \times 10^{-3}$ & 22 & 140 \\
\hline 6 & 14.0 & $3.6 \times 10^{-3}$ & 22 & 180 \\
\hline 7 & 3.6 & $3.6 \times 10^{-3}$ & 35 & 35 \\
\hline 8 & 3.6 & $3.6 \times 10^{-3}$ & 50 & 20 \\
\hline 9 & 3.6 & $2.0 \times 10^{-3}$ & 22 & 60 \\
\hline 10 & 3.6 & $1.0 \times 10^{-3}$ & 22 & 45 \\
\hline
\end{tabular}

Table 1.3-2. The Influence of Conditions on the Time of Reduction ( $t$ ) of $3.6 \times 10^{-3} \mathrm{M}$ $\mathrm{KMnO}_{4}$ to $\delta-\mathrm{MnO}_{2}$ by Sulfite in $\mathrm{NaOH}$ Solutions.

\begin{tabular}{|c|c|c|c|c|}
\hline Noro & Maom1 M & T. 8. & $(50,1, \mathrm{M}$ & 1. ninutes \\
\hline 1 & 0.45 & 20 & 0.045 & 0.4 \\
\hline 2 & 0.90 & 20 & 0.045 & 2.0 \\
\hline 3 & 1.8 & 20 & 0.045 & 5.0 \\
\hline 4 & 3.3 & 20 & 0.045 & 20 \\
\hline 5 & 5.8 & 20 & 0.045 & 50 \\
\hline 6 & 11.5 & 20 & 0.045 & $>90$ \\
\hline 7 & 0.9 & 50 & 0.045 & 0.4 \\
\hline 8 & 3.3 & 50 & 0.045 & 2.0 \\
\hline 9 & 8.1 & 50 & 0.045 & 20 \\
\hline 10 & 11.5 & 50 & 0.045 & 30 \\
\hline 11 & 3.3 & 50 & 0.015 & 8.0 \\
\hline 12 & 3.3 & 50 & 0.025 & 5.0 \\
\hline
\end{tabular}


These data indicate that the reduction rate of manganate by excess $\mathrm{SO}_{3}^{2-}$ decreases as the alkali concentration increases. At greater than $11 \mathrm{M} \mathrm{NaOH}$ and without heating, bright colored solutions remained stable and transparent for a few hours. The reduction rate increased markedly at $50^{\circ} \mathrm{C}$. At this temperature, manganese dioxide is slowly formed even in $11.5 \mathrm{M} \mathrm{NaOH}$ solutions. The influence of alkali concentration on the rate of $\mathrm{MnO}_{4}^{-}$ reduction by $\mathrm{HCOO}^{-}$is opposite to that observed by sulfite. However, in both cases, it is carrying out the process with heating is desirable.

The coagulation of $\delta-\mathrm{MnO}_{2}$ precipitates, obtained from $\mathrm{KMnO}_{4}$ alkaline solution by sodium sulfite or formate reductants, begins even as manganate is being reduced. These reductions occur in the same general way as those for $\mathrm{H}_{2} \mathrm{O}_{2}$ reductant.

Table 1.3-3. The Influence of Conditions on the Time of Reduction (t) of $3.6 \times 10^{-3} \mathrm{M}$ $\mathrm{KMnO}_{4}$ to $\delta-\mathrm{MnO}_{2}$ by Formate in $\mathrm{NaOH}$ Solutions.

\begin{tabular}{|c|c|c|c|c|}
\hline No. & [NaOH] M & T. ${ }^{\circ} \mathrm{C}$ & {$[\mathrm{HCOO}], \mathrm{M}$} & , ninutes \\
\hline 1 & 0.45 & 20 & 0.045 & 40 \\
\hline 2 & 0.90 & 20 & 0.045 & 35 \\
\hline 3 & 3.3 & 20 & 0.045 & 30 \\
\hline 4 & 5.8 & 20 & 0.045 & 25 \\
\hline 5 & 8.1 & 20 & 0.045 & 20 \\
\hline 6 & 3.3 & 50 & 0.045 & 6 \\
\hline 7 & 5.8 & 50 & 0.045 & 5 \\
\hline 8 & 11.5 & 50 & 0.045 & 20 \\
\hline 9 & 3.3 & 50 & 0.015 & 22 \\
\hline 10 & 3.3 & 50 & 0.025 & 15 \\
\hline
\end{tabular}

Based on these experimental data, the following conditions may be proposed to obtain manganese dioxide from $\mathrm{MnO}_{4}^{-}$or $\mathrm{MnO}_{4}^{2-}$ in alkaline solutions:

1. With $\mathrm{H}_{2} \mathrm{O}_{2}$ as the reductant, the process can be conducted without heating. The quantity of reductant should exceed stoichiometry about twofold. If the alkali concentration is not higher than $6 \mathrm{M}$, the precipitate may be coagulated by stirring for 2 hours. At higher $\mathrm{NaOH}$ concentration, the time of coagulation should be increased to 3 or 4 hours. 
2. Sodium sulfite and formate also may be used as reductants for permanganate and manganate. Sulfite is effective in solutions of less than $6 \mathrm{M} \mathrm{NaOH}$; formate is effective in solutions with greater than $6 \mathrm{M} \mathrm{NaOH}$. Twofold stoichiometric excess of the reductants provides optimum precipitation; the temperature should be about 40 to $50^{\circ} \mathrm{C}$ and the process time about 2 hours.

3. The $\delta-\mathrm{MnO}_{2}$ produced from reducing $\mathrm{MnO}_{4}^{-}$or $\mathrm{MnO}_{4}^{2-}$ in alkaline solutions must be separated from the mother solution by centrifugation or filtration.

\subsection{MANGANESE(II) HYDROXIDE ISOLATION FROM $\mathrm{MnO}_{4}^{-}$AND $\mathrm{MnO}_{4}^{2-}$ ALKALINE SOLUTIONS}

Besides manganese dioxide, $\mathrm{Mn}(\mathrm{OH})_{2}$ also can be considered as a prospective carrier for coprecipitation of TUE from alkaline manganate or permanganate solutions. Manganese(II) hydroxide is a compound with low solubility and can be prepared from alkaline $\mathrm{KMnO}_{4}$ solutions using the MAR. Manganese(II) hydroxide is prepared only by the reaction of $\mathrm{MnO}_{4}^{-}$or $\mathrm{MnO}_{4}^{2-}$ with quite strong reductants (Gmelin 1973b). Hydrazine and hydroxylamine were considered the most promising of the possible reductants described in the literature.

Manganese(II) hydroxide is isolated from solution as an amorphous and slightly yellow precipitate. Its aqueous solubility is about $4 \times 10^{-3}$ molal at $25^{\circ} \mathrm{C}$ (Fox et al. 1941). The solubility of $\mathrm{Mn}(\mathrm{OH})_{2}$ is practically the same in $\mathrm{KOH}$ and $\mathrm{NaOH}$ solutions under equal conditions and increases with increasing alkali concentration and temperature, as shown in Figure 1.3-1 (Fox et al. 1941 and Kozawa et al. 1966). In boiling 50\% $\mathrm{NaOH}$, the solubility of $\mathrm{Mn}(\mathrm{OH})_{2}$ is approximately $12 \mathrm{~g} / \mathrm{L}$ (Scholder and Kolb 1951).

Unfortunately, the reductions of $\mathrm{Mn}$ (VII) and (VI) to $\mathrm{Mn}$ (II) are poorly described in the scientific literature. Nitrogen gas $\left(\mathrm{N}_{2}\right)$ is known to be the primary product of $\mathrm{N}_{2} \mathrm{H}_{4}$ and $\mathrm{NH}_{2} \mathrm{OH}$ oxidation by permanganate in alkaline media, but the stoichiometries of the reactions are not exact (Gmelin 1973b and Hlasivcová and Novák 1971). To supplement this knowledge, a number of experiments were conducted on isolating $\mathrm{Mn}(\mathrm{OH})_{2}$ from $\mathrm{KMnO}_{4}$ alkaline solutions by hydrazine or hydroxylamine reduction.

The experiments were conducted by the following general method. First, $4 \mathrm{~mL}$ aliquots of alkali were placed in centrifuge test tubes and warmed to constant temperature by 10 to 15 minutes' residence in a thermostat. Measured volumes of $0.15 \mathrm{M} \mathrm{KMnO}_{4}$ and $2.0 \mathrm{M} \mathrm{N}_{2} \mathrm{H}_{4}$ (or $\mathrm{NH}_{2} \mathrm{OH}$ ) were added. After mixing, the formation of precipitates, their color changes, and behaviors over time were observed. Periodically, the tubes were centrifuged for 4 minutes; if the mother solution was found transparent and clear, the coagulation process was judged to be complete. If not, the precipitates were stirred and the test tubes were returned to the thermostat and the heating continued. Control tests, using the method described by Sharlo (1969), showed that manganese concentrations in mother solutions after coagulation and centrifugation were close to the solubility of $\mathrm{Mn}(\mathrm{OH})_{2}$ observed under similar conditions (Figure 1.3-1). 
Figure 1.3-1. Solubility of $\mathrm{Mn}(\mathrm{OH})_{2}$ in $\mathrm{NaOH}$ or $\mathrm{KOH}$ Solutions.

(Fox et al. 1941 and Kozawa et al. 1966)

$$
\mathrm{T},{ }^{\circ} \mathrm{C}: 1-23,2-50,3-70 \text {. }
$$

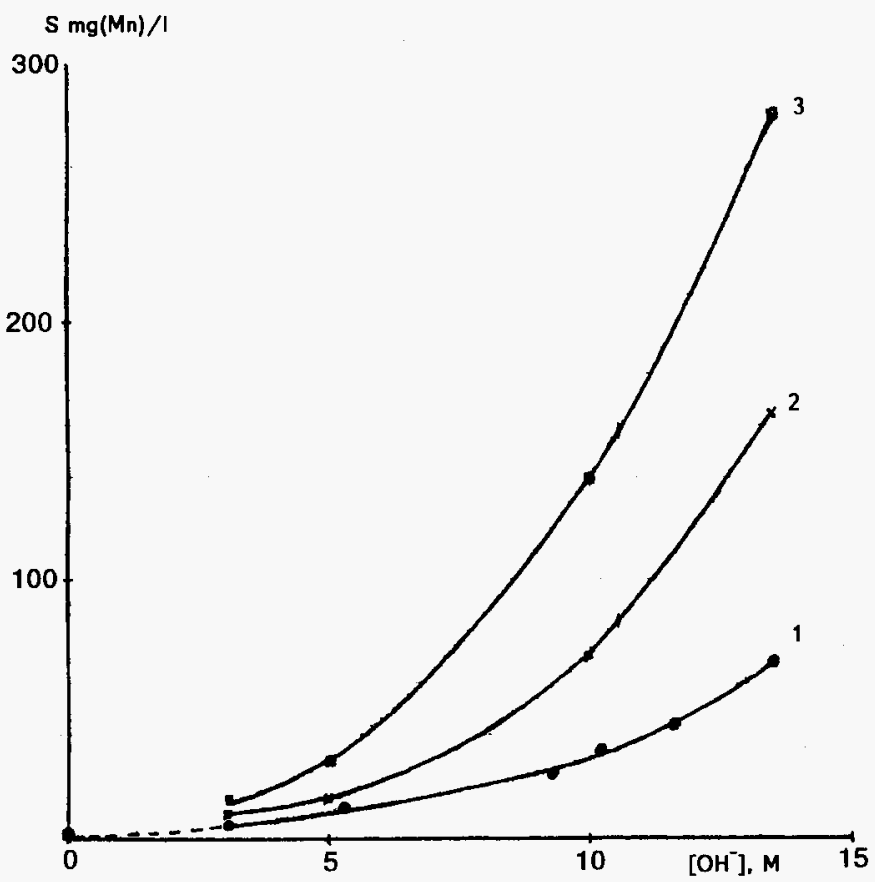


A brown sediment forms immediately after adding $\mathrm{N}_{2} \mathrm{H}_{4}$ to alkaline $\mathrm{KMnO}_{4}$ solutions. The sediment becomes lighter in color and finally, after time $t_{1}$, takes its final color; light yellow if pure $\mathrm{Mn}(\mathrm{OH})_{2}$ is obtained and brownish if some admixture of manganese dioxide remains present in the precipitate. The influence of experimental conditions on the time $t_{1}$ and on the color of the precipitates is shown in Table 1.3-4.

The results show that pure $\mathrm{Mn}(\mathrm{OH})_{2}$ can be obtained as a final product of $\mathrm{KMnO}_{4}$ reduction in alkaline media using hydrazine only if the initial concentration of $\mathrm{MnO}_{4}^{-}$is not higher than $2 \times 10^{-3} \mathrm{M}$ and the $\mathrm{NaOH}$ concentration is greater than $2 \mathrm{M}$. Any deviation from these conditions yields manganese dioxide admixtures in the $\mathrm{Mn}(\mathrm{OH})_{2}$ precipitates. Solution heating has a negligible effect on the process.

In contrast with $\mathrm{N}_{2} \mathrm{H}_{4}$, excess hydroxylamine converts $\mathrm{MnO}_{4}^{-}$and $\mathrm{MnO}_{4}^{2-}$ to $\mathrm{Mn}(\mathrm{OH})_{2}$ very rapidly over a wide range of $\mathrm{NaOH}$ concentration (from 0.5 to $14.0 \mathrm{M}$ ) even at room temperature. Though the process proceeds through the intermediate formation of manganese(IV), the time of mixing of the reagents is sufficient to generate a fine disperse $\mathrm{Mn}(\mathrm{OH})_{2}$ suspension. These solids gradually transform to flake-like precipitates. The time of such transformation increases with increasing alkali concentration (Table 1.3-5).

Manganese(II) hydroxide precipitates obtained from alkaline solution by hydrazine or hydroxylamine reduction require a long time to settle, especially in highly alkaline solutions at room temperature. Heating of such solutions is not desirable because the precipitate solubility markedly increases. Hence centrifugation or filtration are recommended over decantation to separate $\mathrm{Mn}(\mathrm{OH})_{2}$ from supernatant solution. If the initial $\mathrm{KMnO}_{4}$ concentration is $4 \times 10^{-3} \mathrm{M}$, the volume of $\mathrm{Mn}(\mathrm{OH})_{2}$ precipitate after centrifugation is about 1 percent of the liquid-phase volume.

The optimum conditions to obtain $\mathrm{Mn}(\mathrm{OH})_{2}$ from alkaline solutions as a TUE coprecipitation carrier are to reduce $\mathrm{KMnO}_{4}$ at room temperature using excess hydroxylamine, coagulate the precipitate for 2 to 3 hours, and separate the solids from the mother solution by centrifugation or filtration. Initial alkali concentration should not exceed 7 to $8 \mathrm{M}$. 
Table 1.3-4. Reduction of $\mathrm{KMnO}_{4}$ to $\mathrm{Mn}(\mathrm{OH})_{2}$ by $0.05 \mathrm{M} \mathrm{N}_{2} \mathrm{H}_{4}$.

\begin{tabular}{|c|c|c|c|c|c|}
\hline 19. & Wa $10 \%$ & 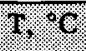 & 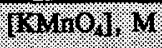 & 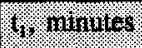 & 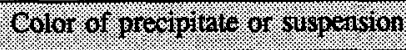 \\
\hline 1 & 0.5 & 19 & 0.002 & 5 & brown \\
\hline 2 & 1.0 & 19 & 0.002 & 5 & light brown \\
\hline 3 & 2.0 & 19 & 0.002 & 10 & light yellow \\
\hline 4 & 4.8 & 19 & 0.002 & 0.1 & light yellow \\
\hline 5 & 6.3 & 19 & 0.002 & $<0.1$ & light yellow \\
\hline 6 & 12.7 & 19 & 0.002 & $<0.1$ & light yellow \\
\hline 7 & 3.6 & 19 & 0.001 & $<0.1$ & light yellow \\
\hline 8 & 3.6 & 19 & 0.002 & $<0.1$ & light yellow \\
\hline 9 & 3.6 & 19 & 0.004 & 5 & light brown \\
\hline 10 & 3.6 & 19 & 0.006 & 10 & light brown \\
\hline 11 & 0.5 & 60 & 0.01 & 5 & brownish \\
\hline 12 & 2.0 & 60 & 0.01 & 5 & brownish \\
\hline 13 & 3.6 & 60 & 0.01 & 5 & brownish \\
\hline 14 & 3.6 & 60 & 0.01 & 0.1 & light yellow \\
\hline
\end{tabular}


Table 1.3-5. Estimated Time of $\mathrm{Mn}(\mathrm{OH})_{2}$ Coagulation ( $\mathrm{t}$ ) Under Various Conditions by the Reaction of $\mathrm{KMnO}_{4}$ with $0.05 \mathrm{M} \mathrm{NH}_{2} \mathrm{OH}$ in $\mathrm{NaOH}$ Solutions.

\begin{tabular}{|c|c|c|c|c|}
\hline $1 \% \%$ & Whas 1,1 & THMal. M & $1.9 \mathrm{C}$ & i, rinules \\
\hline 1 & 0.5 & 0.004 & 20 & 20 \\
\hline 2 & 1.0 & 0.004 & 20 & 30 \\
\hline 3 & 2.0 & 0.004 & 20 & 45 \\
\hline 4 & 3.6 & 0.004 & 20 & 60 \\
\hline 5 & 4.8 & 0.004 & 20 & 70 \\
\hline 6 & 6.3 & 0.004 & 20 & 100 \\
\hline 7 & 8.8 & 0.004 & 20 & 120 \\
\hline 8 & 12.7 & 0.004 & 20 & 180 \\
\hline 9 & 3.6 & 0.002 & 20 & 60 \\
\hline 10 & 3.6 & 0.01 & 20 & 40 \\
\hline 11 & 0.5 & 0.01 & 40 & 15 \\
\hline 12 & 2.0 & 0.01 & 40 & 20 \\
\hline 13 & 3.6 & 0.01 & 40 & 30 \\
\hline 14 & 0.5 & 0.01 & 60 & 10 \\
\hline 15 & 2.0 & 0.01 & 60 & 15 \\
\hline 16 & 3.6 & 0.01 & 60 & 20 \\
\hline
\end{tabular}




\subsection{IRON(III) HYDROXIDE ISOLATION FROM FeO ${ }_{4}^{2-}$ ALKALINE SOLUTIONS}

Iron(III) hydroxide is the carrier most often applied to coprecipitation of radionuclides. It is generally obtained by the hydrolysis of $\mathrm{Fe}^{3+}$ with increasing solution $\mathrm{pH}$. Many publications describe investigations of iron(III) hydroxide composition, structure, and properties; they are summarized in a number of reviews (for example, Datta 1981).

The iron(III) hydroxide is isolated from solution as an amorphous product of composition $\mathrm{FeOOH} \cdot \mathrm{xH}_{2} \mathrm{O}$ and is known to exist in three modifications (Krivoruchenko et al. 1977, Kobayashi and Uda 1982, and Pechenjuk and Rogachev 1985). At high $\mathrm{pH}$, the $\alpha$-form is the most stable. It is transformed to $\alpha-\mathrm{Fe}_{2} \mathrm{O}_{3}$ with heating and dehydration.

Iron(III) hydroxide forms ion and colloid species, the ratio of which depends on alkali concentration and temperature (Beljaev et al. 1975). The $\mathrm{Fe}(\mathrm{OH})_{4}^{-}$anion apparently predominates over other forms (Beljaev et al. 1975 and Ezhov et al. 1987). The hydroxo complexes tend to polymerize in time and to precipitate with intermediate formation of sols. The iron solution concentration depends on precipitation and coagulation conditions. Because of this, the literature data concerning Fe(III) hydroxide solubility in alkali are contradictory (Beljaev et al. 1975, Ezhov 1987, and Reiter and Anan'evskii 1978).

The conversion of $\mathrm{Fe}(\mathrm{VI})$ ions to $\mathrm{Fe}(\mathrm{III})$ hydroxide in alkaline media proceeds readily by adding any reductant; the most attractive are hydrazine and hydrogen peroxide. Reactions of $\mathrm{FeO}_{4}^{2-}$ with $\mathrm{N}_{2} \mathrm{H}_{4}$ and $\mathrm{H}_{2} \mathrm{O}_{2}$ are very fast in $\mathrm{NaOH}$ concentrations ranging from 0.5 to $14.0 \mathrm{M}$. The reactions are complete in the time of solution mixing at room temperature, if a small excess of reductants is used. However, the Fe(III) hydroxide precipitate forms slowly.

The following experiments were conducted to estimate the influence of conditions on the rate of this process. Aliquots of titrated alkali solution $(6 \mathrm{~mL})$ were placed in centrifuge test tubes. Measured volumes of freshly prepared $0.5 \mathrm{M} \mathrm{K}_{2} \mathrm{FeO}_{4}$ solution in $3.6 \mathrm{M} \mathrm{NaOH}$ were added and, after heating to a fixed temperature, excess $2 \mathrm{M} \mathrm{N}_{2} \mathrm{H}_{4}$ was introduced. The test tubes were kept thermostatted. Periodically, test aliquots were taken of the centrifuge-clarified mother solutions and the iron concentration determined by the thiocyanate method (Sharlo 1969). Experimental results indicate that increasing alkali concentration decreases both the rate and completeness of $\mathrm{Fe}$ (III) hydroxide separation (Table 1.3-6 and Figure 1.3-2).

The coagulation time for solutions having greater than $8 \mathrm{M} \mathrm{NaOH}$ is about 3 hours. In more dilute alkali solutions, 1.5 to 2 hours are required. The time required for coagulation decreases with increasing temperature; however, the residual iron concentration in the mother solution after centrifugation increases. The iron solution concentration exceeds the reported solubility of Fe(III) hydroxide about threefold (Reiter and Anan'evskii 1978) but coincides with other reported values (Belyaev et al. 1975 and Ezhov et al. 1987). 
Table 1.3-6. The Influence of Conditions on Completeness of $\mathrm{Fe}(\mathrm{III})$ Hydroxide

Separation from $2.5 \times 10^{-2} \mathrm{M} \mathrm{FeO}_{4}^{2-}$ Solutions After Addition of $4 \times 10^{-2} \mathrm{M} \mathrm{N}_{2} \mathrm{H}_{4}$.

\begin{tabular}{|c|c|c|c|c|c|c|}
\hline \multirow{2}{*}{ No. } & \multirow{2}{*}{ 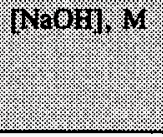 } & \multirow{2}{*}{ 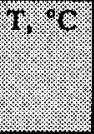 } & \multicolumn{4}{|c|}{ 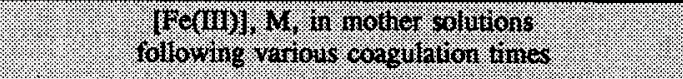 } \\
\hline & & & 6.5 hours & 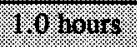 & 2.019601 & 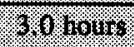 \\
\hline 1 & 0.5 & 22 & $2.4 \times 10^{-5}$ & $1.9 \times 10^{-5}$ & $1.8 \times 10^{-5}$ & $2.0 \times 10^{-5}$ \\
\hline 2 & 1.0 & 22 & $4.8 \times 10^{-5}$ & $2.7 \times 10^{-5}$ & $2.0 \times 10^{-5}$ & $1.9 \times 10^{-5}$ \\
\hline 3 & 1.9 & 22 & $1.4 \times 10^{-4}$ & $8.1 \times 10^{-5}$ & $5.5 \times 10^{-5}$ & $5.2 \times 10^{-5}$ \\
\hline 4 & 3.4 & 22 & $2.4 \times 10^{-4}$ & $1.7 \times 10^{-4}$ & $1.2 \times 10^{-4}$ & $1.2 \times 10^{-4}$ \\
\hline 5 & 4.8 & 22 & $6.2 \times 10^{-4}$ & $4.2 \times 10^{-4}$ & $2.0 \times 10^{-4}$ & $1.9 \times 10^{-4}$ \\
\hline 6 & 5.1 & 22 & - & $3.6 \times 10^{-4}$ & $2.1 \times 10^{-4}$ & $2.1 \times 10^{-4}$ \\
\hline 7 & 6.5 & 22 & - & $3.5 \times 10^{-4}$ & $2.9 \times 10^{-4}$ & $2.7 \times 10^{-4}$ \\
\hline 8 & 7.8 & 22 & - & $7.9 \times 10^{-4}$ & $5.2 \times 10^{-4}$ & $5.3 \times 10^{-4}$ \\
\hline 9 & 8.2 & 22 & - & $9.6 \times 10^{-4}$ & $7.1 \times 10^{-4}$ & $6.9 \times 10^{-4}$ \\
\hline 10 & 11.8 & 22 & - & $1.7 \times 10^{-3}$ & $1.0 \times 10^{-3}$ & $9.7 \times 10^{-4}$ \\
\hline 11 & 12.1 & 22 & - & $1.6 \times 10^{-3}$ & $9.6 \times 10^{-4}$ & $9.9 \times 10^{-4}$ \\
\hline 12 & 0.5 & 40 & $1.9 \times 10^{-4}$ & $7.0 \times 10^{-5}$ & $3.9 \times 10^{-5}$ & $4.0 \times 10^{-5}$ \\
\hline 13 & 3.3 & 40 & $4.7 \times 10^{-4}$ & $3.9 \times 10^{-4}$ & $2.1 \times 10^{-4}$ & $2.2 \times 10^{-4}$ \\
\hline 14 & 1.0 & 50 & $7.4 \times 10^{-5}$ & $4.3 \times 10^{-5}$ & $4.5 \times 10^{-5}$ & $4.1 \times 10^{-5}$ \\
\hline 15 & 2.0 & 50 & $1.4 \times 10^{-4}$ & $8.7 \times 10^{-5}$ & $6.1 \times 10^{-5}$ & $5.9 \times 10^{-5}$ \\
\hline 16 & 4.0 & 50 & $5.6 \times 10^{-4}$ & $4.9 \times 10^{-4}$ & $3.3 \times 10^{-4}$ & $2.8 \times 10^{-4}$ \\
\hline 17 & 6.0 & 50 & - & $9.3 \times 10^{-4}$ & $7.9 \times 10^{-4}$ & $6.4 \times 10^{-4}$ \\
\hline 18 & 8.0 & 50 & - & $1.3 \times 10^{-3}$ & $1.1 \times 10^{-3}$ & $1.1 \times 10^{-3}$ \\
\hline 19 & 10.0 & 50 & - & $1.5 \times 10^{-3}$ & $1.3 \times 10^{-3}$ & $1.3 \times 10^{-3}$ \\
\hline
\end{tabular}


Figure 1.3-2. Influence of $\mathrm{NaOH}$ Concentration and Temperature on the Residual $\mathrm{Fe}(\mathrm{III})$ Solution Concentration after Reduction of $2.5 \times 10^{-2} \mathrm{M} \mathrm{FeO}_{4}^{2-}$ by $4 \times 10^{-2} \mathrm{M}$ Hydrazine.

T, ${ }^{\circ} \mathrm{C}: 1 .-22,2 .-50$.

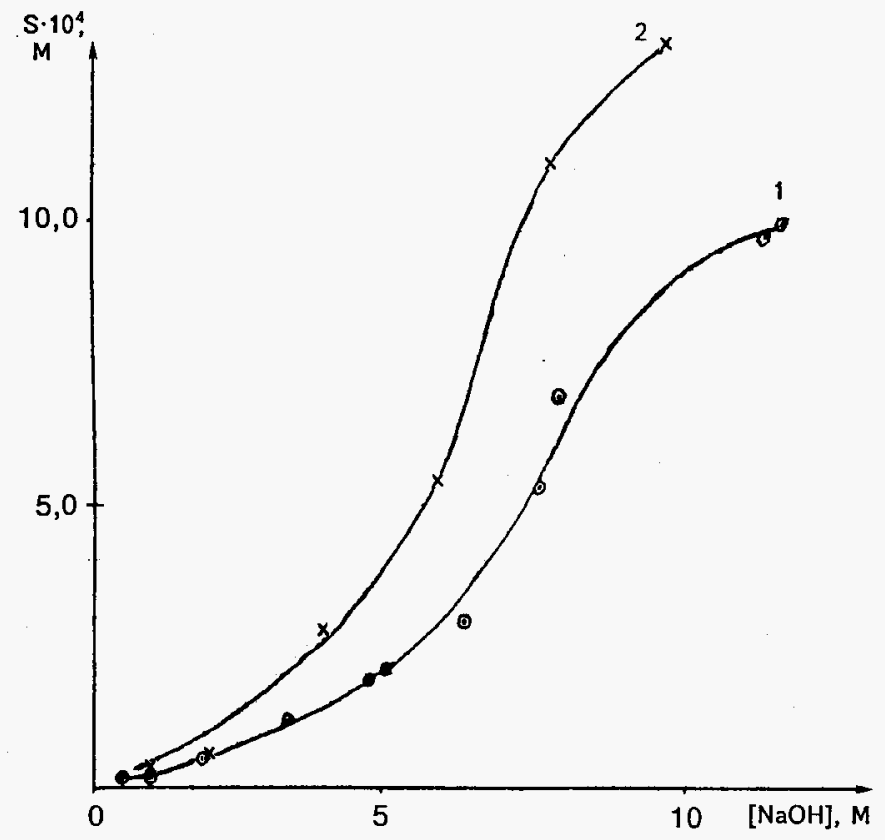


Based on the experimental data, the following conditions to precipitate Fe(III) hydroxide as a TUE coprecipitating agent from $\mathrm{FeO}_{4}^{2-}$ alkaline solution are recommended.

1. To an initial room-temperature solution not exceeding $8 \mathrm{M} \mathrm{NaOH}$, add potassium ferrate to a final concentration of $(2$ to 3$) \times 10^{-2} \mathrm{M}$.

2. After mixing, add hydrazine at up to a $1 \times 10^{-2} \mathrm{M}$ excess.

3. Coagulate the precipitates, with stirring, for 2 to 3 hours at room temperature.

4. Separate the precipitates from the mother solution by centrifugation or filtration.

\subsection{IRON(III) HYDROXIDE ISOLATION FROM NITROPRUSSIDE ALKALINE SOLUTIONS}

Iron(III) hydroxide can also be obtained by the hydrolysis of freely soluble alkaline cyanide complexes of di- and trivalent iron. Of the available cyanide complexes, sodium nitroprusside, $\mathrm{Na}_{2}\left[\mathrm{Fe}(\mathrm{CN})_{5} \mathrm{NO}\right] \cdot 2 \mathrm{H}_{2} \mathrm{O}$, was selected for study based on its availability and its susceptibility to hydrolytic decomposition.

The chemistry of sodium nitroprusside, and particularly its inclination to hydrolysis, are well known (Gmelin 1936). However, systematic data on the kinetics and completeness of Fe(III) hydroxide isolation from alkaline nitroprusside solutions in 0.5 to $14 \mathrm{M} \mathrm{NaOH}$ were not found in the literature.

To determine the hydrolysis behavior of sodium nitroprusside in strong alkaline solution, the following experiments were performed. First $10-\mathrm{mL}$ alkali aliquots were warmed to the selected temperature for 10 to 15 minutes in centrifuge test tubes. Then, aliquots of $0.7 \mathrm{M}$ nitroprusside were added to attain selected final concentrations and time measurement was started. Periodically, 1- to 2-mL test aliquots were taken, diluted two- to threefold using cold alkaline solution, and centrifuged if required for clarification. The light absorption of the solution then was measured at $470 \mathrm{~nm}$. The experiment was complete after the mother solution became colorless.

The iron(III) hydroxide precipitate did not form immediately in hot alkaline solutions, but only after an induction period $t_{1}$. The induction period depended on the composition and temperature of the solution. The isolation of the precipitate and decoloration rate of the solutions are described by kinetic curves in Figure 1.3-3. The induction period $t_{1}$ and the time required to decrease color intensity twofold $\left(\mathrm{t}_{2}\right)$ were used to describe semiquantitatively the rate of nitroprusside hydrolytic decomposition under various conditions. 
As shown in Table 1.3-7, values of $t_{1}$ and $t_{2}$ sharply decrease with increasing temperature. Increasing alkali concentration considerably decelerates nitroprusside hydrolysis; at greater than $10 \mathrm{M} \mathrm{NaOH}$, iron(III) hydroxide precipitate does not form at all. Iron(III) hydroxide precipitate, obtained by the hydrolysis of $(2$ to 4$) \times 10^{-2} \mathrm{M}$ nitroprusside and separated from the mother solution by centrifugation, occupies less than 1 percent of the initial solution volume.

Based on these data, the optimum procedure for precipitating Fe(III) hydroxide from alkaline nitroprusside solutions using the MAR is proposed. Add enough sodium nitroprusside to reach a final concentration of (2 to 4$) \times 10^{-2} \mathrm{M}$ to the initial solution having an alkali concentration not higher than $8 \mathrm{M}$. Heat the solution at 75 to $80^{\circ} \mathrm{C}$ for 2 to 3 hours. To attain the most complete isolation of Fe(III) hydroxide, cool the solution, with stirring, to room temperature and separate the precipitate by centrifugation or filtration.

\subsection{SODIUM URANATE ISOLATION FROM $\left[\mathrm{UO}_{2}\left(\mathrm{O}_{2}\right)_{3}\right]^{4-}$ ALKALINE SOLUTIONS}

The compositions of uranyl peroxo complexes are quite varied. Data concerning their formation, structure, and properties have been collected and systematized (Chernaiev 1964). Of the available peroxouranates, compounds containing the $\left[\mathrm{UO}_{2}\left(\mathrm{O}_{2}\right)_{3}\right]^{4-}$ complex appear to be the most interesting for TUE coprecipitation using the MAR. Such compounds are very stable in alkaline media (Ratner et al. 1958).

In our experiments, we found that (1 to 5) $\times 10^{-3} \mathrm{M}\left[\mathrm{UO}_{2}\left(\mathrm{O}_{2}\right)_{3}\right]^{4-}$ solutions in 2-, 4-, and $8 \mathrm{M} \mathrm{NaOH}$ do not undergo any marked decomposition with 3 hours' heating on a boiling water bath. Uranyl complexes with a ratio $\mathrm{O}_{2}^{2-}: \mathrm{U}$ of less than three give precipitates at the transition from neutral aqueous to alkaline solution apparently because they decompose to $\left[\mathrm{UO}_{2}\left(\mathrm{O}_{2}\right)_{3}\right]^{4-}$ and uranates.

The sodium salt of triperoxouranate has low solubility in water and $\mathrm{NaOH}$ solutions (Figure 1.3-4) (Ratner et al. 1957). Therefore, introducing the sodium salt of $\left[\mathrm{UO}_{2}\left(\mathrm{O}_{2}\right)_{3}\right]^{4-}$ into radioactive waste as an initial reagent is not useful. The potassium salt, whose solubility in water is about $1.6 \mathrm{M}$ (Gurevich and Polozhenskaja 1961), is more promising, but it is not stable. Lithium peroxouranate is the most advantageous because it is both stable and freely soluble.

Solutions of $\mathrm{Li}_{4} \mathrm{UO}_{2}\left(\mathrm{O}_{2}\right)_{3}$ can be readily prepared by consecutive additions of excess $\mathrm{H}_{2} \mathrm{O}_{2}$ and $\mathrm{LiOH}$ to low-acid solutions of uranyl nitrate. By this method, the initially formed uranium peroxide precipitate dissolves to give the bright orange $\left[\mathrm{UO}_{2}\left(\mathrm{O}_{2}\right)_{3}\right]^{4-}$ complex solution.

Because of the high thermal stability of $\left[\mathrm{UO}_{2}\left(\mathrm{O}_{2}\right)_{3}\right]^{4}$, its decomposition to form a precipitated uranate salt in alkaline solution by heating is impossible. However, preliminary experiments have shown that uranate precipitation can be attained using redox reagents or catalysts to 
Table 1.3-7. The Influence of Various Parameters on $\left[\mathrm{Fe}(\mathrm{CN})_{5} \mathrm{NO}\right]^{2-}$ Hydrolysis in $\mathrm{NaOH}$ Solutions.

\begin{tabular}{|c|c|c|c|c|c|}
\hline No. & Magra1. M & 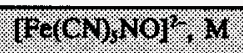 & T. $: 0$ & 1. ninumes & 6. mimiter \\
\hline 1 & 0.6 & 0.023 & 60 & 25 & 70 \\
\hline 2 & 1.2 & 0.023 & 60 & 50 & 90 \\
\hline 3 & 3.6 & 0.023 & 60 & 65 & 120 \\
\hline 4 & 6.3 & 0.023 & 60 & 130 & 220 \\
\hline 5 & 0.6 & 0.023 & 70 & 10 & 55 \\
\hline 6 & 1.2 & 0.023 & 70 & 15 & 75 \\
\hline 7 & 2.0 & 0.023 & 70 & 20 & 80 \\
\hline 8 & 3.6 & 0.023 & 70 & 25 & 90 \\
\hline 9 & 5.0 & 0.023 & 70 & 30 & 100 \\
\hline 10 & 3.6 & 0.023 & 75 & 12 & 45 \\
\hline 11 & 0.7 & 0.023 & 80 & 2 & 15 \\
\hline 12 & 1.2 & 0.023 & 80 & 4 & 25 \\
\hline 13 & 2.4 & 0.023 & 80 & 7 & 30 \\
\hline 14 & 3.6 & 0.023 & 80 & 8 & 35 \\
\hline 15 & 6.3 & 0.023 & 80 & 20 & 45 \\
\hline 16 & 8.4 & 0.023 & 80 & 30 & 50 \\
\hline 17 & 3.6 & 0.014 & 75 & 15 & 40 \\
\hline 18 & 3.6 & 0.035 & 75 & 12 & 60 \\
\hline 19 & 3.6 & 0.049 & 75 & 10 & 70 \\
\hline
\end{tabular}


Figure 1.3-3. Kinetic Curves for the Hydrolysis of $2.3 \times 10^{-2} \mathrm{M}\left[\mathrm{Fe}(\mathrm{CN})_{5} \mathrm{NO}\right]^{2-}$ in Alkaline Solutions.

1. $[\mathrm{NaOH}]=0.7 \mathrm{M}, \mathrm{T}=70^{\circ} \mathrm{C} ; 2 .[\mathrm{NaOH}]=4.0 \mathrm{M}, \mathrm{T}=80^{\circ} \mathrm{C}$.

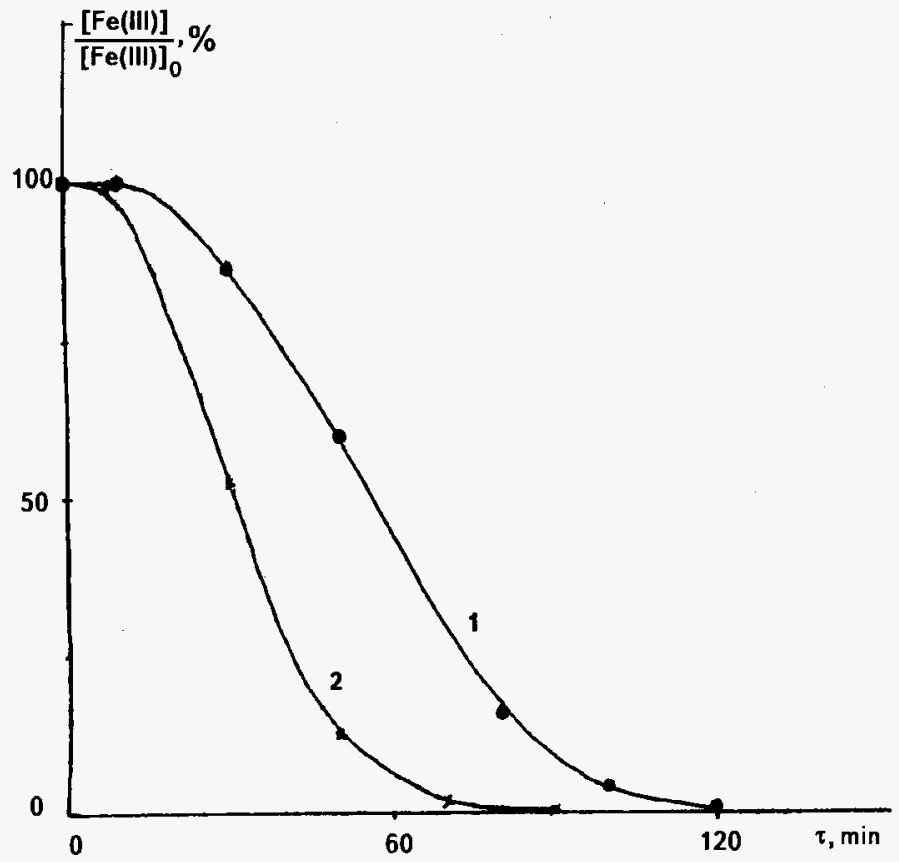


Figure 1.3-4. Dependence of $\mathrm{Na}_{4} \mathrm{UO}_{2}\left(\mathrm{O}_{2}\right)_{3} \cdot 9 \mathrm{H}_{2} \mathrm{O}$ Solubility on $\mathrm{NaOH}$ Concentration at $25{ }^{\circ} \mathrm{C}$.

O - literature data (Ratner et al. 1957); $\times$ - our data.

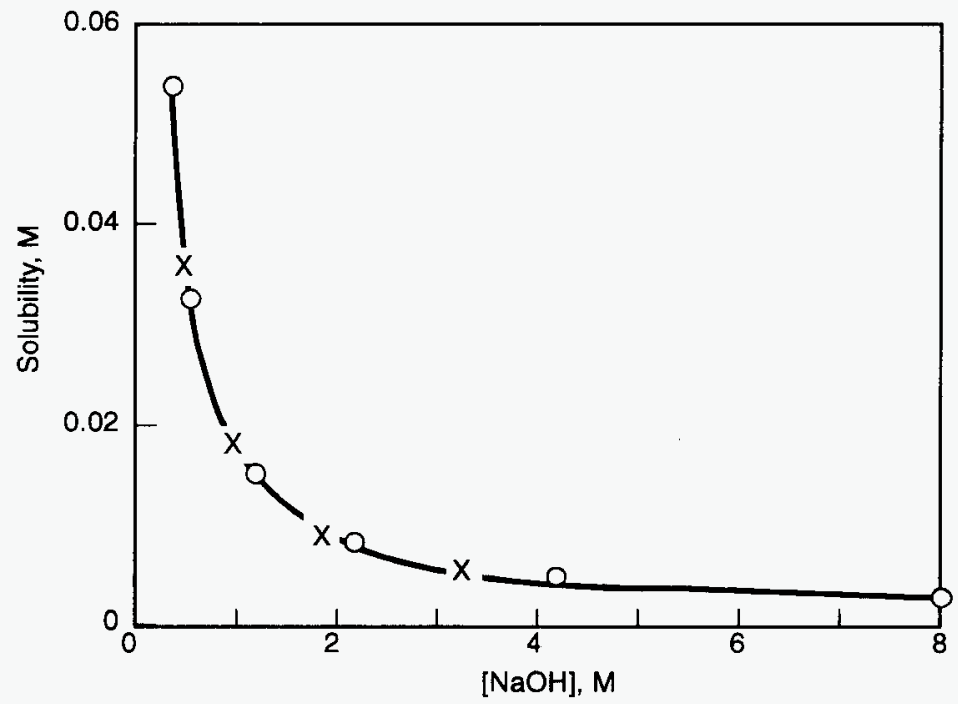

2G95120173.1 
decompose peroxide. For example, destruction of $\left[\mathrm{UO}_{2}\left(\mathrm{O}_{2}\right)_{3}\right]^{4-}$ and the precipitation of uranates can be initiated by adding permanganate or uranium(IV) to alkaline solutions.

However, in the case of $\mathrm{MnO}_{4}^{-}$, the uranate precipitate is contaminated by considerable quantities of manganese dioxide. If uranium(IV) is used to decompose $\left[\mathrm{UO}_{2}\left(\mathrm{O}_{2}\right)_{3}\right]^{4-}$, a large stoichiometric excess of reductant is required. Unfortunately, other reductants, including hydrazine and hydroxylamine, do not react with $\left[\mathrm{UO}_{2}\left(\mathrm{O}_{2}\right)_{3}\right]^{4-}$ even with extended heating. Therefore, catalysts to decompose peroxide are preferred over redox reagents to convert $\left[\mathrm{UO}_{2}\left(\mathrm{O}_{2}\right)_{3}\right]^{4-}$ to uranate precipitates.

Based on scoping experiments, Cu(II) salts were selected as catalysts. To determine optimum conditions for their use, further experiments were conducted. Aliquots of solutions (5 mL volume) with fixed $\mathrm{NaOH}$ and $\left[\mathrm{UO}_{2}\left(\mathrm{O}_{2}\right)_{3}\right]^{4-}$ concentrations were measured into centrifuge test tubes, kept in thermostats for 10 to 15 minutes at the chosen temperature, and timing was started on addition of catalyst. The start of uranate precipitation was determined visually and test aliquots were taken periodically. After centrifugation, the test aliquots were analyzed spectrophotometrically for uranium using the arsenazo III chromophore (Ryabchikov and Senyavin 1962). The experiment was finished when the uranium solution concentration became small and constant.

The experiments showed that the temperature and the concentrations of alkali and catalyst all affect the transformation of $\left[\mathrm{UO}_{2}\left(\mathrm{O}_{2}\right)_{3}\right]^{4-}$ to uranate. The optimum catalyst concentration was about $0.005 \mathrm{M}$. Copper(II) remains completely soluble in solutions with greater than $6 \mathrm{M}$ $\mathrm{NaOH}$. In more dilute alkaline solutions, copper(II) precipitation was observed.

Uranate precipitation begins as soon as the catalyst is added to warm $\left(60^{\circ} \mathrm{C}\right)$ solutions at 0.5 to $0.8 \mathrm{M} \mathrm{NaOH}$. Increasing alkali concentration results in an induction period during which the solutions remain transparent. The duration of the induction period is $2,8,15,20$, and 30 minutes, respectively, for $2,4,6,8$, and $10 \mathrm{M} \mathrm{NaOH}$ solutions [at $60{ }^{\circ} \mathrm{C}$ and $0.005 \mathrm{M} \mathrm{Cu}(\mathrm{II})]$. After the induction period, the uranium(VI) precipitation rate depends slightly on alkali concentration. Under the stated conditions, precipitation is complete in 30 minutes. Higher temperatures greatly decrease the induction period and increase the rate of sodium uranate precipitation (Figure 1.3-5).

To obtain uranate precipitates from $\left[\mathrm{UO}_{2}\left(\mathrm{O}_{2}\right)_{3}\right]^{4-}$ alkaline solutions for TUE coprecipitation using the MAR, the following conditions are recommended. Add $\mathrm{Li}_{4} \mathrm{UO}_{2}\left(\mathrm{O}_{2}\right)_{3}$ at a final concentration of 0.005 to $0.01 \mathrm{M}$ to the initial solution with the concentration of $\mathrm{NaOH}$ no higher than $10 \mathrm{M}$. Heat the solution to 55 to $65^{\circ} \mathrm{C}$, then introduce copper(II) nitrate or sulfate to $5 \times 10^{-3} \mathrm{M}$ concentration. Keep the hot solution stirring about 2 to 3 hours, cool to $25^{\circ} \mathrm{C}$, and centrifuge or filter to separate the solid phase. 
Figure 1.3-5. Rate of Sodium Uranate Precipitation from $4 \times 10^{-3} \mathrm{M}\left[\mathrm{UO}_{2}\left(\mathrm{O}_{2}\right)_{3}\right]^{4-}$ Alkaline Solutions in the Presence of $5 \times 10^{-3} \mathrm{M} \mathrm{Cu}$ (II) and 4.0 M NaOH. $\mathrm{T},{ }^{\circ} \mathrm{C}: 1-40,2-60,3-80$.

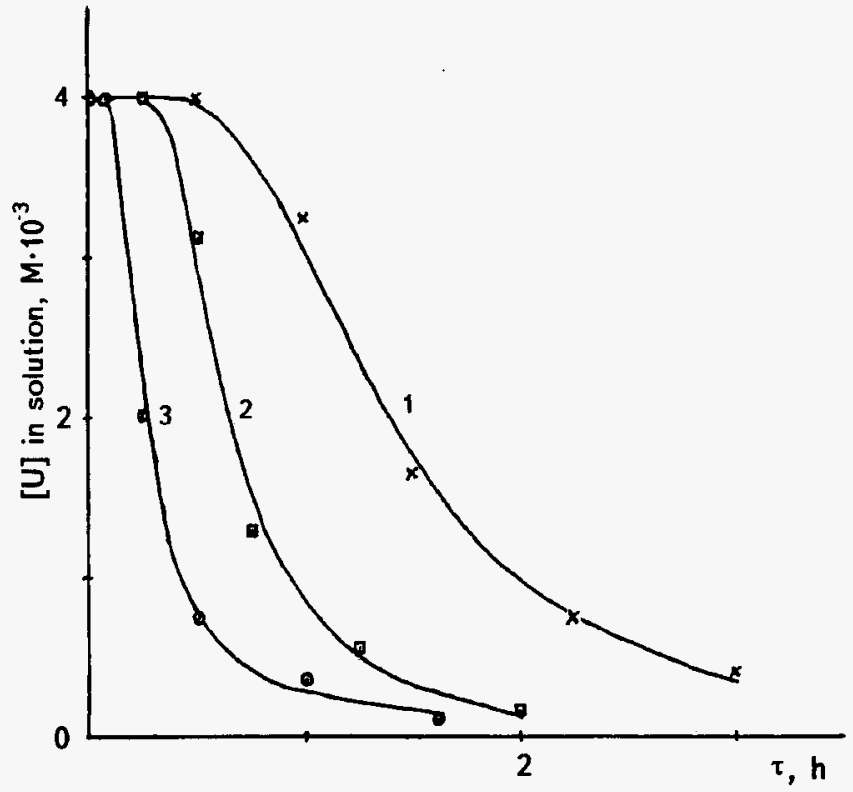




\subsection{COBALT(III) HYDROXIDE ISOLATION FROM $\left[\mathrm{Co}\left(\mathrm{NH}_{3}\right)_{6}\right]^{3+}$ AND $\left[\mathrm{Co}\left(\mathrm{NH}_{3}\right)_{5} \mathrm{Cl}\right]^{2+}$ ALKALINE SOLUTIONS}

The easiest way to obtain cobalt(III) hydroxide precipitate is the hydrolysis of its ammine complexes. These complexes are freely soluble in alkali. Many such compounds are described in the literature (Gmelin 1964). Taking into account chemical properties and availability, the $\left[\mathrm{Co}\left(\mathrm{NH}_{3}\right)_{6}\right] \mathrm{Cl}_{3}$ and $\left[\mathrm{Co}\left(\mathrm{NH}_{3}\right)_{5} \mathrm{Cl}\right] \mathrm{Cl}_{2}$ salts were selected for further examination.

Some literature information is available concerning the hydrolysis of $\left[\mathrm{Co}\left(\mathrm{NH}_{3}\right)_{6}\right]^{3+}$ in heated alkaline media (Barriga et al. 1989 and Yoneda 1958). The product solid phase composition usually is presented as $\mathrm{CoOOH} \cdot \mathrm{xH}_{2} \mathrm{O}$ (Schwarzenbach and Flaschka 1972). However, the reported data are insufficient to determine optimum conditions for the isolation of cobalt(III) hydroxide precipitates from solutions with various concentrations of $\mathrm{NaOH}$ for TUE coprecipitation by MAR.

Additional experiments have been conducted using the following technique to determine optimum precipitation conditions. Solution aliquots $(10 \mathrm{~mL}$ volume) with fixed $\mathrm{NaOH}$ concentration were placed in centrifuge test tubes and warmed for 10 to 15 minutes in a thermostat. After that, 1 millimole of $\mathrm{Co}\left(\mathrm{NH}_{3}\right)_{6} \mathrm{Cl}_{3}$ was added and the time noted.

Periodically, test aliquots were taken and quickly diluted threefold by $0{ }^{\circ} \mathrm{C} 1 \mathrm{M} \mathrm{NaOH}$ (to quench the hydrolysis reaction). The precipitate was separated by 10 minutes' centrifugation. After precipitate separation, the supernatant solution was heated for 10 to 15 minutes to complete the cobalt ammine complex hydrolysis. The solution was acidified by excess $\mathrm{HNO}_{3}$ and 2 to 3 drops of concentrated $\mathrm{H}_{2} \mathrm{O}_{2}$ were added to transform cobalt to the divalent state. Complexometric titration was used to determine the cobalt concentration qualitatively (Gershov and Vanaga 1977).

The curves of cobalt concentration decrease in heated $\left[\mathrm{Co}\left(\mathrm{NH}_{3}\right)_{6}\right]^{3+}$ alkaline solutions (shown in Figure 1.3-6) are typical for autocatalytic reactions. The duration of the induction period decreases with increasing temperature and $\mathrm{NaOH}$ concentration; simultaneously, the rate of the hydrolysis reaction increases (Figures 1.3-6 and 1.3-7). However, considerable cobalt remains dissolved at the end of $\left[\mathrm{Co}\left(\mathrm{NH}_{3}\right)_{6}\right]^{3+}$ decomposition if $\mathrm{NaOH}$ concentration exceeds $6 \mathrm{M}$.

Tests showed that $\left[\mathrm{Co}\left(\mathrm{NH}_{3}\right)_{5} \mathrm{Cl}\right]^{2+}$ is more prone to hydrolytic decomposition in alkaline media than is $\left[\mathrm{Co}\left(\mathrm{NH}_{3}\right)_{6}\right]^{3+}$. The $\left[\mathrm{Co}\left(\mathrm{NH}_{3}\right)_{5} \mathrm{Cl}\right]^{2+}$ decomposition proceeds at $20{ }^{\circ} \mathrm{C}$ lower temperatures than in the $\left[\mathrm{Co}\left(\mathrm{NH}_{3}\right)_{6}\right]^{3+}$ case (Figure 1.3-8). The influence of $\mathrm{NaOH}$ concentration on the decompositions of $\left[\mathrm{Co}\left(\mathrm{NH}_{3}\right)_{6}\right]^{3+}$ and $\left[\mathrm{Co}\left(\mathrm{NH}_{3}\right)_{5} \mathrm{Cl}\right]^{2+}$, however, is similar (Figure 1.3-7 and 1.3-9). 
Figure 1.3-6. $\mathrm{Co}$ (III) Concentration Decrease

on Heating $0.1 \mathrm{M}\left[\mathrm{Co}\left(\mathrm{NH}_{3}\right)_{6}\right]^{3+}$ in $4 \mathrm{M} \mathrm{NaOH}$ Solution.

T, ${ }^{\circ} \mathrm{C}: 1-50,2-60,3-70,4-80$.

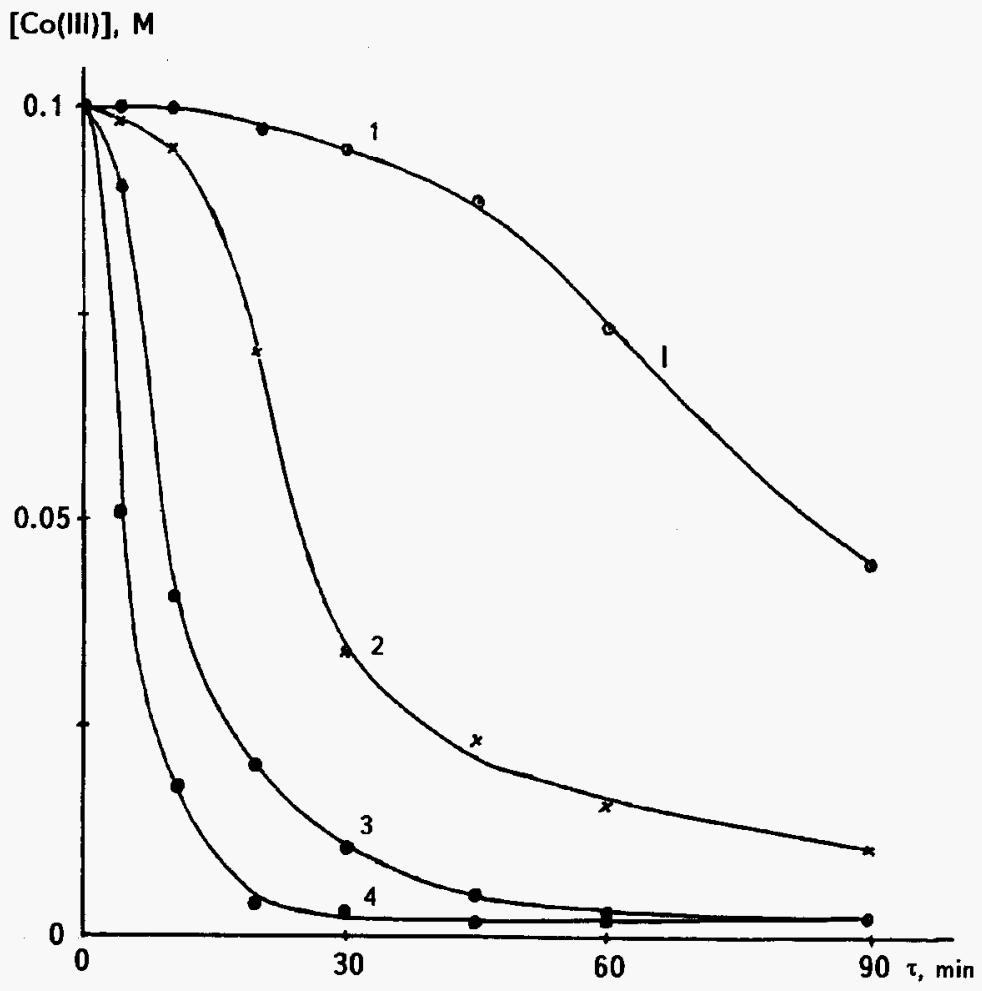


Figure 1.3-7. Influence of $\mathrm{NaOH}$ Concentration on $0.1 \mathrm{M}\left[\mathrm{Co}\left(\mathrm{NH}_{3}\right)_{6}\right]^{3+}$ Decomposition at $80{ }^{\circ} \mathrm{C}$.

$[\mathrm{NaOH}], \mathrm{M}: 1-1,2-2,3-4,4-6$.

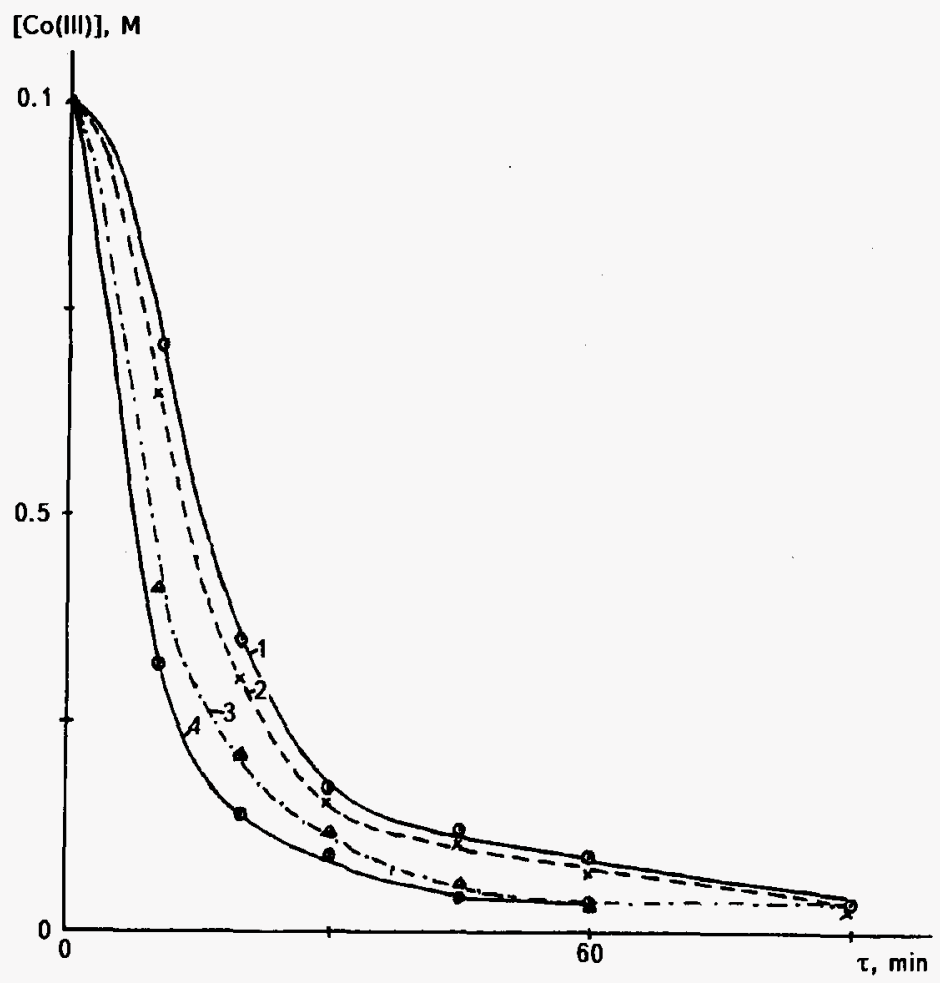


To obtain Co(III) hydroxide precipitate as a carrier in a TUE coprecipitation process from $\left[\mathrm{Co}\left(\mathrm{NH}_{3}\right)_{6}\right]^{3+}$ or $\left[\mathrm{Co}\left(\mathrm{NH}_{3}\right)_{5} \mathrm{Cl}\right]^{2+}$ alkaline solutions, we propose the following conditions.

1. The stock solutions should have $\mathrm{NaOH}$ concentration not higher than $6 \mathrm{M}$ after the cobalt spike addition.

2. The solutions should be kept for 1.5 to 2 hours at 80 or $60{ }^{\circ} \mathrm{C}$, respectively, to allow the hydrolysis reaction to occur.

3. The solutions with precipitates should be cooled to room temperature with stirring and the solid phase separated by centrifugation or filtration.

\subsection{COBALT(II) HYDROXIDE ISOLATION FROM $\left[\mathrm{Co}\left(\mathrm{NH}_{3}\right)_{6}\right]^{3+}$ AND $\left[\mathrm{Co}\left(\mathrm{NH}_{3}\right)_{5} \mathrm{Cl}\right]^{2+}$ ALKALINE SOLUTIONS}

With sufficiently strong reductants, $\mathrm{Co}(\mathrm{OH})_{2}$ is the final product of $\left[\mathrm{Co}\left(\mathrm{NH}_{3}\right)_{6}\right]^{3+}$ and $\left[\mathrm{Co}\left(\mathrm{NH}_{3}\right)_{5} \mathrm{Cl}\right]^{2+}$ hydrolysis in alkaline media. Preliminary experiments showed $\mathrm{N}_{2} \mathrm{H}_{4}$ was the most convenient and effective reductant among those tested (sodium sulfite, ascorbic acid, hydroxylamine, and hydrazine). Moreover, $\left[\mathrm{Co}\left(\mathrm{NH}_{3}\right)_{5} \mathrm{Cl}\right]^{2+}$ was found to have some advantages over $\left[\mathrm{Co}\left(\mathrm{NH}_{3}\right)_{6}\right]^{3+}$ as the initial species to obtain the $\mathrm{Co}(\mathrm{OH})_{2}$ precipitate because hydrolysis of hexamminocobalt in the presence of $\mathrm{N}_{2} \mathrm{H}_{4}$ can result in partial reduction to metallic cobalt (El-Chandour 1978).

More detailed study of $\left[\mathrm{Co}\left(\mathrm{NH}_{3}\right)_{5} \mathrm{Cl}\right]^{2+}$ hydrolysis in $\mathrm{NaOH}$ solutions in the presence of hydrazine was conducted using the following technique. To preheated $10-\mathrm{mL}$ samples of alkaline solution having 0.1 to $0.4 \mathrm{M} \mathrm{N}_{2} \mathrm{H}_{4}$ concentration, 1 millimole of $\left[\mathrm{Co}\left(\mathrm{NH}_{3}\right)_{5} \mathrm{Cl}\right]^{2+}$ was added and timing begun. Periodically, aliquots were taken, quickly diluted by adding cooled $1 \mathrm{M} \mathrm{NaOH}$ and, after separating the precipitate, the mother solutions were analyzed for cobalt concentration as described previously.

As shown in Figure 1.3-10, $\mathrm{Co}(\mathrm{OH})_{2}$ precipitation from $\left[\mathrm{Co}\left(\mathrm{NH}_{3}\right)_{5} \mathrm{Cl}\right]^{2+}$ alkaline solutions in the presence of hydrazine proceeds rapidly only at temperatures higher than $50{ }^{\circ} \mathrm{C}$. Generation of $\mathrm{Co}(\mathrm{OH})_{2}$ decelerates with increasing alkali concentration; moreover, at greater than $4 \mathrm{M} \mathrm{NaOH}$, cobalt partially reduces to metal. Therefore, to use $\mathrm{Co}(\mathrm{OH})_{2}$ as a TUE coprecipitation carrier, the following solutions are recommended.

1. Sodium hydroxide concentrations should be less than $4 \mathrm{M}$.

2. The $\left[\mathrm{Co}\left(\mathrm{NH}_{3}\right)_{5} \mathrm{Cl}\right]^{2+}$ hydrolysis takes about 2 hours at $60{ }^{\circ} \mathrm{C}$.

3. Following hydrolysis, the solutions should be cooled to 20 to $25^{\circ} \mathrm{C}$ with stirring and the precipitates separated by centrifugation or filtration. 
Figure 1.3-8. Co(III) Concentration Decrease

on Heating of $0.1 \mathrm{M}\left[\mathrm{Co}\left(\mathrm{NH}_{3}\right)_{5} \mathrm{Cl}\right]^{2+}$ in $4 \mathrm{M} \mathrm{NaOH}$.

$\mathrm{T},{ }^{\circ} \mathrm{C}: 1-40,2-50,3-60$.

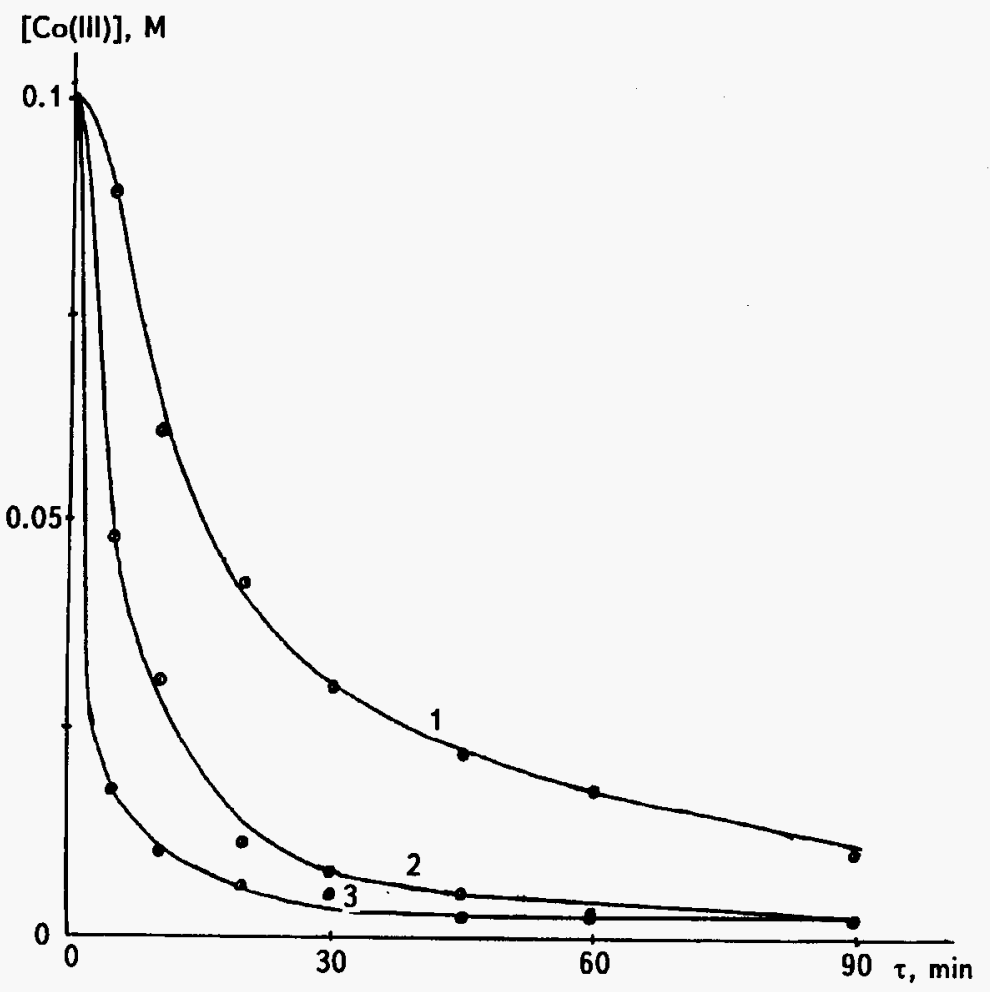


Figure 1.3-9. Influence of $\mathrm{NaOH}$ Concentration on $0.1 \mathrm{M}\left[\mathrm{Co}\left(\mathrm{NH}_{3}\right)_{5} \mathrm{Cl}\right]^{2+}$ Decomposition at $60{ }^{\circ} \mathrm{C}$. [NaOH], M: 1 - 1, 2 - 4, 3- 10.

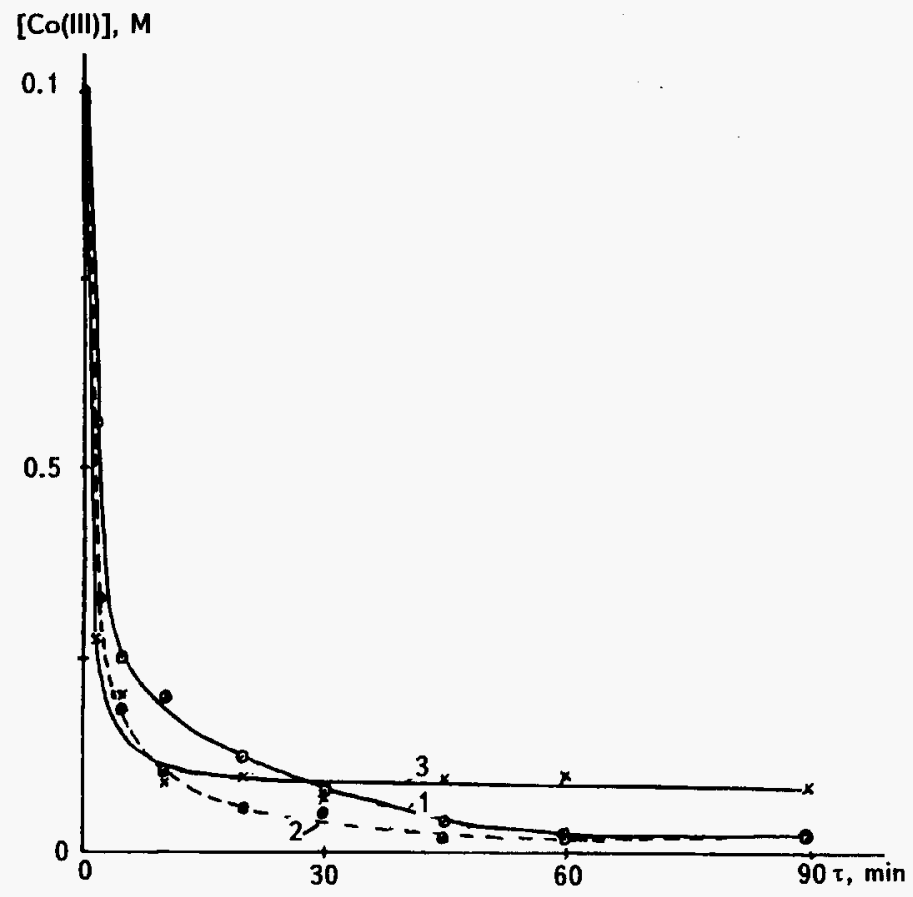


Figure 1.3-10. Cobalt Concentration Decrease on Heating of $0.1 \mathrm{M}\left[\mathrm{Co}\left(\mathrm{NH}_{3}\right)_{5} \mathrm{Cl}^{2+}\right.$ in $4 \mathrm{M} \mathrm{NaOH}$ in the Presence of $0.2 \mathrm{M} \mathrm{N}_{2} \mathrm{H}_{4}$. $\mathrm{T},{ }^{\circ} \mathrm{C}: 1-40,2-50,3-60$.

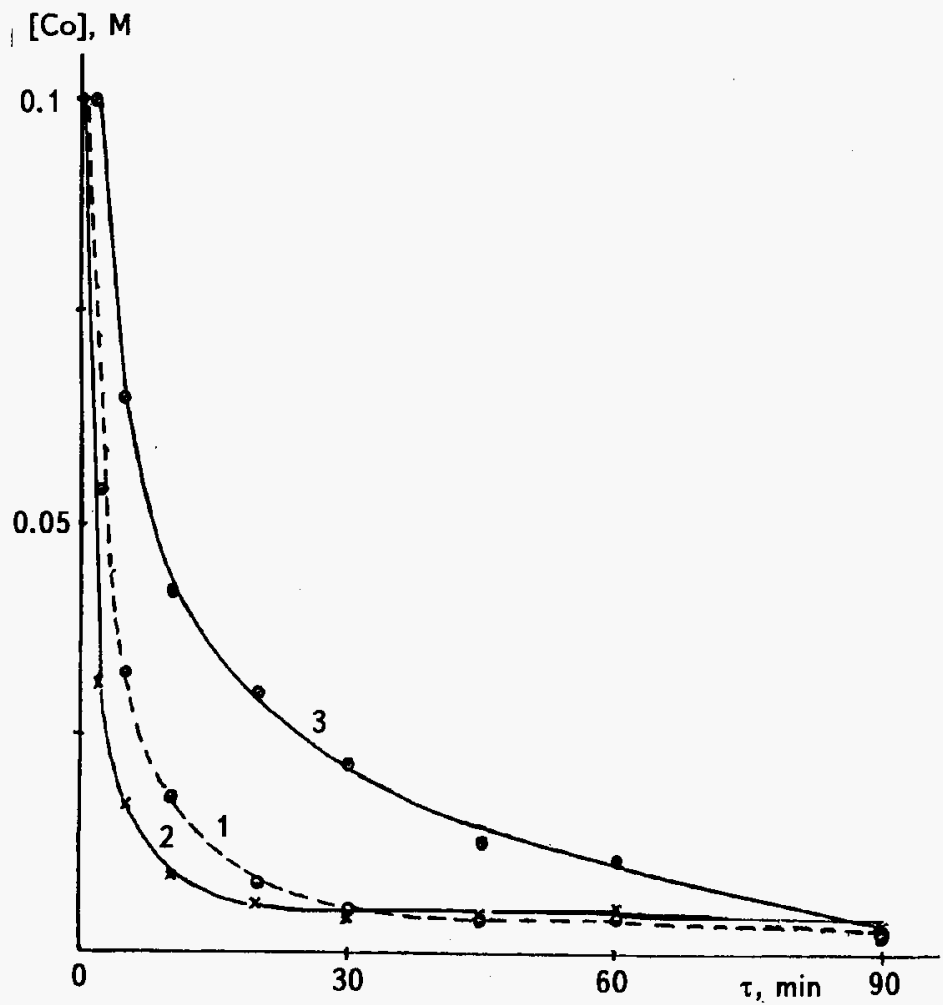




\subsection{CHROMIUM(III) HYDROXIDE ISOLATION FROM $\mathrm{CrO}_{4}^{2-}$ OR $\mathrm{Cr}$ (III) ALKALINE SOLUTIONS}

The stability of chromate at high $\mathrm{pH}$ is well known; strongly reducing conditions are necessary to reduce chromate to chromium(III) hydroxide. The technical literature contains reports of $\mathrm{CrO}_{4}^{2-}$ reduction in alkaline solution by electrochemical methods (Sazou and Kokkinidis 1989), by metallic aluminum powder (Antoniu et al. 1983), by $\mathrm{BH}_{4}^{-}$ (Khain et al. 1988), and by hydrazine, hydroxylamine, and other reagents (Gmelin 1962a). Based on these data, chromium(III) hydroxide (applied to TUE coprecipitation from alkaline solutions) can be most conveniently obtained by hydrazine or hydroxylamine reduction of $\mathrm{CrO}_{4}^{2-}$. Accordingly, these reagents were selected for further consideration.

The published data are insufficient to substantiate and choose optimum conditions for the reduction of chromate by $\mathrm{N}_{2} \mathrm{H}_{4}$ and $\mathrm{NH}_{2} \mathrm{OH}$ over a wide range of $\mathrm{NaOH}$ concentrations. Therefore, experiments were conducted to investigate the reaction rates of $\mathrm{CrO}_{4}^{2-}$ and hydrazine or hydroxylamine as functions of alkali concentration, excess reductant, and temperature. The experimental method included preparing chromium(VI) alkaline solutions, maintaining them at thermostatted conditions, adding fixed hydrazine or hydroxylamine excess, and periodically measuring $\mathrm{CrO}_{4}^{2-}$ concentrations in test aliquots. The sampled test aliquots were quickly diluted two- to threefold by cooled $\mathrm{H}_{2} \mathrm{O}$ to quench the redox reactions and were separated from the precipitate by centrifugation. The concentration of chromate, using absorption spectrophotometry, was determined at a $372 \mathrm{~nm}$ wavelength. Preliminary experiments showed that the $\mathrm{CrO}_{4}^{2-}$ molar extinction coefficient is practically independent of $\mathrm{NaOH}$ concentration in the range 0.5 to $10.0 \mathrm{M}$.

The experiments showed that chromate can be reduced by hydroxylamine in alkaline solutions at an acceptable rate only at temperatures exceeding $70^{\circ} \mathrm{C}$. The reaction rate decreases with increasing alkali concentration (Figure 1.3-11). The reduction of chromium(VI) by hydrazine in alkaline solution is faster than the analogous reduction by hydroxylamine. However, with hydrazine, the solution also must be heated to $70{ }^{\circ} \mathrm{C}$. The reaction between $\mathrm{CrO}_{4}^{2-}$ and $\mathrm{N}_{2} \mathrm{H}_{4}$ accelerates with increasing $\mathrm{NaOH}$ concentration (Figure 1.3-12), but the $\mathrm{Cr}$ (III) precipitation rate decelerates in concentrated alkaline solutions at $70^{\circ} \mathrm{C}$, which was also observed in subsequent studies of $\mathrm{Cr}$ (III) salt hydrolysis.

Based on these tests, hydrazine is preferable to hydroxylamine as a reductant to precipitate $\mathrm{Cr}(\mathrm{OH})_{3}$ from alkaline $\mathrm{CrO}_{4}^{2-}$ solutions. The recommended $\mathrm{Cr}(\mathrm{III})$ reduction conditions are $8 \mathrm{M} \mathrm{NaOH}$ and 3 hours reaction at $80{ }^{\circ} \mathrm{C}$ using $0.5 \mathrm{M}$ excess $\mathrm{N}_{2} \mathrm{H}_{4}$. After reaction, the suspension should be cooled with stirring to room temperature and the precipitate separated by centrifugation or filtration. 
Figure 1.3-11. Kinetic Curves for $0.05 \mathrm{M} \mathrm{CrO}_{4}^{2-}$ Reduction by $0.19 \mathrm{M}$ Hydroxylamine in Alkaline Solution at $70^{\circ} \mathrm{C}$. [NaOH], $\mathrm{M}: 1-0.5,2-2.0,3-4.0,4-8.0$.

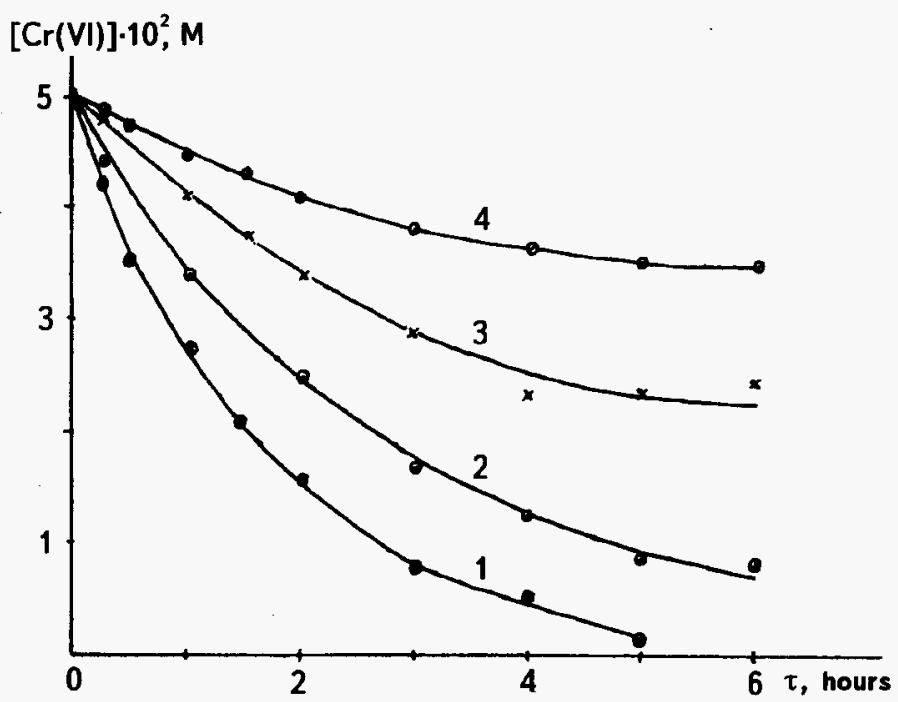


Figure 1.3-12. Kinetic Curves for $0.05 \mathrm{M} \mathrm{CrO}_{4}^{2-}$ Reduction by $0.09 \mathrm{M}$ Hydrazine in Alkaline Solutions at $70^{\circ} \mathrm{C}$.

[NaOH], M: $1-0.5,2-2.0,3-4.0$.

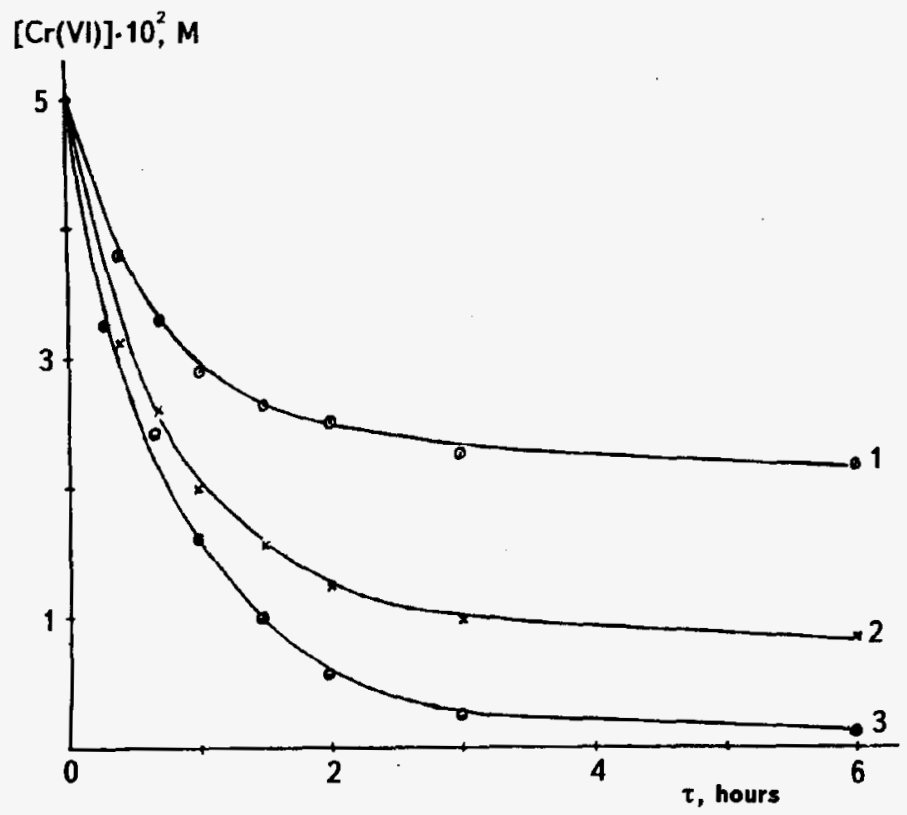


The use of Cr(III) hydroxide, obtained by the reduction of chromate, as a TUE coprecipitating agent using the MAR has a fundamental drawback, however. Considerable quantities of chromium (160 tonnes) are present in Hanford Site radioactive waste (Delegard et al. 1994). With the goal of vitrified HLW waste volume minimization, it is desirable that the chromium in the tank wastes remain in the soluble hexavalent state and be consigned to the LLW fraction. Introduction of strong reductants to the waste might cause precipitation of this waste chromate and cause its partitioning to the HLW fraction.

Therefore alkali-soluble $\mathrm{Cr}$ (III) compounds may be more desirable starting compounds to obtain the Cr(III) hydroxide precipitate using the MAR. Chromium(III) hydroxide forms when alkali is added to ordinary salts of hydrated $\mathrm{Cr}^{3+}$ (for example, nitrate, chloride, formate, or acetate). With time, the initially formed $\mathrm{Cr}(\mathrm{OH})_{3}$ precipitate dissolves to yield soluble hydroxo complexes (Gmelin 1962b). The soluble complexes then polymerize and decompose (slowly in the cold and more rapidly with heating) to give $\mathrm{Cr}_{2} \mathrm{O}_{3} \cdot \mathrm{xH}_{2} \mathrm{O}$ precipitate (Gmelin 1962b, Rai et al. 1987, and Spicca 1988).

Literature data on $\mathrm{Cr}$ (III) precipitation from alkaline solution were insufficient to determine optimum conditions for process performance over a wide range of $\mathrm{NaOH}$ concentrations. Therefore, kinetic curves for $\mathrm{Cr}_{2} \mathrm{O}_{3} \cdot \mathrm{xH}_{2} \mathrm{O}$ isolation from alkaline $\mathrm{Cr}(\mathrm{III})$ acetate solutions as functions of $\mathrm{NaOH}$ concentration and temperature were obtained. The $\mathrm{Cr}$ (III) concentrations in alkaline supernates were determined by spectrophotometry after oxidation to $\mathrm{CrO}_{4}^{2-}$ by hydrogen peroxide.

As shown in Figures 1.3-13 and 1.3-14, the kinetic curves for $\mathrm{Cr}$ (III) precipitation from alkaline solutions have induction periods, the duration of which decrease with increasing temperature. The dependence of the induction period on $\mathrm{NaOH}$ concentration is nonmonotonous; increasing alkali concentration decelerates the rate of $\mathrm{Cr}_{2} \mathrm{O}_{3} \cdot \mathrm{xH}_{2} \mathrm{O}$ precipitation.

The experiments showed that $\mathrm{Cr}$ (III) hydroxide is best precipitated from $\mathrm{Cr}$ (III) salts in alkaline solution using 3 hours heating at about 80 to $85^{\circ} \mathrm{C}$ and from solutions having less than $8 \mathrm{M} \mathrm{NaOH}$. After precipitation, the solution should be cooled with stirring and the precipitate separated by centrifugation or filtration. 
Figure 1.3-13. Variation of $\mathrm{Cr}(\mathrm{III})$ Concentration with Heating Time for $0.083 \mathrm{M} \mathrm{Cr}\left(\mathrm{CH}_{3} \mathrm{COO}\right)_{3}$ and $4 \mathrm{M} \mathrm{NaOH}$ Solutions.

$\mathrm{T},{ }^{\circ} \mathrm{C}: 1-40,2-60,3-80$.

$\left[\mathrm{CrAc}_{3}\right] /\left[\mathrm{CrAc}_{3}\right]_{0}, \%$

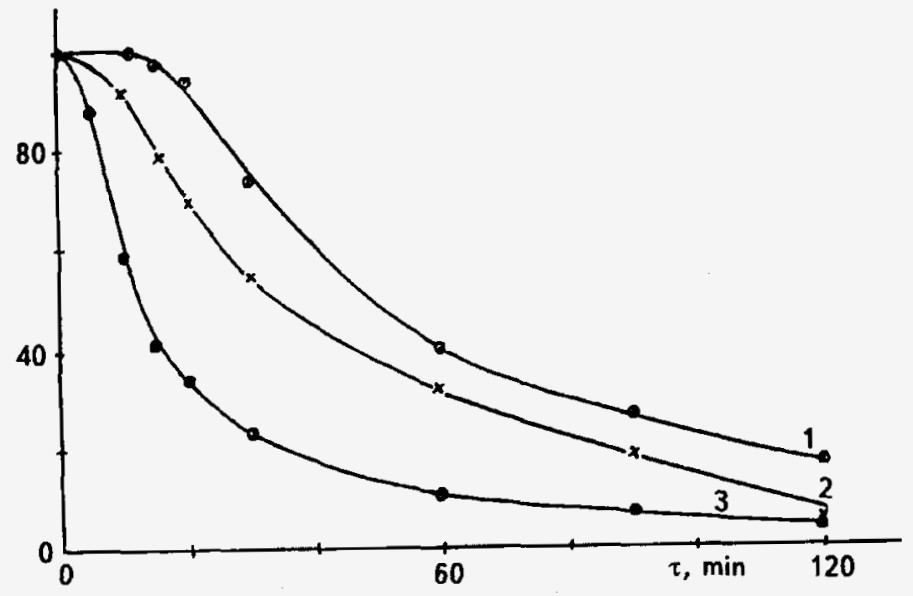


Figure 1.3-14. $\mathrm{Cr}$ (III) Hydroxide Precipitation at $80^{\circ} \mathrm{C}$ and $0.083 \mathrm{M} \mathrm{Cr}\left(\mathrm{CH}_{3} \mathrm{COO}\right)_{3}$ in Various $\mathrm{NaOH}$ Solutions.

$[\mathrm{NaOH}$ ], $\mathrm{M}: 1-0.5,2-2.0,3-4.0,4-8.0,5-10.0$.

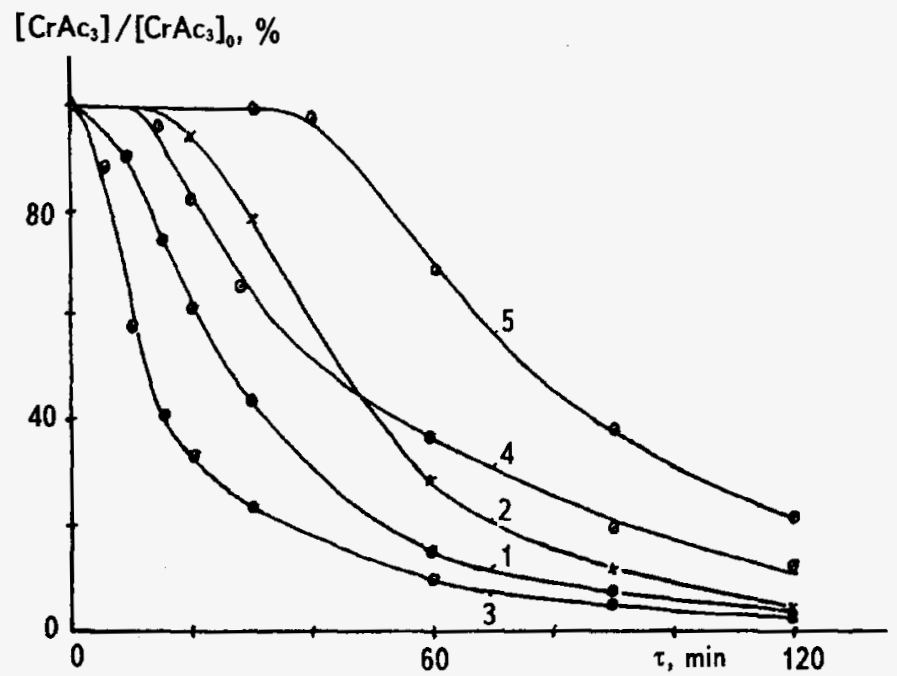




\subsection{CONCLUSIONS}

1. Based on literature studies, a preliminary selection of compounds potentially useable as carriers for the coprecipitation of transuranium elements from 0.5 to $14.0 \mathrm{M}$ $\mathrm{NaOH}$ solutions was conducted. Manganese(IV) oxide; the hydroxides of $\mathrm{Mn}$ (II), $\mathrm{Fe}(\mathrm{III}), \mathrm{Co}(\mathrm{III})$ and (II), and $\mathrm{Cr}$ (III); and sodium uranates were identified as potential carriers.

2. Reagents that are soluble in alkalis but that can readily be transformed to the desired carrier precipitates by redox reactions, hydrolysis, or catalytic decomposition were identified.

3. Taking into account the rate and completeness of precipitate isolation, laboratory studies established optimum conditions for the formation of carrier precipitates from alkaline solutions using the MAR. 
This page intentionally left blank. 


\section{INVESTIGATION OF THE COPRECIPITATION OF TRANSURANIUM ELEMENTS FROM ALKALINE SOLUTION BY THE METHOD OF APPEARING REAGENTS}

\section{PART 2: COPRECIPITATION OF Np(VI,V) AND Pu(VI, V) WITH THE SELECTED CARRIERS}

\subsection{INTRODUCTION}

In Part 1, results were presented on the first stage of research to develop a method for removing trace TUE from alkaline solutions. The method can be applied to the processing of alkaline high-activity waste stored in the underground tanks on the Hanford Site. The process is envisioned to decontaminate alkaline solutions of TUE by coprecipitating them with carriers. Soluble multivalent metal ion species undergo reduction, hydrolysis, or catalytic decomposition reactions to produce the sparingly soluble carrier precipitate compounds. This process is called the Method of Appearing Reagents (MAR).

The hydroxides of manganese(II), iron(III), cobalt(III) and (II), and chromium(III); manganese(IV) oxide; and sodium uranates were chosen as carriers for further consideration. For each carrier, initial alkali-soluble precursor compounds were found, reactions of their transformation into precipitates were demonstrated, and optimum conditions for the reactions were determined, based on the rates and the completeness of isolation of product solid phases.

Part 2 describes the continuing research carried out regarding the coprecipitation of $\mathrm{Np}(\mathrm{V}, \mathrm{VI})$ and $\mathrm{Pu}(\mathrm{V}, \mathrm{VI})$ with various carriers obtained using the MAR. 
This page intentionally left blank. 


\subsection{EXPERIMENTAL MATERIALS AND METHODS}

\subsection{REAGENTS AND EQUIPMENT}

Solutions of plutonium and neptunium in the (V) and (VI) oxidation states were required for the coprecipitation tests.

Plutonium solutions were prepared from an initial stock ${ }^{239} \mathrm{Pu}$ (IV) nitrate solution purified by ion exchange. The Pu(IV) stock concentration was determined by gravimetry. To prepare the $\mathrm{Pu}$ (VI) stock, $\mathrm{Pu}(\mathrm{IV})$ stock, containing 0.25 to $0.5 \mu$ moles of plutonium, was aliquoted and $0.5 \mathrm{~mL}$ of concentrated $\mathrm{HClO}_{4}$ added. The acid solutions were evaporated by slow boiling to damp salts and the dry residue dissolved in $25 \mathrm{~mL}$ of twice-distilled water. The resulting low-acid ( $\mathrm{pH}$ 4) solutions contained (1 to 2) $\times 10^{-4} \mathrm{M} \mathrm{Pu}(\mathrm{VI})$ concentrations and were used within 3 days. Radiolytic reduction of $\mathrm{Pu}$ (VI) was not detectible in this period.

Plutonium(V) solutions were prepared immediately before use by adding stoichiometric amounts of $\mathrm{H}_{2} \mathrm{O}_{2}$ or $\mathrm{N}_{2} \mathrm{H}_{4}$ to aliquots of low-acid $\mathrm{Pu}(\mathrm{VI})$ solutions.

Neptunium solutions were prepared from standard ${ }^{237} \mathrm{~Np}(\mathrm{~V})$ nitrate solution purified by ion exchange. To prepare the $\mathrm{Np}(\mathrm{VI})$ stock, aliquots of $\mathrm{Np}(\mathrm{V})$ stock diluted in $2 \mathrm{M} \mathrm{HNO}_{3}$ were evaporated to damp salts; the dry residue was dissolved in bidistilled water. The completeness of neptunium oxidation to the hexavalent state was checked by spectrophotometry and indicated by the absence of an absorption band at $981 \mathrm{~nm}$.

To produce $\mathrm{Np}(\mathrm{V})$ solutions, $\mathrm{Np}(\mathrm{V})$ hydroxide first was precipitated by adding ammonia, in the presence of nitrite, to the stock acid nitrate solution. The resulting $\mathrm{Np}(\mathrm{V})$ hydroxide precipitate then was thoroughly washed with water to the point of peptization. Neutral $\mathrm{Np}(\mathrm{V})$ solutions were obtained by dissolving the freshly precipitated $\mathrm{NpO}_{2} \mathrm{OH}$ in a stoichiometric amount of dilute $\mathrm{HNO}_{3}$ and volumetric dilution of the dissolved solids.

Other (nonradioactive) working solutions were prepared as described in Part 1. Much of the laboratory equipment used in this study (for example, thermostats and centrifuges)was described in Part 1. In addition, radiometric counting devices were used to measure alpha and gamma activity quantitatively. The model 20026 device (produced by VEB RTF Messeelektronik "Ottoschön" of Dresden, Germany) was used to measure $\alpha$ - and $\gamma$-activity. These measurements used a comparative technique in which corresponding neptunium- or plutonium-spiked standards were produced for measurement calibration. To determine $\alpha$-activity, a scintillation detector based on $\mathrm{ZnS}$ was used. To eliminate the influence of ${ }^{233} \mathrm{~Pa}$ radiation, the $\gamma$-activity of ${ }^{237} \mathrm{~Np}$ was measured by a semiconductor intrinsic germanium detector (model DGDC-63; resolution $1.5 \mathrm{keV}$ for $100 \mathrm{keV}$ ) with multichannel analyzer electronics (model AMO-03, Russian production). The errors of radiometric measurements were usually not higher than 10 percent. 


\subsection{EXPERIMENTAL METHODS}

The same general technique was used to investigate the coprecipitation of Pu(VI,V) and $\mathrm{Np}(\mathrm{VI}, \mathrm{V})$ by the various candidate reagents. First, $5 \mathrm{~mL}$ of plutonium or neptunium solution of the desired valence were added to centrifuge test tubes. The tubes and contents were thermostatted for 10 to 15 minutes to reach the selected temperature. Then, 5 to $7 \mathrm{~mL}$ of prewarmed $\mathrm{NaOH}$ solution were added rapidly with stirring. The carrier precursor then was added to the spiked alkaline solution. The precipitating carrier was allowed to form by the respective hydrolysis, reduction, or catalytic decomposition reactions under the optimum conditions identified in Part 1.

After precipitate coagulation, the test tube and contents were cooled to room temperature and centrifuged for 5 to 10 minutes. A 4- to 5-mL aliquot of mother solution was then withdrawn for analysis. Centrifugation was resumed for a further 5 to 10 minutes and a second sample withdrawn for analysis. The coincidence of the two analytical results was taken as evidence of the complete separation of solution and solid phases. If the results did not agree, the solution was centrifuged for a longer time, then the analysis was repeated.

To determine plutonium concentrations, samples of the mother solution were acidified with concentrated $\mathrm{HNO}_{3}$ to $\mathrm{pH}$ less than 3 . Two to three $3 \mathrm{mg}$ of lanthanum (as nitrate) were added to the acidified solution and $\mathrm{La}(\mathrm{OH})_{3}$ precipitated by addition of ammonia. The precipitate was coagulated at room temperature for 10 to 20 minutes, centrifuged, washed 3 to 4 times with $0.1 \mathrm{M} \mathrm{NH}_{4} \mathrm{OH}$ to remove entrained $\mathrm{NaNO}_{3}$, and dissolved in $5 \mathrm{~mL}$ of 0.5 to $1 \mathrm{M} \mathrm{HNO}_{3}$. Quantitative 0.05-to $0.1-\mathrm{mL}$ aliquots of the resulting solution were deposited onto counting planchets and, after drying and annealing, radiometric measurements were made. In parallel, the specific activities of the initial plutonium(VI) or (V) solutions were measured. The concentration data were used to calculate the solution decontamination factor (DF), which was equal to the ratio of the specific activities of initial and mother solutions (following coprecipitation).

Neptunium concentrations in mother solutions were measured by their specific gamma activities in glass test tubes. Sample volumes were 2 to $4 \mathrm{~mL}$. Neptunium concentrations in the initial alkaline solutions also were measured and decontamination factors calculated. 


\subsection{RESULTS AND DISCUSSION}

\subsection{COPRECIPITATION OF Np(VI,V) AND Pu(VI,V) WITH COBALT(III) HYDROXIDE}

In Part 1, two methods are described to obtain cobalt(III) hydroxide precipitate in alkaline solutions by MAR. The methods are based on the hydrolyses of $\left[\mathrm{Co}\left(\mathrm{NH}_{3}\right)_{6}\right]^{3+}$ and $\left[\mathrm{Co}\left(\mathrm{NH}_{3}\right)_{5} \mathrm{Cl}\right]^{2+}$, respectively. Recommended conditions for the hydrolysis of $\left[\mathrm{Co}\left(\mathrm{NH}_{3}\right)_{6}\right]^{3+}$ require heating solutions at $80^{\circ} \mathrm{C}$ for approximately 2 hours. Over the same time period, complete decomposition of [Co( $\left.\left(\mathrm{NH}_{3}\right)_{5} \mathrm{Cl}\right]^{2+}$ with formation of cobalt(III) hydroxide happens at $60^{\circ} \mathrm{C}$. These conditions were used to obtain the $\mathrm{Co}(\mathrm{OH})_{3}$ precipitates.

Results of preliminary experiments showed that the $\mathrm{Pu}(\mathrm{VI}) \mathrm{DF}$ in the precipitation of $\mathrm{Co}(\mathrm{OH})_{3}$ depends primarily on the completeness of precipitate separation from the mother solution. For solutions with 4 to $8 \mathrm{M} \mathrm{NaOH}$, the DF reached constant values only for centrifugation times of at least 10 minutes. Therefore 10 minutes' centrifugation was used for all experiments involving $\mathrm{Co}(\mathrm{OH})_{3}$.

As shown in Table 2.3-1, under conditions that ensured complete hydrolytic decomposition of $\left[\mathrm{Co}\left(\mathrm{NH}_{3}\right)_{6}\right]^{3+}$, effective coprecipitation of $\mathrm{Pu}(\mathrm{VI})$ with $\mathrm{Co}(\mathrm{III})$ hydroxide precipitate occurred over a wide range of $\mathrm{NaOH}$ concentrations. It is evident that the decontamination of alkaline solutions from Pu(VI) increases with increasing carrier concentration and becomes essentially complete at $\left[\mathrm{Co}\left(\mathrm{NH}_{3}\right)_{6}\right]^{3+}$ concentrations higher than $0.02 \mathrm{M}$. The DF values decrease significantly with increasing alkali concentration, although they are still large up to $8 \mathrm{M} \mathrm{NaOH}$. Variations of $\left[\mathrm{Co}\left(\mathrm{NH}_{3}\right)_{6}\right]^{3+}$ hydrolysis temperature (from 70 to $90{ }^{\circ} \mathrm{C}$ ) and time of precipitate coagulation (from 1 to 3 hours) have minimal influence on the DF. 
Table 2.3-1. Decontamination of $\mathrm{NaOH}$ Solutions from Pu(VI) by the Precipitation of $\mathrm{Co}(\mathrm{III})$ Hydroxide from Hydrolysis of $\left[\mathrm{Co}\left(\mathrm{NH}_{3}\right)_{6}\right]^{3+}$.

\begin{tabular}{|c|c|c|c|c|c|c|}
\hline \multirow[t]{2}{*}{ Mo. } & \multirow[t]{2}{*}{ Maomir Y } & \multirow{2}{*}{ [eag(N) } & \multirow{2}{*}{$\begin{array}{l}\text { Woun } \\
\times .1 \%\end{array}$} & \multicolumn{2}{|c|}{ Rif drolysus conditions } & \multirow[t]{2}{*}{ DF } \\
\hline & & & & 1.9 & 17. Irons. & \\
\hline 1 & 4.0 & 0.003 & 1.00 & 80 & 2 & 20 \\
\hline 2 & 4.0 & 0.006 & 1.00 & 80 & 2 & 60 \\
\hline 3 & 4.0 & 0.012 & 1.00 & 80 & 2 & 200 \\
\hline 4 & 4.0 & 0.024 & 1.00 & 80 & 2 & 1,400 \\
\hline 5 & 4.0 & 0.050 & 1.00 & 80 & 2 & $-2,000$ \\
\hline 6 & 0.5 & 0.024 & 0.98 & 80 & 2 & 600 \\
\hline 7 & 1.0 & 0.024 & 0.98 & 80 & 2 & $-1,500$ \\
\hline 8 & 2.0 & 0.024 & 0.98 & 80 & 2 & $-1,500$ \\
\hline 9 & 4.0 & 0.024 & 0.98 & 80 & 2 & 900 \\
\hline 10 & 7.0 & 0.024 & 0.98 & 80 & 2 & 600 \\
\hline 11 & $\overline{8.5}$ & 0.024 & 1.1 & 80 & 2 & 200 \\
\hline 12 & $\overline{10.0}$ & 0.024 & 0.98 & 80 & 2 & 6 \\
\hline 13 & 4.0 & 0.024 & 0.98 & 70 & 2 & 850 \\
\hline 14 & $\overline{4.0}$ & 0.024 & 0.98 & 80 & 2 & 1,300 \\
\hline 15 & 4.0 & 0.024 & 0.98 & 90 & 2 & 650 \\
\hline 16 & 4.0 & 0.024 & 0.98 & 70 & 1 & 700 \\
\hline 17 & 4.0 & 0.024 & 0.98 & 70 & 3 & 1,000 \\
\hline
\end{tabular}

Results of the coprecipitation of $\mathrm{Pu}(\mathrm{VI})$ with $\mathrm{Co}(\mathrm{III})$ hydroxide, obtained by hydrolysis of $\left[\mathrm{Co}\left(\mathrm{NH}_{3}\right)_{5} \mathrm{Cl}\right]^{2+}$ (Table 2.3-2), generally reproduce the results obtained with $\left[\mathrm{Co}\left(\mathrm{NH}_{3}\right)_{6}\right]^{3+}$ although the DF values under comparable conditions are a little lower. The difference likely can be explained by disparities in the plutonium redox and $\mathrm{Co}$ (III) hydroxide precipitate coagulation reactions. Also, in the case of $\left[\mathrm{Co}\left(\mathrm{NH}_{3}\right)_{5} \mathrm{Cl}\right]^{2+}$ and in contrast with $\left[\mathrm{Co}\left(\mathrm{NH}_{3}\right)_{6}\right]^{3+}$, lowering the temperature and decreasing the time of coagulation by $10{ }^{\circ} \mathrm{C}$ and 1 hour, respectively, lead to significant decreases in DF. 
Table 2.3-2. Decontamination of $\mathrm{NaOH}$ Solutions from $\mathrm{Pu}(\mathrm{VI})$ by the Precipitation of Co(III) Hydroxide from the Hydrolysis of $\left[\mathrm{Co}\left(\mathrm{NH}_{3}\right)_{5} \mathrm{Cl}\right]^{2+}$.

\begin{tabular}{|c|c|c|c|c|c|c|}
\hline \multirow{2}{*}{ Mo. } & \multirow[t]{2}{*}{ M. } & \multirow{2}{*}{ Modifom } & \multirow{2}{*}{ (Prow 10} & \multicolumn{2}{|c|}{ Myldrolysis conditions? } & \multirow[t]{2}{*}{18} \\
\hline & & & & (3. & (1. Inomirs & \\
\hline 1 & 4.0 & 0.003 & 1.00 & 60 & 2 & 20 \\
\hline 2 & 4.0 & 0.006 & 1.00 & 60 & 2 & 30 \\
\hline 3 & 4.0 & 0.012 & 1.00 & 60 & 2 & 150 \\
\hline 4 & 4.0 & 0.024 & 1.00 & 60 & 2 & 400 \\
\hline 5 & 4.0 & 0.050 & 1.00 & 60 & 2 & 800 \\
\hline 6 & 0.5 & 0.024 & 0.98 & 60 & 2 & 150 \\
\hline 7 & 1.0 & 0.024 & 0.98 & 60 & 2 & 500 \\
\hline 8 & 2.0 & 0.024 & 0.98 & 60 & 2 & 350 \\
\hline 9 & 4.0 & 0.024 & 0.98 & 60 & 2 & 390 \\
\hline 10 & 7.0 & 0.024 & 0.98 & 60 & 2 & 110 \\
\hline 11 & 10.0 & 0.024 & 0.98 & 60 & 2 & 5 \\
\hline 12 & 4.0 & 0.024 & 0.98 & 50 & 2 & 10 \\
\hline 13 & 4.0 & 0.024 & 0.98 & 70 & 2 & 160 \\
\hline 14 & 4.0 & 0.024 & 0.98 & 60 & 1 & 15 \\
\hline 15 & 4.0 & 0.024 & 0.98 & 60 & 3 & 450 \\
\hline
\end{tabular}

The coprecipitation of $\mathrm{Pu}(\mathrm{V})$ from alkaline solutions with cobalt(III) hydroxide, obtained by the hydrolysis of $\left[\mathrm{Co}\left(\mathrm{NH}_{3}\right)_{6}\right]^{3+}$ or $\left[\mathrm{Co}\left(\mathrm{NH}_{3}\right)_{5} \mathrm{Cl}\right]^{2+}$, occurs with the same efficiency as in the case of $\mathrm{Pu}(\mathrm{VI})$ (Tables 2.3-3 and 2.3-4). Moreover, in the case of $\mathrm{Pu}(\mathrm{V})$, the DF remains high even if the carrier concentration is deceased to $0.003 \mathrm{M}$. Comparison of the data of Tables 2.3-3 and 2.3-4 shows that partial or complete transformation of Pu(VI) to (V) in the initial alkaline solution (caused by radiolysis or reaction with reductants produced by hydrolysis of $\left[\mathrm{Co}\left(\mathrm{NH}_{3}\right)_{6}\right]^{3+}$ and $\left.\left[\mathrm{Co}\left(\mathrm{NH}_{3}\right)_{5} \mathrm{Cl}\right]^{2+}\right)$ will not seriously affect the extent to which plutonium is removed from the solution. 
Table 2.3-3. Decontamination of $\mathrm{NaOH}$ Solutions from $\mathrm{Pu}(\mathrm{V})$ by the Precipitation of $\mathrm{Co}$ (III) Hydroxide from the Hydrolysis of $\left[\mathrm{Co}\left(\mathrm{NH}_{3}\right)_{6}\right]^{3+}$.

\begin{tabular}{|c|c|c|c|c|c|c|}
\hline \multirow{2}{*}{ 1.0.: } & \multirow{2}{*}{ ARom W } & \multirow{2}{*}{ 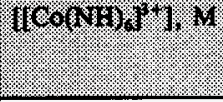 } & \multirow{2}{*}{ Irum $10 \%$} & \multicolumn{2}{|c|}{ Hifirolysis condiktons } & \multirow[t]{2}{*}{ Br } \\
\hline & & & & 1.8 & . 1. 10910 & \\
\hline 1 & 4.0 & 0.003 & 0.79 & 80 & 2 & 200 \\
\hline 2 & 4.0 & 0.012 & 0.79 & 80 & 2 & 400 \\
\hline 3 & 4.0 & 0.024 & 0.79 & 80 & 2 & 600 \\
\hline 4 & 4.0 & 0.050 & 0.79 & 80 & 2 & 500 \\
\hline 5 & 0.5 & 0.024 & 0.79 & 80 & 2 & 2,000 \\
\hline 6 & 1.0 & 0.024 & 0.79 & 80 & 2 & 1,500 \\
\hline 7 & 2.0 & 0.024 & 0.79 & 80 & 2 & 600 \\
\hline 8 & 7.0 & 0.024 & 0.79 & 80 & 2 & 500 \\
\hline 9 & 4.0 & 0.024 & 0.79 & 70 & 2 & 450 \\
\hline 10 & 4.0 & 0.024 & 0.79 & 90 & 2 & 650 \\
\hline
\end{tabular}

The behaviors of $\mathrm{Np}(\mathrm{VI})$ and $(\mathrm{V})$ during the precipitation of Co(III) hydroxide from alkaline solutions of $\left[\mathrm{Co}\left(\mathrm{NH}_{3}\right)_{6}\right]^{3+}$ and $\left[\mathrm{Co}\left(\mathrm{NH}_{3}\right)_{5} \mathrm{Cl}\right]^{2+}$ using the MAR differ markedly from those of $\mathrm{Pu}(\mathrm{VI})$ and $(\mathrm{V})$. As seen in Tables 2.3-5 and 2.3-6, the coprecipitation of $\mathrm{Np}(\mathrm{VI})$ or (V) with $\mathrm{Co}$ (III) hydroxide obtained from $\left[\mathrm{Co}\left(\mathrm{NH}_{3}\right)_{6}\right]^{3+}$ hydrolysis is appreciable only at $0.5 \mathrm{M}$ $\mathrm{NaOH}$.

In more concentrated alkaline solutions, independent of the initial oxidation state, neptunium coprecipitation is very poor. The neptunium oxidation state's lack of influence on the DF is explained by the fact that $\left[\mathrm{Co}\left(\mathrm{NH}_{3}\right)_{6}\right]^{3+}$ hydrolysis side reactions reduce $\mathrm{Np}(\mathrm{VI})$ to $\mathrm{Np}(\mathrm{V})$. This reduction was confirmed by direct absorption spectra measurements of $\mathrm{HNO}_{3}$-acidified mother solutions. 
Table 2.3-4. Decontamination of $\mathrm{NaOH}$ Solutions from $\mathrm{Pu}(\mathrm{V})$ by the Precipitation of $\mathrm{Co}$ (III) Hydroxide from the Hydrolysis of $\left[\mathrm{Co}\left(\mathrm{NH}_{3}\right)_{5} \mathrm{Cl}\right]^{2+}$.

\begin{tabular}{|c|c|c|c|c|c|c|}
\hline \multirow{2}{*}{ No } & \multirow{2}{*}{ Marom. } & \multirow{2}{*}{ Mongmingm } & \multirow{2}{*}{ moris) } & \multicolumn{2}{|c|}{ Hydrowy is condifisus } & \multirow[t]{2}{*}{ BI? } \\
\hline & & & & 1.90 & $1.70010:$ & \\
\hline 1 & 4.0 & 0.003 & 0.79 & 60 & 2 & 150 \\
\hline 2 & 4.0 & 0.012 & 0.79 & 60 & 2 & 200 \\
\hline 3 & 4.0 & 0.024 & 0.79 & 60 & 2 & 400 \\
\hline 4 & 4.0 & 0.050 & 0.79 & 60 & 2 & 400 \\
\hline 5 & 0.5 & 0.024 & 0.98 & 60 & 2 & 450 \\
\hline 6 & 1.0 & 0.024 & 0.98 & 60 & 2 & 400 \\
\hline 7 & 2.0 & 0.024 & 0.98 & 60 & 2 & 350 \\
\hline 8 & 4.0 & 0.024 & 0.98 & 60 & 2 & 390 \\
\hline 9 & 7.0 & 0.024 & 0.98 & 60 & 2 & 220 \\
\hline
\end{tabular}

Table 2.3-5. Decontamination of $\mathrm{NaOH}$ Solutions from $\mathrm{Np}$ (VI) by the Precipitation of $\mathrm{Co}$ (III) Hydroxide from the Hydrolysis of $\left[\mathrm{Co}\left(\mathrm{NH}_{3}\right)_{6}\right]^{3+}$.

$$
[\mathrm{Np}(\mathrm{VI})]_{0}=2.8 \times 10^{-4} \mathrm{M} \text {. }
$$

\begin{tabular}{|c|c|c|c|c|c|}
\hline \multirow{2}{*}{ 16. } & \multirow{2}{*}{ 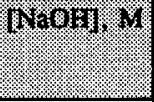 } & \multirow{2}{*}{ 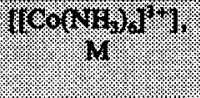 } & \multicolumn{2}{|c|}{ ligdrolysis conditrons } & \multirow[t]{2}{*}{ (1) } \\
\hline & & & T. & I. hours & \\
\hline 1 & 1.0 & 0.003 & 80 & 2 & 7 \\
\hline 2 & 1.0 & 0.006 & 80 & 2 & 7 \\
\hline 3 & 1.0 & 0.012 & 80 & 2 & 11 \\
\hline 4 & 1.0 & 0.024 & 80 & 2 & 12 \\
\hline 5 & 1.0 & 0.05 & 80 & 2 & 15 \\
\hline 6 & 0.5 & 0.024 & 80 & 2 & 10 \\
\hline 7 & 2.0 & 0.024 & 80 & 2 & 3 \\
\hline 8 & 4.0 & 0.024 & 80 & 2 & 2 \\
\hline 9 & 7.0 & 0.024 & 80 & 2 & 1 \\
\hline 10 & 10 & 0.024 & 80 & 2 & 1 \\
\hline
\end{tabular}


Table 2.3-6. Decontamination of $\mathrm{NaOH}$ Solutions from $\mathrm{Np}(\mathrm{V})$ by the Precipitation of $\mathrm{Co}(\mathrm{III})$ Hydroxide from the Hydrolysis of $\left[\mathrm{Co}\left(\mathrm{NH}_{3}\right)_{6}\right]^{3+}$.

$$
[\mathrm{Np}(\mathrm{V})]_{0}=2.8 \times 10^{-4} \mathrm{M} \text {. }
$$

\begin{tabular}{|c|c|c|c|c|c|}
\hline \multirow{2}{*}{ No. } & \multirow{2}{*}{ E) M } & \multirow{2}{*}{ 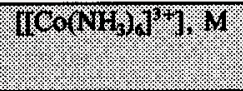 } & \multicolumn{2}{|c|}{ Tydrolysis conditivens } & \multirow{2}{*}{ IIf: } \\
\hline & & & . & I. 1 lomens & \\
\hline 1 & 1.0 & 0.003 & 80 & 2 & 6 \\
\hline 2 & 1.0 & 0.012 & 80 & 2 & 10 \\
\hline 3 & 1.0 & 0.024 & 80 & 2 & 13 \\
\hline 4 & 1.0 & 0.05 & 80 & 2 & 15 \\
\hline 5 & 0.5 & 0.024 & 80 & 2 & 20 \\
\hline 6 & 2.0 & 0.024 & 80 & 2 & 2 \\
\hline 7 & 4.5 & 0.024 & 80 & 2 & 2 \\
\hline 8 & 7.0 & 0.024 & 80 & 2 & 1 \\
\hline 9 & 10.0 & 0.024 & 80 & 2 & 1 \\
\hline
\end{tabular}

The reduction of $\mathrm{Np}(\mathrm{VI})$ to $\mathrm{Np}(\mathrm{V})$ also is observed in the hydrolysis of $\left[\mathrm{Co}\left(\mathrm{NH}_{3}\right)_{5} \mathrm{Cl}\right]^{2+}$. Therefore, only $\mathrm{Np}(\mathrm{V})$ was used in experiments to study neptunium coprecipitation with Co(III) hydroxide obtained from $\left[\mathrm{Co}\left(\mathrm{NH}_{3}\right)_{5} \mathrm{Cl}\right]^{2+}$. As shown in Table 2.3-7, the DF values are small, especially for solutions with high alkali concentrations.

Table 2.3-7. Decontamination of $\mathrm{NaOH}$ Solutions from $\mathrm{Np}(\mathrm{V})$ by the Precipitation of $\mathrm{Co}(\mathrm{III})$ Hydroxide from the Hydrolysis of $\left[\mathrm{Co}\left(\mathrm{NH}_{3}\right)_{5} \mathrm{Cl}\right]^{2+}$.

$[\mathrm{Np}(\mathrm{V})]_{0}=2.8 \times 10^{-4} \mathrm{M}$.

\begin{tabular}{|c|c|c|c|c|c|}
\hline \multirow{2}{*}{ No. } & \multirow{2}{*}{ MaOfI, } & \multirow{2}{*}{ Howory W } & \multicolumn{2}{|c|}{ Hyorolsis conditions } & \multirow[t]{2}{*}{$\mathrm{DF} F$} \\
\hline & & & I. & I. 130010 & \\
\hline 1 & 1.0 & 0.003 & 60 & 2 & 1.5 \\
\hline 2 & 1.0 & 0.006 & 60 & 2 & 2 \\
\hline 3 & $\overline{1.0}$ & 0.012 & 60 & 2 & 2 \\
\hline 4 & 1.0 & 0.024 & 60 & 2 & 2 \\
\hline 5 & 1.0 & 0.05 & 60 & 2 & 4 \\
\hline 6 & 0.5 & 0.024 & 60 & 2 & 12 \\
\hline 7 & 2.0 & 0.024 & 60 & 2 & 5 \\
\hline 8 & 4.0 & 0.024 & 60 & 2 & 2 \\
\hline 9 & $\overline{7.0}$ & 0.024 & 60 & 2 & 1 \\
\hline
\end{tabular}


The poor coprecipitation of $\mathrm{Np}(\mathrm{V})$ with $\mathrm{Co}$ (III) hydroxide could be caused by the presence of neptunium in the form of complex anions of the type $\mathrm{NpO}_{2}(\mathrm{OH})_{\mathrm{n}}^{(1-n)-}$ (Tananaev 1994). With higher alkali concentration, the yield of neptunyl hydroxo complexes of increasingly negative charge grows. As a result, capture of neptunium by the precipitate decreases. In contrast with neptunium, $\mathrm{Pu}(\mathrm{VI})$ and $(\mathrm{V})$ possibly are reduced to $\mathrm{Pu}(\mathrm{IV})$ during the hydrolysis of $\left[\mathrm{Co}\left(\mathrm{NH}_{3}\right)_{6}\right]^{3+}$ and $\left[\mathrm{Co}\left(\mathrm{NH}_{3}\right)_{5} \mathrm{Cl}\right]^{2+}$. The $\mathrm{Pu}(\mathrm{IV})$ would be expected to coprecipitate well with Co(III) hydroxide. Unfortunately, this hypothesis cannot be verified by direct measurements of the absorption spectra of the acid-dissolved precipitates. This is because Co(III), a strong oxidant in acid media, would readily oxidize the carried plutonium and mask any plutonium reduction occurring on the alkaline side.

\subsection{COPRECIPITATION OF Np(VI,V) AND Pu(VI,V) WITH COBALT(II) HYDROXIDE}

According to results related in Part 1, the preparation of $\mathrm{Co}(\mathrm{OH})_{2}$ precipitate by MAR is best accomplished by heating solutions of $\left[\mathrm{Co}\left(\mathrm{NH}_{3}\right)_{5} \mathrm{Cl}\right]^{2+}$ in the presence of $0.1 \mathrm{M}$ hydrazine to $60{ }^{\circ} \mathrm{C}$ for 2 hours. The $\mathrm{NaOH}$ concentration should not exceed $4 \mathrm{M}$.

Results of the coprecipitation of $\mathrm{Pu}(\mathrm{VI})$ achieved under these conditions are presented in Table 2.3-8. The results show that high DF values are observed only for carrier concentrations of 0.006 to $0.024 \mathrm{M}$ in dilute alkaline solutions. The DF drops sharply for $\mathrm{NaOH}$ concentrations higher than $1 \mathrm{M}$. These results indicate that $\mathrm{Co}(\mathrm{OH})_{2}$ is unsatisfactory for plutonium coprecipitation from alkaline solutions.

Table 2.3-8. Decontamination of $\mathrm{NaOH}$ Solutions from $\mathrm{Pu}(\mathrm{VI})$ by the Precipitation of $\mathrm{Co}(\mathrm{OH})_{2}$ from the Hydrolysis of $\left[\mathrm{Co}\left(\mathrm{NH}_{3}\right)_{5} \mathrm{Cl}\right]^{2+}$ in the Presence of $0.1 \mathrm{M} \mathrm{N}_{2} \mathrm{H}_{4}$.

\begin{tabular}{|c|c|c|c|c|c|c|}
\hline \multirow[t]{2}{*}{10} & \multirow[t]{2}{*}{ Wasoly } & \multirow[t]{2}{*}{ Worow } & \multirow{2}{*}{ 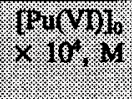 } & \multicolumn{2}{|c|}{ Horogris conditions } & \multirow[t]{2}{*}{10} \\
\hline & & & & 1. & (6) & \\
\hline 1 & 1.0 & 0.003 & 1.15 & 60 & 2 & 100 \\
\hline 2 & 1.0 & 0.006 & 1.15 & 60 & 2 & 200 \\
\hline 3 & 1.0 & 0.012 & 1.15 & 60 & 2 & 200 \\
\hline 4 & 1.0 & 0.024 & 1.15 & 60 & 2 & 300 \\
\hline 5 & 0.5 & 0.024 & 1.15 & 60 & 2 & 320 \\
\hline 6 & 1.0 & 0.024 & 0.98 & 60 & 2 & 290 \\
\hline 7 & 2.0 & 0.024 & 0.98 & 60 & 2 & 75 \\
\hline 8 & 4.0 & 0.024 & 0.98 & 60 & 2 & 25 \\
\hline
\end{tabular}


The precipitation of $\mathrm{Co}(\mathrm{OH})_{2}$ by $\left[\mathrm{Co}\left(\mathrm{NH}_{3}\right)_{5} \mathrm{Cl}\right]^{2+}$ hydrolysis and reduction reactions has an induction period under the strongly reducing conditions created by hydrazine. For this reason, it is certain that $\mathrm{Pu}(\mathrm{VI})$ has time to be reduced to $\mathrm{Pu}(\mathrm{V})$ [and subsequently to $\mathrm{Pu}(\mathrm{IV})$ ] before coprecipitation occurs. Because of the rapid reduction of $\mathrm{Pu}(\mathrm{VI})$ to $\mathrm{Pu}(\mathrm{V})$ by hydrazine, experiments to study Pu(V) behavior were expected to have similar results to those of $\mathrm{Pu}(\mathrm{VI})$. Therefore, experiments of $\mathrm{Pu}(\mathrm{V})$ coprecipitation with $\mathrm{Co}(\mathrm{OH})_{2}$ were not conducted.

Table 2.3-9. Decontamination of $\mathrm{NaOH}$ Solutions from $\mathrm{Np}(\mathrm{V})$ by the Precipitation of $\mathrm{Co}(\mathrm{OH})_{2}$ from the Hydrolysis of $\left[\mathrm{Co}\left(\mathrm{NH}_{3}\right)_{5} \mathrm{Cl}\right]^{2+}$ in the Presence of $0.1 \mathrm{M} \mathrm{N}_{2} \mathrm{H}_{4}$. $[\mathrm{Np}(\mathrm{V})]_{0}=5 \times 10^{-4} \mathrm{M}$.

\begin{tabular}{|c|c|c|c|c|c|}
\hline \multirow[t]{2}{*}{ No. } & \multirow[t]{2}{*}{ NaOH. M } & \multirow{2}{*}{ 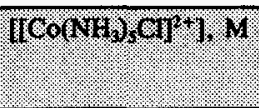 } & \multicolumn{2}{|c|}{ Hydrolysis contifions } & \multirow[t]{2}{*}{ DI } \\
\hline & & & 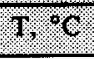 & , hours & \\
\hline 1 & 1.0 & 0.003 & 60 & 2 & 16 \\
\hline 2 & 1.0 & 0.006 & 60 & 2 & 16 \\
\hline 3 & 1.0 & 0.012 & 60 & 2 & 17 \\
\hline 4 & 1.0 & 0.024 & 60 & 2 & 45 \\
\hline 5 & 0.5 & 0.024 & 60 & 2 & 50 \\
\hline 6 & 1.0 & 0.024 & 60 & 2 & 30 \\
\hline 7 & 2.0 & 0.024 & 60 & 2 & 11 \\
\hline 8 & 4.0 & 0.024 & 60 & 2 & 4 \\
\hline
\end{tabular}

The coprecipitation behavior of $\mathrm{Np}(\mathrm{V})$ with $\mathrm{Co}(\mathrm{OH})_{2}$ is given in Table 2.3-9. The $\mathrm{Np}(\mathrm{V})$ DF values in this case are significantly lower than those observed for $\mathrm{Pu}(\mathrm{VI})$. However, the coprecipitation of $\mathrm{Np}(\mathrm{V})$ with $\mathrm{Co}(\mathrm{OH})_{2}$ is noticeably higher than with $\mathrm{Co}(\mathrm{OH})_{3}$ (Table 2.3-6). The higher DF can be explained by the partial reduction of $\mathrm{Np}(\mathrm{V})$ to $\mathrm{Np}(\mathrm{IV})$ by hydrazine in the course of $\left[\mathrm{Co}\left(\mathrm{NH}_{3}\right)_{5} \mathrm{Cl}\right]^{2+}$ hydrolysis.

Because $\mathrm{Np}(\mathrm{VI})$ in alkaline solutions is reduced very rapidly to $\mathrm{Np}(\mathrm{V})$ by hydrazine, its behavior during the precipitation of $\mathrm{Co}(\mathrm{OH})_{2}$ should not differ from that of $\mathrm{Np}(\mathrm{V})$. For this reason, no studies of $\mathrm{Np}(\mathrm{VI})$ coprecipitation by $\mathrm{Co}(\mathrm{OH})_{2}$ were performed. 


\subsection{COPRECIPITATION OF Np(VI,V) AND Pu(VI,V) WITH CHROMIUM(III) HYDROXIDE}

As shown in Part 1, chromium(III) hydroxide in alkaline solutions can be precipitated (using the MAR) by the reduction of $\mathrm{CrO}_{4}^{2-}$ or by the polymerization of soluble hydroxo complexes formed in alkali from hydrated $\mathrm{Cr}^{3+}$. The second method is preferred because it permits simple regulation of the carrier concentration and retains dissolved $\mathrm{CrO}_{4}^{2-}$ in the decontaminated alkaline wastes. For these reasons, $\mathrm{Np}(\mathrm{VI}, \mathrm{V})$ and $\mathrm{Pu}(\mathrm{VI}, \mathrm{V})$ coprecipitation studies by $\mathrm{Cr}(\mathrm{OH})_{3}$ were limited to those involving hydrolysis of $\mathrm{Cr}^{3+}$ by heating.

Optimum conditions to obtain the $\mathrm{Cr}(\mathrm{OH})_{3}$ precipitate from alkaline solutions ( 3 hours' heating at 80 to $85^{\circ} \mathrm{C}$ and $\mathrm{NaOH}$ concentrations not higher than $8 \mathrm{M}$ ) were established in the initial MAR studies. Conditions similar or identical to these were used to study the coprecipitation of penta- and hexavalent $\mathrm{TUE}$ with $\mathrm{Cr}(\mathrm{III})$ hydroxide.

As in the case of $\mathrm{Co}(\mathrm{OH})_{3}$, data from preliminary experiments showed that the DFs of alkaline solutions from $\mathrm{Pu}(\mathrm{VI})$ during $\mathrm{Cr}(\mathrm{OH})_{3}$ precipitation depend primarily on the completeness of the solid-liquid separation. For solutions with 4 to $8 \mathrm{M} \mathrm{NaOH}$, the DFs reached constant values only with 20 minutes' or more centrifugation. This centrifugation time was used for all further experiments.

It also was noticed that the coprecipitation of $\mathrm{Pu}(\mathrm{VI})$ depends to some extent on which initial compound is used to obtain the $\mathrm{Cr}$ (III) hydroxo complexes. With $\mathrm{Cr}$ (III) nitrate or potassium chromium sulfate $\left[\mathrm{KCr}\left(\mathrm{SO}_{4}\right)_{2} \cdot 12 \mathrm{H}_{2} \mathrm{O}\right.$ ], the DF is 1.5 to 2 times lower than with the acetate. Based on these observations, the alkaline $\mathrm{Cr}$ (III) test solutions were prepared using the acetate salt.

As shown in Table 2.3-10, the coprecipitation of $\mathrm{Pu}(\mathrm{VI})$ with $\mathrm{Cr}(\mathrm{III})$ hydroxide, formed during the heating of alkaline solutions to $80^{\circ} \mathrm{C}$, is efficient over a broad range of $\mathrm{NaOH}$ concentration. The DF values for $4 \mathrm{M}$ alkali exceed 100 even with $0.002 \mathrm{M}$ carrier concentration. However, to ensure high decontamination of $\mathrm{Pu}(\mathrm{VI})$ solutions of various compositions, $0.01 \mathrm{M} \mathrm{Cr}$ (III) initial concentrations are recommended.

Other conditions being equal, increasing $\mathrm{NaOH}$ concentration results in decreased DF. Lower temperatures and decreased precipitate coagulation time also decrease DF. Based on these results, a coagulation time of 5 hours, not 3 hours (as proposed in the initial nonspike studies) is recommended. 
Table 2.3-10. Decontamination of $\mathrm{NaOH}$ Solutions from Pu(VI) by the Precipitation of $\mathrm{Cr}$ (III) Hydroxide from $\mathrm{Cr}\left(\mathrm{OOCCH}_{3}\right)_{3}$ Hydrolysis.

$[\mathrm{Pu}(\mathrm{VI})]_{0}=1 \times 10^{-4} \mathrm{M}$.

\begin{tabular}{|c|c|c|c|c|c|}
\hline \multirow{2}{*}{ No. } & \multirow{2}{*}{ Mand W } & \multirow{2}{*}{ 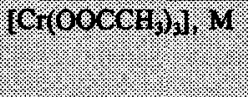 } & \multicolumn{2}{|c|}{ Thy loly gis conditions. } & \multirow[t]{2}{*}{ DF } \\
\hline & & & T. T. 9 & I. hours & \\
\hline 1 & 0.5 & 0.01 & 80 & 5 & 260 \\
\hline 2 & 1.0 & 0.01 & 80 & 5 & 2,300 \\
\hline 3 & 2.0 & 0.01 & 80 & 5 & 960 \\
\hline 4 & 4.0 & 0.01 & 80 & 5 & 300 \\
\hline 5 & 6.0 & 0.01 & 80 & 5 & 120 \\
\hline 6 & 8.0 & 0.01 & 80 & 5 & 86 \\
\hline 7 & 10 & 0.01 & 80 & 5 & 37 \\
\hline 8 & 1.0 & 0.005 & 80 & 5 & 1,600 \\
\hline 9 & 2.0 & 0.005 & 80 & 5 & 630 \\
\hline 10 & 4.0 & 0.005 & 80 & 5 & 240 \\
\hline 11 & 6.0 & 0.005 & 80 & 5 & 130 \\
\hline 12 & 8.0 & 0.005 & 80 & 5 & 84 \\
\hline 13 & 4.0 & 0.002 & 80 & 5 & 140 \\
\hline 14 & 4.0 & 0.02 & 80 & 5 & 360 \\
\hline 15 & 4.0 & 0.05 & 80 & 5 & 430 \\
\hline 16 & 4.0 & 0.01 & 80 & 7 & 320 \\
\hline 17 & 4.0 & 0.01 & 80 & 3 & 190 \\
\hline 18 & 4.0 & 0.01 & 80 & 2 & 90 \\
\hline 19 & 4.0 & 0.01 & 80 & 1 & 16 \\
\hline 20 & 4.0 & 0.01 & 60 & 3 & 15 \\
\hline 21 & 4.0 & 0.01 & 70 & 3 & 90 \\
\hline 22 & 4.0 & 0.01 & 90 & 3 & 120 \\
\hline
\end{tabular}


The general behavior of $\mathrm{Pu}(\mathrm{VI})$ in coprecipitation reactions with $\mathrm{Cr}(\mathrm{III})$ hydroxide also is largely observed with $\mathrm{Pu}(\mathrm{V})$ (Table 2.3-11). Optimum conditions for precipitation again are $0.01 \mathrm{M}$ carrier concentration, $80{ }^{\circ} \mathrm{C}$ solution temperature, and 5 hours precipitate coagulation.

In contrast with $\mathrm{Pu}(\mathrm{V}), \mathrm{Np}(\mathrm{V})$ coprecipitates poorly with $\mathrm{Cr}(\mathrm{OH})_{3}$ (Table 2.3-12). To determine the reason for this disparity, a qualitative study was performed of the stability of hexa- and pentavalent neptunium and plutonium in alkaline solutions containing $\mathrm{Cr}$ (III) hydroxo complexes heated to $80^{\circ} \mathrm{C}$. At selected time intervals, the absorption spectra of acidified mother solutions and $3 \mathrm{M} \mathrm{HClO}_{4}$ acid-dissolved precipitates were measured. The spectral evidence shows that $\mathrm{Np}(\mathrm{VI})$ and $\mathrm{Pu}(\mathrm{VI})$ in heated alkaline solutions of $\mathrm{Cr}(\mathrm{III})$ acetate are reduced rather rapidly to their pentavalent states. With time, the product $N p(V)$ remains unchanged while the $\mathrm{Pu}(\mathrm{V})$ gradually transforms to the tetravalent state and concentrates in the $\mathrm{Cr}(\mathrm{OH})_{3}$ precipitate.

Table 2.3-11. Decontamination of $\mathrm{NaOH}$ Solutions from $\mathrm{Pu}(\mathrm{V})$ by the Precipitation of $\mathrm{Cr}(\mathrm{III}) \mathrm{Hydroxide}$ from $\mathrm{Cr}\left(\mathrm{OOCCH}_{3}\right)_{3}$ Hydrolysis.

$$
[\mathrm{Pu}(\mathrm{V})]_{0}=1 \times 10^{-4} \mathrm{M} \text {. }
$$

\begin{tabular}{|c|c|c|c|c|c|}
\hline \multirow[t]{2}{*}{110} & \multirow{2}{*}{ NaOH, M } & \multirow{2}{*}{ Ifrogernofl, w } & \multicolumn{2}{|c|}{ Hydrolyfis gonations } & \multirow[t]{2}{*}{$\mathrm{DF}$} \\
\hline & & & T. T. & i. frours & \\
\hline 1 & 0.5 & 0.01 & 80 & 5 & 340 \\
\hline 2 & 1.0 & 0.01 & 80 & 5 & $\sim 2,000$ \\
\hline 3 & 2.0 & 0.01 & 80 & 5 & 1,100 \\
\hline 4 & 4.0 & 0.01 & 80 & 5 & 450 \\
\hline 5 & 6.0 & 0.01 & 80 & 5 & 180 \\
\hline 6 & 8.0 & 0.01 & 80 & 5 & 100 \\
\hline 7 & 4.0 & 0.005 & 80 & 5 & 130 \\
\hline 8 & 4.0 & 0.01 & 80 & 5 & 310 \\
\hline 9 & 4.0 & 0.02 & 80 & 5 & 420 \\
\hline 10 & 4.0 & 0.05 & 80 & 5 & 680 \\
\hline 11 & 4.0 & 0.01 & 80 & 3 & 100 \\
\hline
\end{tabular}


Table 2.3-12. Decontamination of $\mathrm{NaOH}$ Solutions from $\mathrm{Np}(\mathrm{V})$ by the Precipitation of $\mathrm{Cr}$ (III) Hydroxide from $\mathrm{Cr}\left(\mathrm{OOCCH}_{3}\right)_{3}$ Hydrolysis.

$[\mathrm{Np}(\mathrm{V})]_{0}=2.5 \times 10^{-4} \mathrm{M}$.

\begin{tabular}{|c|c|c|c|c|c|}
\hline \multirow{2}{*}{ No: } & \multirow{2}{*}{ marm, in } & \multirow{2}{*}{ Iemoromingin } & \multicolumn{2}{|c|}{ Inydrolysis conditions. } & \multirow[t]{2}{*}{ DF } \\
\hline & & & T. T: 9 & it hours & \\
\hline 1 & 0.5 & 0.01 & 80 & 5 & 300 \\
\hline 2 & 1.0 & 0.01 & 80 & 5 & 140 \\
\hline 3 & 2.0 & 0.01 & 80 & 5 & 13 \\
\hline 4 & 4.0 & 0.01 & 80 & 5 & 2.7 \\
\hline 5 & 7.0 & 0.01 & 80 & 5 & 1.1 \\
\hline 6 & 10 & 0.01 & 80 & 5 & 1 \\
\hline 7 & 4.0 & 0.005 & 80 & 5 & 1.5 \\
\hline 8 & 4.0 & 0.02 & 80 & 5 & 4 \\
\hline 9 & 4.0 & 0.05 & 80 & 5 & 6 \\
\hline
\end{tabular}

The difference in the way neptunium and plutonium behave during the production of $\mathrm{Cr}(\mathrm{OH})_{3}$ by heating their hydroxo complexes can be explained by the fact that they are reduced and concentrated in the precipitate in different oxidation states; $\mathrm{Pu}(\mathrm{IV})$ is extracted from the solution very completely, but $\mathrm{Np}(\mathrm{V})$ only partially. The mechanism of these differing redox reactions must be considered more fully.

One possible explanation is that $\mathrm{Pu}(\mathrm{V})$, in contrast with $\mathrm{Np}(\mathrm{V})$, disproportionates [to the (IV) and (VI) states] on heating in alkaline solution. At the same time, both $\mathrm{Pu}(\mathrm{VI})$ and $\mathrm{Np}(\mathrm{VI})$ are reduced by water to their pentavalent states. Because of disproportionation, the plutonium ultimately becomes entirely $\mathrm{Pu}(\mathrm{IV})$ while the neptunium reduces only to $\mathrm{Np}(\mathrm{V})$.

Because neptunium(VI) is unstable in hot alkaline solutions of $\mathrm{Cr}$ (III) acetate, its coprecipitation with $\mathrm{Cr}(\mathrm{OH})_{3}$ must be the same as that of $\mathrm{Np}(\mathrm{V})$. Therefore, additional studies of $\mathrm{Np}$ (VI) coprecipitation by $\mathrm{Cr}(\mathrm{III})$ hydroxide were not performed.

\subsection{COPRECIPITATION OF Np(VI,V) AND Pu(VI,V) WITH IRON(III) HYDROXIDE}

In the investigations described in Part 1, two techniques for the precipitation of Fe(III) hydroxide from alkaline solutions using the MAR were studied: the reduction of $\mathrm{FeO}_{4}^{-2}$ and the hydrolysis of $\left[\mathrm{Fe}(\mathrm{CN})_{5} \mathrm{NO}\right]^{2-}$. Recommended conditions to form $\mathrm{Fe}(\mathrm{III})$ hydroxide from 
ferrate included room temperature precipitation followed by 2 hours coagulation. However, preliminary experiments on the coprecipitation of $\mathrm{Pu}(\mathrm{VI})$ with $\mathrm{Fe}(\mathrm{III})$ hydroxide showed that decontamination is more effective if the carrier coagulation occurs with 50 to $60^{\circ} \mathrm{C}$ heating. Therefore, $\mathrm{FeO}_{4}^{2-}$ reduction and precipitate coagulation were accomplished with heating. To achieve complete precipitation of Fe(III) hydroxide, the suspensions were cooled to room temperature before centrifugation.

As demonstrated in Table 2.3-13, the coprecipitation of Pu(VI) with Fe(III) hydroxide, formed by the reduction of ferrate with hydrazine, is effective over the entire 0.5 to $8 \mathrm{M} \mathrm{NaOH}$ range studied. The DF values for $4 \mathrm{M}$ alkali decrease with decreasing initial $\mathrm{FeO}_{4}^{2-}$ concentration but still exceed 100 even for carrier concentrations of $0.003 \mathrm{M}$. However, to ensure high decontamination of various solutions from $\mathrm{Pu}(\mathrm{VI})$, the initial concentration of $\mathrm{FeO}_{4}^{2-}$ should be $0.01 \mathrm{M}$. Variations in the temperature $\left(50\right.$ to $\left.70^{\circ} \mathrm{C}\right)$ and the duration of precipitate coagulation ( 1 to 3 hours) have no significant influence on DF.

Table 2.3-13. Decontamination of $\mathrm{NaOH}$ Solutions from $\mathrm{Pu}(\mathrm{VI})$ by the Precipitation of $\mathrm{Fe}(\mathrm{III})$ Hydroxide from $\mathrm{FeO}_{4}^{2-}$ Reduction with $0.02 \mathrm{M}$ Excess $\mathrm{N}_{2} \mathrm{H}_{4}$.

$$
[\mathrm{Pu}(\mathrm{VI})]_{0}=1 \times 10^{-4} \mathrm{M} \text {. }
$$

\begin{tabular}{|c|c|c|c|c|c|}
\hline \multirow{2}{*}{ No. } & \multirow{2}{*}{ MaOm } & \multirow[t]{2}{*}{ Ireo, 11} & \multicolumn{2}{|c|}{ Hydrolysts conditions } & \multirow[t]{2}{*}{ DP: } \\
\hline & & & T. & 1, 1001 is & \\
\hline 1 & 0.5 & 0.01 & 60 & 2 & 370 \\
\hline 2 & 1.0 & 0.01 & 60 & 2 & 510 \\
\hline 3 & 2.0 & 0.01 & 60 & 2 & 1,000 \\
\hline 4 & 4.0 & 0.01 & 60 & 2 & 420 \\
\hline 5 & 6.0 & 0.01 & 60 & 2 & 260 \\
\hline 6 & 8.0 & 0.01 & 60 & 2 & 140 \\
\hline 7 & 4.0 & 0.003 & 60 & 2 & 190 \\
\hline 8 & 4.0 & 0.006 & 60 & 2 & 300 \\
\hline 9 & 4.0 & 0.01 & 60 & 2 & 490 \\
\hline 10 & 4.0 & 0.02 & 60 & 2 & 930 \\
\hline 11 & 4.0 & 0.03 & 60 & 2 & 1,600 \\
\hline 12 & 4.0 & 0.004 & 70 & 1 & 210 \\
\hline 13 & 4.0 & 0.004 & 70 & 3 & 340 \\
\hline 14 & 4.0 & 0.004 & 50 & 1 & 120 \\
\hline 15 & 4.0 & 0.004 & 50 & 3 & 170 \\
\hline
\end{tabular}


The behaviors of $\mathrm{Pu}(\mathrm{V})$ and $\mathrm{Np}(\mathrm{V})$ during the coprecipitation of $\mathrm{Fe}(\mathrm{III})$ hydroxide from alkaline ferrate solutions using the MAR cannot differ from the behavior of the hexavalent forms of these elements. This is because $\mathrm{Pu}(\mathrm{V})$ and $\mathrm{Np}(\mathrm{V})$ in alkaline solutions are oxidized rapidly by $\mathrm{FeO}_{4}^{2-}$ to $\mathrm{Pu}(\mathrm{VI})$ and $\mathrm{Np}(\mathrm{VI})$, respectively. Thus, no matter whether plutonium and neptunium in the alkaline media are initially present in the penta- or hexavalent forms, their oxidation states after ferrate addition are hexavalent.

Similarly, in the presence of excess hydrazine, hexavalent plutonium is reduced first to the pentavalent then to the tetravalent state; hexavalent neptunium is reduced primarily to the pentavalent state (Shilov et al. 1996). For these reasons, additional experiments on the coprecipitation of $\mathrm{Np}(\mathrm{V})$ and $\mathrm{Pu}(\mathrm{V})$ with $\mathrm{Fe}(\mathrm{III})$ hydroxide by reduction of ferrate with hydrazine were not performed.

The coprecipitation of Pu(VI) with Fe(III) hydroxide, obtained by hydrolytic decomposition of nitroprusside, proceeds as effectively as was observed using ferrate for the initial reagent (Table 2.3-14). In both cases, the dependence of DF on the carrier and alkali concentrations remains the same. Additionally, the DF observed in the decomposition of $\left[\mathrm{Fe}(\mathrm{CN})_{5} \mathrm{NO}\right]^{2-}$ to form Fe(III) hydroxide is not affected by the initial plutonium oxidation state (Table 2.3-15). Apparently, in the course of coprecipitation, the plutonium is stabilized in the same chemical form, independent of its initial oxidation state. 
Table 2.3-14. Decontamination of $\mathrm{NaOH}$ Solutions from $\mathrm{Pu}(\mathrm{VI})$ by the Precipitation of $\mathrm{Fe}(\mathrm{III})$ Hydroxide from $\left[\mathrm{Fe}(\mathrm{CN})_{5} \mathrm{NO}\right]^{2-}$ Hydrolysis.

$[\mathrm{Pu}(\mathrm{VI})]_{0}=5 \times 10^{-5} \mathrm{M}$.

\begin{tabular}{|c|c|c|c|c|c|}
\hline \multirow[t]{2}{*}{180.} & \multirow{2}{*}{ W.1.1. } & \multirow{2}{*}{ 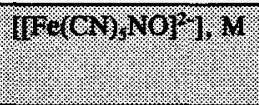 } & \multicolumn{2}{|c|}{ IIVdrolysis conditions } & \multirow[t]{2}{*}{$\mathrm{Br}$} \\
\hline & & & 1. 1.0 & 1. 13ars & \\
\hline 1 & 0.5 & 0.02 & 80 & 3 & $\sim 2,000$ \\
\hline 2 & 1.0 & 0.02 & 80 & 3 & $\sim 1,300$ \\
\hline 3 & 2.0 & 0.02 & 80 & 3 & $\sim 1,500$ \\
\hline 4 & 4.0 & 0.02 & 80 & 3 & 800 \\
\hline 5 & 7.0 & 0.02 & 80 & 3 & 90 \\
\hline 6 & 10.0 & 0.02 & 80 & 3 & 45 \\
\hline 7 & 4.0 & 0.003 & 80 & 3 & 40 \\
\hline 8 & 4.0 & 0.01 & 80 & 3 & 210 \\
\hline 9 & 4.0 & 0.02 & 80 & 3 & 500 \\
\hline 10 & 4.0 & 0.03 & 80 & 3 & 880 \\
\hline 11 & 4.0 & 0.01 & 70 & 3 & 810 \\
\hline 12 & 4.0 & 0.01 & 90 & 3 & 390 \\
\hline 13 & 4.0 & 0.01 & 80 & 1 & 240 \\
\hline 14 & 4.0 & 0.01 & 80 & 2 & 620 \\
\hline 15 & 4.0 & 0.01 & 80 & 4 & 300 \\
\hline
\end{tabular}


Table 2.3-15. Decontamination of $\mathrm{NaOH}$ Solutions from $\mathrm{Pu}(\mathrm{V})$ by the Precipitation of $\mathrm{Fe}(\mathrm{III})$ Hydroxide from $\left[\mathrm{Fe}(\mathrm{CN})_{5} \mathrm{NO}^{2-}\right.$ Hydrolysis.

$$
[\mathrm{Pu}(\mathrm{V})]_{0}=5 \times 10^{-5} \mathrm{M} \text {. }
$$

\begin{tabular}{|c|c|c|c|c|c|}
\hline \multirow{2}{*}{ 19. } & \multirow{2}{*}{ Ma.6191. } & \multirow{2}{*}{ 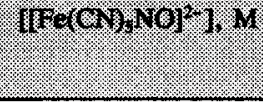 } & \multicolumn{2}{|c|}{ Irydrolyor condinions } & \multirow[t]{2}{*}{ DF } \\
\hline & & & T. 9. & 4. 16ours & \\
\hline 1 & 0.5 & 0.02 & 80 & 3 & $\sim 3,000$ \\
\hline 2 & 2.0 & 0.02 & 80 & 3 & $\sim 1,500$ \\
\hline 3 & 10.0 & 0.02 & 80 & 3 & 70 \\
\hline 4 & 4.0 & 0.003 & 80 & 3 & 30 \\
\hline 5 & 4.0 & 0.01 & 80 & 3 & 530 \\
\hline 6 & 4.0 & 0.03 & 80 & 3 & 830 \\
\hline 7 & 4.0 & 0.01 & 70 & 3 & 860 \\
\hline 8 & 4.0 & 0.01 & 90 & 3 & $\sim 1,000$ \\
\hline 9 & 4.0 & 0.01 & 80 & 1 & 300 \\
\hline 10 & 4.0 & 0.01 & 80 & 4 & 800 \\
\hline
\end{tabular}

The coprecipitation of $\mathrm{Np}(\mathrm{VI})$ with $\mathrm{Fe}(\mathrm{III})$ hydroxide, formed by the reduction of $\mathrm{FeO}_{4}^{2-}$ by hydrazine, yields significantly lower DF values than those observed with Pu(VI) (Table 2.3-16). Evidently, as was mentioned before, this is because neptunium is only partially reduced to the poorly soluble tetravalent state whereas plutonium is reduced to this state quantitatively.

In contrast with $\mathrm{Pu}(\mathrm{VI})$ and $(\mathrm{V}), \mathrm{Np}(\mathrm{VI})$ and $(\mathrm{V})$ yield very low DF values in their coprecipitation with $\mathrm{Fe}(\mathrm{III})$ hydroxide produced by $\left[\mathrm{Fe}(\mathrm{CN})_{5} \mathrm{NO}^{2-}\right.$ hydrolysis (Tables 2.3-17 and 2.3-18). Again, it seems the difference in the final neptunium and plutonium oxidation states is responsible for their different coprecipitation behaviors. 
Table 2.3-16. Decontamination of $\mathrm{NaOH}$ Solutions from $\mathrm{Np}$ (VI) by the Precipitation of $\mathrm{Fe}(\mathrm{III}) \mathrm{Hydroxide}$ from $\mathrm{FeO}_{4}^{2-}$ Reduction with $0.02 \mathrm{M}$ Excess $\mathrm{N}_{2} \mathrm{H}_{4}$. $[\mathrm{Np}(\mathrm{VI})]_{0}=2.5 \times 10^{-4} \mathrm{M}$.

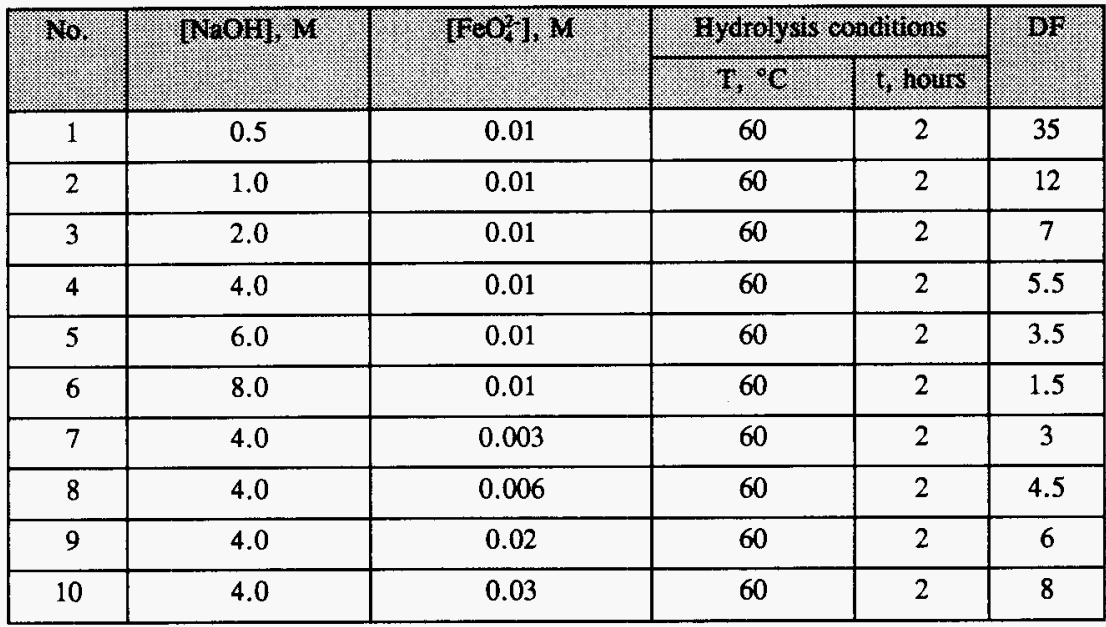


Table 2.3-17. Decontamination of $\mathrm{NaOH}$ Solutions from $\mathrm{Np}$ (VI) by the Precipitation of $\mathrm{Fe}(\mathrm{III})$ Hydroxide from $\left[\mathrm{Fe}(\mathrm{CN})_{5} \mathrm{NO}\right]^{2-}$ Hydrolysis.

$[\mathrm{Np}(\mathrm{VI})]_{0}=2.5 \times 10^{-4} \mathrm{M}$.

\begin{tabular}{|c|c|c|c|c|c|}
\hline \multirow{2}{*}{$\frac{119}{10}$} & \multirow{2}{*}{ magrim: 9} & \multirow{2}{*}{ 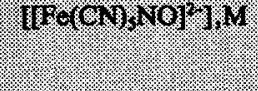 } & \multicolumn{2}{|c|}{ Tyydrolysts ceridincons } & \multirow[t]{2}{*}{ DF } \\
\hline & & & T. & 1.10013 & \\
\hline 1 & 0.5 & 0.015 & 80 & 3 & 25 \\
\hline 2 & 1.0 & 0.015 & 80 & 3 & 18 \\
\hline 3 & 2.0 & 0.015 & 80 & 3 & 11 \\
\hline 4 & 4.0 & 0.015 & 80 & 3 & 7 \\
\hline 5 & 6.0 & 0.015 & 80 & 3 & 5 \\
\hline 6 & 4.0 & 0.008 & 80 & 3 & 2.5 \\
\hline 7 & 4.0 & 0.01 & 80 & 3 & 3 \\
\hline 8 & 4.0 & 0.02 & 80 & 3 & 5 \\
\hline 9 & 4.0 & 0.03 & 80 & 3 & 5.5 \\
\hline 10 & 4.0 & 0.02 & 70 & 2 & 5.2 \\
\hline 11 & 4.0 & 0.02 & 90 & 2 & 7.5 \\
\hline 12 & 4.0 & 0.02 & 70 & 1 & 4.5 \\
\hline 13 & 4.0 & 0.02 & 90 & 1 & 4.2 \\
\hline
\end{tabular}


Table 2.3-18. Decontamination of $\mathrm{NaOH}$ Solutions from $\mathrm{Np}(\mathrm{V})$ by the Precipitation of $\mathrm{Fe}(\mathrm{III})$ Hydroxide from $\left[\mathrm{Fe}(\mathrm{CN})_{5} \mathrm{NO}^{2-}\right.$ Hydrolysis.

$$
[\mathrm{Np}(\mathrm{V})]_{0}=2.5 \times 10^{-4} \mathrm{M} \text {. }
$$

\begin{tabular}{|c|c|c|c|c|c|}
\hline \multirow[t]{2}{*}{ 10. } & \multirow[t]{2}{*}{ MX:\% } & \multirow[t]{2}{*}{ 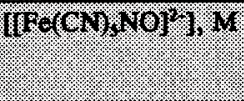 } & \multicolumn{2}{|c|}{ Hordigly sis sondilons } & \multirow[t]{2}{*}{ 1917 } \\
\hline & & & 1. & 1. & \\
\hline 1 & 0.5 & 0.02 & 80 & 3 & 14 \\
\hline 2 & 2.0 & 0.02 & 80 & 3 & 3.5 \\
\hline 3 & 4.0 & 0.02 & 80 & 3 & 2.5 \\
\hline 4 & 7.0 & 0.02 & 80 & 3 & 1.5 \\
\hline 5 & 4.0 & 0.003 & 80 & 3 & 3 \\
\hline 6 & 4.0 & 0.01 & 80 & 3 & 2.7 \\
\hline 7 & 4.0 & 0.03 & 80 & 3 & 5 \\
\hline
\end{tabular}

\subsection{COPRECIPITATION OF Np(VI,V) AND Pu(VI,V) WITH MANGANESE DIOXIDE}

It was shown earlier that hydrogen peroxide, sulfite, and formate are effective reductants to obtain manganese dioxide from alkaline $\mathrm{KMnO}_{4}$ solutions using the $\mathrm{MAR}$. The reaction with $\mathrm{H}_{2} \mathrm{O}_{2}$ proceeds rapidly even in the cold. Preliminary experiments on the coprecipitation of Pu(VI) with manganese dioxide have shown that the efficiency of the process does not depend on which permanganate reductant is used. Therefore, subsequent experiments were conducted using only $\mathrm{H}_{2} \mathrm{O}_{2}$ to precipitate manganese dioxide.

To accelerate precipitate coagulation, the reaction was accomplished with heating. However, centrifugation was conducted only after cooling the solutions to room temperature. In performing the experiments, it was recognized that alkaline $\mathrm{MnO}_{4}^{-}$solutions oxidize $\mathrm{Pu}(\mathrm{V})$ and $\mathrm{Np}(\mathrm{V})$ to their hexavalent states very rapidly. Thus, it was reasonable, in the course of the $\mathrm{KMnO}_{4}$ reduction and manganese dioxide precipitation studies, to examine only the behaviors of $\mathrm{Pu}(\mathrm{VI})$ and $\mathrm{Np}(\mathrm{VI})$. Evidently, $\mathrm{Pu}(\mathrm{VI})$ and $\mathrm{Np}(\mathrm{VI})$ are rapidly reduced to their pentavalent forms after excess $\mathrm{H}_{2} \mathrm{O}_{2}$ is added to the alkaline solutions. The pentavalent $\mathrm{Np}$ and $\mathrm{Pu}$ are then coprecipitated by manganese dioxide.

As shown in Table 2.3-19, the decontamination of alkaline solutions from plutonium is poor under all studied conditions. With the exception of 0.5 to $1 \mathrm{M}$ alkali, the DF remains low independent of the $\mathrm{NaOH}$ and carrier concentrations, the temperature, and the time of coagulation. Similar results are observed for $\mathrm{Np}$ (VI) (Table 2.3-20). 
Table 2.3-19. Decontamination of $\mathrm{NaOH}$ Solutions from $\mathrm{Pu}(\mathrm{VI})$ by the Precipitation of $\mathrm{MnO}_{2}$ from $\mathrm{MnO}_{4}^{-}$Reduction with $0.05 \mathrm{M} \mathrm{H}_{2} \mathrm{O}_{2}$. $[\mathrm{Pu}(\mathrm{VI})]_{0}=5 \times 10^{-5} \mathrm{M}$.

\begin{tabular}{|c|c|c|c|c|c|}
\hline \multirow{2}{*}{ 160 } & \multirow{2}{*}{ 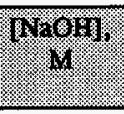 } & \multirow[t]{2}{*}{ I Who I, M } & \multicolumn{2}{|c|}{ Roduction condritions } & \multirow[t]{2}{*}{ 13?: } \\
\hline & & & 1.80 & t. hours & \\
\hline 1 & 0.5 & 0.01 & 50 & 3 & 70 \\
\hline 2 & 1.0 & 0.01 & 50 & 3 & 80 \\
\hline 3 & 2.0 & 0.01 & 50 & 3 & 4 \\
\hline 4 & 4.0 & 0.01 & 50 & 3 & 4 \\
\hline 5 & 7.0 & 0.01 & 50 & 3 & 2 \\
\hline 6 & 4.0 & 0.005 & 50 & 3 & 8 \\
\hline 7 & 4.0 & 0.01 & 50 & 3 & 4 \\
\hline 8 & 4.0 & 0.02 & 50 & 3 & 3 \\
\hline 9 & 4.0 & 0.03 & 50 & 3 & 5 \\
\hline 10 & 4.0 & 0.01 & 25 & 3 & 9 \\
\hline 11 & 4.0 & 0.01 & 25 & 2 & 7 \\
\hline
\end{tabular}


Table 2.3-20. Decontamination of $\mathrm{NaOH}$ Solutions from $\mathrm{Np}(\mathrm{VI})$ by the Precipitation of $\mathrm{MnO}_{2}$ from $\mathrm{MnO}_{4}^{-}$Reduction with $0.05 \mathrm{M} \mathrm{H}_{2} \mathrm{O}_{2}$.

$[\mathrm{Np}(\mathrm{VI})]_{0}=5 \times 10^{-4} \mathrm{M}$.

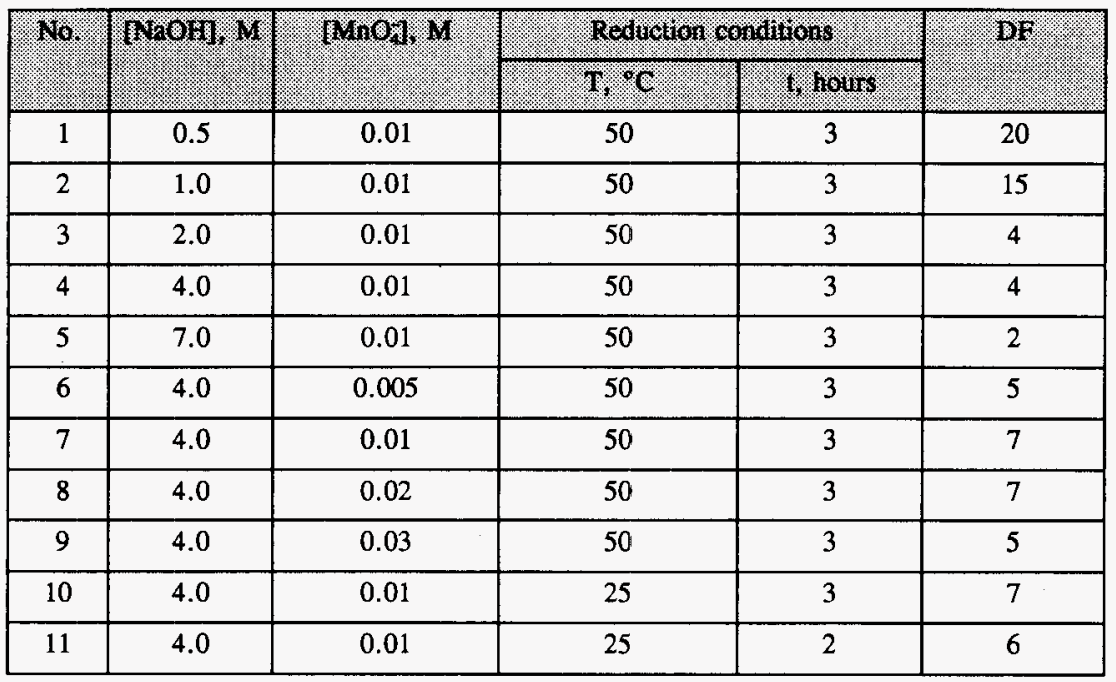

The results are consistent and caused by the peculiar features of manganese dioxide as a sorbent. At high $\mathrm{pH}$, manganese dioxide primarily captures cations from solution (Egorov et al. 1961 and Leont'eva and Vol'khin 1968) whereas the TUE(VI,V) are present in alkaline solution in the form of anionic hydroxo complexes (Visyascheva et al. 1984, Tananaev 1990, and Tananaev 1994). Based on these results, manganese dioxide precipitate cannot be recommended as a carrier in the MAR for the decontamination of solutions from TUE in the penta- or hexavalent forms.

\subsection{COPRECIPITATION OF Np(VI,V) AND Pu(VI,V) WITH MANGANESE(II) HYDROXIDE}

According to the results of Part 1 of this project, the precipitation of $\mathrm{Mn}\left(\mathrm{OH}_{2}\right.$ from alkaline solutions of $\mathrm{KMnO}_{4}$ is best conducted by adding excess hydroxylamine followed by 2 to 3 hours' precipitate coagulation at room temperature. However, preliminary experiments have shown that the completeness of $\mathrm{Pu}(\mathrm{VI})$ coprecipitation with $\mathrm{Mn}(\mathrm{OH})_{2}$ increases if the precipitate is coagulated by heating to 40 to $60^{\circ} \mathrm{C}$. Therefore, the behavior of $\mathrm{Np}(\mathrm{VI})$ and $\mathrm{Pu}(\mathrm{IV})$ during precipitation of $\mathrm{Mn}(\mathrm{OH})_{2}$ from hot solutions was studied. As in the case of 
the precipitation of manganese dioxide, neptunium and plutonium were introduced to the alkaline test solutions only in the hexavalent state, because $\mathrm{Np}(\mathrm{V})$ and $\mathrm{Pu}(\mathrm{V})$ are rapidly oxidized by $\mathrm{MnO}_{4}^{-}$.

From the data presented in Table 2.3-21, it follows that the precipitation of $\mathrm{Mn}(\mathrm{OH})_{2}$ from alkaline solutions containing $\mathrm{Pu}(\mathrm{VI})$ and $\mathrm{MnO}_{4}^{-}$by adding excess $\mathrm{NH}_{2} \mathrm{OH}$ provides ample transfer of plutonium to the solid phase. As expected, the DF increases with increasing initial $\mathrm{KMnO}_{4}$ concentration. To guarantee high decontamination of the solutions from plutonium, $\mathrm{KMnO}_{4}$ concentrations should be 0.01 to $0.02 \mathrm{M}$. Since DF decreases with increasing alkali concentration, $\mathrm{NaOH}$ concentrations should not exceed $4 \mathrm{M}$.

Table 2.3-21. Decontamination of $\mathrm{NaOH}$ Solutions from $\mathrm{Pu}(\mathrm{VI})$ by the Precipitation of $\mathrm{Mn}(\mathrm{OH})_{2}$ from $\mathrm{MnO}_{4}^{-}$Reduction with $0.05 \mathrm{M} \mathrm{NH}_{2} \mathrm{OH}$.

$[\mathrm{Pu}(\mathrm{VI})]_{0}=1 \times 10^{-4} \mathrm{M}$.

\begin{tabular}{|c|c|c|c|c|c|}
\hline \multirow[t]{2}{*}{ No. } & \multirow{2}{*}{ Hoshoris } & \multirow[t]{2}{*}{ 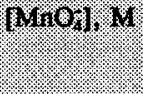 } & \multicolumn{2}{|c|}{ 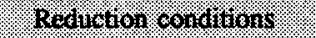 } & \multirow[t]{2}{*}{ DH. } \\
\hline & & & 1.4 & 6. & \\
\hline 1 & 0.5 & 0.01 & 50 & 3 & 430 \\
\hline 2 & 1.0 & 0.01 & 50 & 3 & 260 \\
\hline 3 & 2.0 & 0.01 & 50 & 3 & 250 \\
\hline 4 & 4.0 & 0.01 & 50 & 3 & 200 \\
\hline 5 & 7.0 & 0.01 & 50 & 3 & 30 \\
\hline 6 & 4.0 & 0.005 & 50 & 3 & 70 \\
\hline 7 & 4.0 & 0.01 & 50 & 3 & 210 \\
\hline 8 & 4.0 & 0.02 & 50 & 3 & 400 \\
\hline 9 & 4.0 & 0.03 & 50 & 3 & $>1,500$ \\
\hline 10 & 4.0 & 0.02 & 50 & 1 & 350 \\
\hline 11 & 4.0 & 0.02 & 50 & 4 & 420 \\
\hline 12 & 4.0 & 0.01 & 40 & 3 & 180 \\
\hline 13 & 4.0 & 0.01 & 60 & 3 & 200 \\
\hline
\end{tabular}

The decontamination of alkaline solutions from $\mathrm{Np}(\mathrm{VI})$ by coprecipitation with $\mathrm{Mn}(\mathrm{OH})_{2}$, obtained from $\mathrm{KMnO}_{4}$ using the MAR, is noticeably lower than for $\mathrm{Pu}(\mathrm{VI})$, especially at high $\mathrm{NaOH}$ concentrations (Table 2.3-22). The difference in behavior can be explained by the fact that under the conditions of $\mathrm{Mn}$ (VII) reduction to $\mathrm{Mn}$ (II) by hydroxylamine, $\mathrm{Pu}$ (VI) 
rapidly reduces to $\mathrm{Pu}(\mathrm{V})$ and then to $\mathrm{Pu}(\mathrm{IV})$. Under the same conditions, $\mathrm{Np}(\mathrm{VI})$ is reduced rapidly only to $\mathrm{Np}(\mathrm{V})$, which is rather stable towards further reduction in alkaline solutions against all reductants including hydroxylamine. Consequently, under the test conditions, almost all the plutonium, present as Pu(IV), is coprecipitated; little of the neptunium, present as $\mathrm{Np}(\mathrm{V})$, coprecipitates with $\mathrm{Mn}(\mathrm{OH})_{2}$.

Table 2.3-22. Decontamination of $\mathrm{NaOH}$ Solutions from $\mathrm{Np}(\mathrm{VI})$ by the Precipitation of $\mathrm{Mn}(\mathrm{OH})_{2}$ by $\mathrm{MnO}_{4}^{-}$Reduction with $0.05 \mathrm{M} \mathrm{NH}_{2} \mathrm{OH}$.

$[\mathrm{Np}(\mathrm{VI})]_{0}=2.5 \times 10^{-4} \mathrm{M}$.

\begin{tabular}{|c|c|c|c|c|c|}
\hline \multirow[t]{2}{*}{ No. } & \multirow{2}{*}{ 6) } & \multirow[t]{2}{*}{$489 \%$} & \multicolumn{2}{|c|}{ rodiletion condiliois } & \multirow[t]{2}{*}{ (o) } \\
\hline & & & $1 \%$ & Whoun & \\
\hline 1 & 0.5 & 0.01 & 50 & 3 & 52 \\
\hline 2 & 1.0 & 0.01 & 50 & 3 & 17 \\
\hline 3 & 2.0 & 0.01 & 50 & 3 & 10 \\
\hline 4 & 4.0 & 0.01 & 50 & 3 & 3 \\
\hline 5 & 7.0 & 0.01 & 50 & 3 & 2.5 \\
\hline 6 & 4.0 & 0.005 & 50 & 3 & 2 \\
\hline 7 & 4.0 & 0.02 & 50 & 3 & 3.3 \\
\hline 8 & 4.0 & 0.03 & 50 & 3 & 4 \\
\hline 9 & 4.0 & 0.01 & 50 & 1 & 3.3 \\
\hline 10 & 4.0 & 0.01 & 50 & 4 & 3.2 \\
\hline 11 & 4.0 & 0.01 & 40 & 3 & 4 \\
\hline 12 & 4.0 & 0.01 & 60 & 3 & 3.5 \\
\hline
\end{tabular}

\subsection{COPRECIPITATION OF Np(VI,V) AND Pu(VI,V) WITH SODIUM URANATES}

The optimum conditions for isolating sodium uranates from alkaline solutions of the uranyl peroxide complex $\left(\left[\mathrm{UO}_{2}\left(\mathrm{O}_{2}\right)_{3}\right]^{4}\right)$ were identified in Part 1. These conditions are $0.005 \mathrm{M} \mathrm{Cu}(\mathrm{II})$ catalyst concentration, $60-^{\circ} \mathrm{C}$ temperature, and 3-hours heating time. The completeness of the coprecipitation of hexa- and pentavalent neptunium and plutonium as functions of the concentrations of carrier and alkali were studied under these conditions.

Results of the investigations, presented in Tables 2.3-23 to 2.3-26, show that the decontamination of alkaline solutions from $\mathrm{Pu}(\mathrm{VI})$ is, under comparable conditions, 
somewhat higher than from $\mathrm{Np}(\mathrm{VI})$. In both cases the decontamination decreases with increasing alkali concentration. The change from the hexavalent to the pentavalent state of neptunium or plutonium has little influence on DF values. This similarity can be explained by the fact that during the addition of $\mathrm{Li}_{4} \mathrm{UO}_{2}\left(\mathrm{O}_{2}\right)_{3}$, which contains excess $\mathrm{H}_{2} \mathrm{O}_{2}, \mathrm{~Np}(\mathrm{VI})$ and $\mathrm{Pu}(\mathrm{VI})$ in alkaline solution are rapidly reduced to their respective pentavalent states and form peroxo complexes (Musicas 1970, Musicas 1971, and Musicas 1974). As a result, the neptunium and plutonium proceed to their same respective final oxidation states during the isolation of uranate precipitates whether or not hexa- or pentavalent TUE was initially present in the alkaline solutions. It is also likely that during the decomposition of the peroxo complexes, $\mathrm{Pu}(\mathrm{V})$, in contrast with $\mathrm{Np}(\mathrm{V})$, partially reduces to the tetravalent state (Musicas 1971). Because of this, the DF values for plutonium are somewhat higher than those observed for neptunium.

Table 2.3-23. Decontamination of $\mathrm{NaOH}$ Solutions from $\mathrm{Pu}(\mathrm{VI})$ by Sodium Uranate Precipitation from the Catalytic Decomposition of $\left[\mathrm{UO}_{2}\left(\mathrm{O}_{2}\right)_{3}\right]^{4-}$ by $5 \times 10^{-3} \mathrm{M} \mathrm{Cu}(\mathrm{II})$.

$$
[\mathrm{Pu}(\mathrm{VI})]_{0}=5 \times 10^{-5} \mathrm{M} \text {. }
$$

\begin{tabular}{|c|c|c|c|c|c|}
\hline \multirow[t]{2}{*}{40} & \multirow[t]{2}{*}{ Wo } & \multirow[t]{2}{*}{$\mathrm{HO}_{4}(\mathrm{~W}) \mathrm{H}$} & \multicolumn{2}{|c|}{ 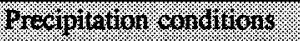 } & \multirow[t]{2}{*}{13} \\
\hline & & & 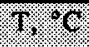 & $16014 \%$ & \\
\hline 1 & 0.5 & 0.01 & 60 & 3 & 610 \\
\hline 2 & 1.0 & 0.01 & 60 & 3 & 860 \\
\hline 3 & 2.0 & 0.01 & 60 & 3 & 320 \\
\hline 4 & 4.0 & 0.01 & 60 & 3 & 170 \\
\hline 5 & 6.0 & 0.01 & 60 & 3 & 60 \\
\hline 6 & 8.0 & 0.01 & 60 & 3 & 30 \\
\hline 7 & 4.0 & 0.002 & 60 & 3 & 25 \\
\hline 8 & 4.0 & 0.004 & 60 & 3 & 80 \\
\hline 9 & 4.0 & 0.008 & 60 & 3 & 330 \\
\hline 10 & 4.0 & 0.012 & 60 & 3 & 410 \\
\hline 11 & 4.0 & 0.016 & 60 & 3 & 450 \\
\hline 12 & 4.0 & 0.020 & 60 & 3 & 500 \\
\hline 13 & 4.0 & 0.01 & 60 & 1 & 150 \\
\hline 14 & 4.0 & 0.01 & 60 & 4 & 120 \\
\hline 15 & 4.0 & 0.01 & 70 & 3 & 110 \\
\hline 16 & 4.0 & 0.01 & 50 & 3 & 140 \\
\hline
\end{tabular}


Table 2.3-24. Decontamination of $\mathrm{NaOH}$ Solutions from $\mathrm{Pu}(\mathrm{V})$ by Sodium Uranate

Precipitation from the Catalytic Decomposition of $\left[\mathrm{UO}_{2}\left(\mathrm{O}_{2}\right)_{3}\right]^{4-}$ by $5 \times 10^{-3} \mathrm{M} \mathrm{Cu}(\mathrm{II})$. $[\mathrm{Pu}(\mathrm{V})]_{0}=5 \times 10^{-5} \mathrm{M}$.

\begin{tabular}{|c|c|c|c|c|c|}
\hline \multirow{2}{*}{ (18: } & \multirow{2}{*}{ 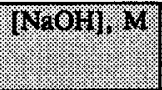 } & \multirow{2}{*}{ Torgand? } & \multicolumn{2}{|c|}{ Preginintion condigions } & \multirow[t]{2}{*}{ DI } \\
\hline & & & 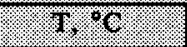 & $1.78011 \%$ & \\
\hline 1 & 0.5 & 0.01 & 60 & 3 & 590 \\
\hline 2 & 1.0 & 0.01 & 60 & 3 & 360 \\
\hline 3 & 4.0 & 0.01 & 60 & 3 & 150 \\
\hline 4 & 6.0 & 0.01 & 60 & 3 & 90 \\
\hline 5 & 8.0 & 0.01 & 60 & 3 & 40 \\
\hline 6 & 4.0 & 0.002 & 60 & 3 & 25 \\
\hline 7 & 4.0 & 0.008 & 60 & 3 & 240 \\
\hline 8 & 4.0 & 0.01 & 60 & 3 & 210 \\
\hline 9 & 4.0 & 0.02 & 60 & 3 & 280 \\
\hline 10 & 4.0 & 0.01 & 60 & 1 & 130 \\
\hline 11 & 4.0 & 0.01 & 60 & 4 & 180 \\
\hline
\end{tabular}

Table 2.3-25. Decontamination of $\mathrm{NaOH}$ Solutions from $\mathrm{Np}$ (VI) by Sodium Uranate Precipitation from the Catalytic Decomposition of $\left[\mathrm{UO}_{2}\left(\mathrm{O}_{2}\right)_{3}\right]^{4-}$ by $5 \times 10^{-3} \mathrm{M} \mathrm{Cu}$ (II). $[\mathrm{Np}(\mathrm{VI})]_{0}=2.5 \times 10^{-4} \mathrm{M}$.

\begin{tabular}{|c|c|c|c|c|c|}
\hline \multirow{2}{*}{ No. } & \multirow{2}{*}{ MVOI1) } & \multirow[t]{2}{*}{ 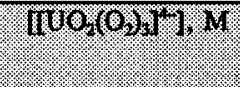 } & \multicolumn{2}{|c|}{ Bteciphaten conditions. } & \multirow{2}{*}{ Br } \\
\hline & & & 1.9 & I. hours & \\
\hline 1 & 0.5 & 0.02 & 60 & 3 & 230 \\
\hline 2 & 1.0 & 0.02 & 60 & 3 & 160 \\
\hline 3 & 2.0 & 0.02 & 60 & 3 & 110 \\
\hline 4 & 4.0 & 0.02 & 60 & 3 & 80 \\
\hline 5 & 6.0 & 0.02 & 60 & 3 & 16 \\
\hline 6 & 8.0 & 0.02 & 60 & 3 & 10 \\
\hline 7 & 4.0 & 0.008 & 60 & 3 & 8 \\
\hline 8 & 4.0 & 0.012 & 60 & 3 & 25 \\
\hline 9 & 4.0 & 0.016 & 60 & 3 & 40 \\
\hline 10 & 4.0 & 0.022 & 60 & 3 & 85 \\
\hline
\end{tabular}


Table 2.3-26. Decontamination of $\mathrm{NaOH}$ Solutions from $\mathrm{Np}(\mathrm{V})$ by Sodium Uranate Precipitation from the Catalytic Decomposition of $\left[\mathrm{UO}_{2}\left(\mathrm{O}_{2}\right)_{3}\right]^{4-}$ by $5 \times 10^{-3} \mathrm{M} \mathrm{Cu}(\mathrm{II})$. $[\mathrm{Np}(\mathrm{V})]_{0}=2.5 \times 10^{-4} \mathrm{M}$.

\begin{tabular}{|c|c|c|c|c|c|}
\hline \multirow{2}{*}{ No. } & \multirow{2}{*}{ IRaOMin. } & \multirow{2}{*}{ 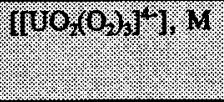 } & \multicolumn{2}{|c|}{ Precigitilion conditions } & \multirow[t]{2}{*}{ TOH } \\
\hline & & & T. $: 0$ & I. hours & \\
\hline 1 & 0.5 & 0.02 & 60 & 3 & 220 \\
\hline 2 & 1.0 & 0.02 & 60 & 3 & 125 \\
\hline 3 & 2.0 & 0.02 & 60 & 3 & 105 \\
\hline 4 & 4.0 & 0.02 & 60 & 3 & 25 \\
\hline 5 & 6.0 & 0.02 & 60 & 3 & 14 \\
\hline 6 & 8.0 & 0.02 & 60 & 3 & 10 \\
\hline 7 & 4.0 & 0.004 & 60 & 3 & 8 \\
\hline 8 & 4.0 & 0.008 & 60 & 3 & 11 \\
\hline 9 & 4.0 & 0.01 & 60 & 3 & 15 \\
\hline 10 & 4.0 & 0.02 & 60 & 3 & 45 \\
\hline
\end{tabular}




\subsection{CONCLUSIONS}

The behaviors of hexa- and pentavalent neptunium and plutonium during the formation of the precipitates of $\mathrm{Fe}(\mathrm{III}), \mathrm{Co}(\mathrm{III})$ and (II), $\mathrm{Mn}$ (II), and $\mathrm{Cr}(\mathrm{III})$ hydroxides; $\mathrm{Mn}$ (IV) oxide; and sodium uranates in alkaline solutions were studied. These precipitates were prepared from alkali-soluble precursor compounds according to conditions identified in Part 1 of the project.

Independent of the initial oxidation state [(V) or (VI)], plutonium was found to coprecipitate well from 0.5 to $4 \mathrm{M} \mathrm{NaOH}$ with all studied carriers except manganese dioxide. The successful plutonium coprecipitation with these carriers is thought to be related to the reduction of plutonium to the poorly soluble tetravalent oxidation state in the course of these reactions.

In contrast, neptunium, present in the initial alkaline solutions in its penta- or hexavalent state, is captured weakly by all hydroxide precipitates, especially at high alkali concentrations. This behavior is thought to be caused by the stabilization of neptunium as anionic $\mathrm{Np}(\mathrm{V})$ hydroxo complexes in the alkaline media. These anionic complexes are assimilated poorly in the formed hydroxide carriers. A significant coprecipitation of $\mathrm{Np}$ (VI) or $(\mathrm{V})$ is, however, observed with sodium uranates. 
WHC-EP-0898

This page intentionally left blank. 


\section{INVESTIGATION OF THE COPRECIPITATION OF TRANSURANIUM ELEMENTS FROM ALKALINE SOLUTION BY THE METHOD OF APPEARING REAGENTS}

\section{PART 3: SUMMARY}

\subsection{DISCUSSION OF THE RESULTS}

The present study, conducted to choose candidate carriers and carrier precursors for the coprecipitation of certain transuranium elements from alkaline solutions, is not complete. It is only the first step to creating effective methods for decontaminating high-activity waste stored in underground tanks on the Hanford Site from long-lived radioelements (e.g., TUE, $\left.{ }^{99} \mathrm{Tc}\right)$. At this stage, prospective carriers have been identified and ways have been tested to precipitate them from alkaline solutions of precursor substances using reduction reactions, hydrolysis, and catalytic decomposition. The behaviors of hexa- and pentavalent neptunium and plutonium during the formation of the product carrier precipitates by the Method of Appearing Reagents (MAR) have been studied.

The hydroxides of $\mathrm{Fe}(\mathrm{III}), \mathrm{Cr}$ (III), $\mathrm{Co}$ (III) and (II), and $\mathrm{Mn}(\mathrm{II}) ; \mathrm{Mn}$ (IV) oxide; and sodium uranates were selected for investigation as prospective carriers for the coprecipitation of TUE from alkaline solutions. Readily available initial (precursor) compounds exist for all these carriers. The precursor compounds have good solubility in alkali and the ability to form amorphous precipitates homogeneously in the bulk alkaline solution by hydrolysis, reduction, or catalytic decomposition reactions.

The rates and the completeness of the isolation of these precipitates depend on their chemical nature. However, most of these processes have a common feature. Namely, with increasing alkali concentration, the formation and coagulation of the precipitates usually decreases. The reasons for this behavior are the increases in density and viscosity of the alkaline solutions, the manifestation of amphoteric properties by the precipitated compounds, and sometimes the inhibition of corresponding redox reactions and hydrolysis as the hydroxide concentration increases. As a result, based on reaction kinetics and the completeness of the isolation of carriers, it is recommended that the alkali concentrations of the initial solutions not be higher than 4 to $6 \mathrm{M}$.

Experimental results on the coprecipitation of neptunium and plutonium, introduced into initial alkaline solutions in their hexa- or pentavalent states, with the previously listed carriers have been gathered. The following points are made based on these studies:

- The decontamination of alkaline solutions from plutonium is usually significantly higher than from neptunium. The most probable reasons for this difference are the corresponding redox reactions these actinides undergo during 
the formation and coagulation of the carrier precipitates. Because of these reactions, plutonium is transferred to the precipitates partially or completely as its tetravalent form. Neptunium is usually stabilized in coprecipitation in its pentavalent state.

- The capture of $\mathrm{Np}(\mathrm{V})$ by the hydroxide precipitates is effective to some extent only for 0.5 to $1 \mathrm{M}$ alkaline solutions. As $\mathrm{NaOH}$ concentration increases, the DF drops sharply. This behavior can be explained by the step formation of the $\mathrm{Np}(\mathrm{V})$ hydroxo complexes $\mathrm{NpO}_{2}(\mathrm{OH})_{2}^{-}, \mathrm{NpO}_{2}(\mathrm{OH})_{3}^{2-}$, and, probably, $\mathrm{NpO}_{2}(\mathrm{OH})_{4}^{3-}$. These anionic complexes are coprecipitated poorly with the transition metal hydroxides, especially as the negative charge of the anion increases.

- The increase in the efficiency of plutonium coprecipitation caused by its reduction to the tetravalent state is obvious and easily explained for carriers that are precipitated in the presence of strong reductants (hydrazine or hydroxylamine). However, the formation of $\mathrm{Pu}(\mathrm{IV})$ during the precipitation of $\mathrm{Co}(\mathrm{III}), \mathrm{Cr}(\mathrm{III})$, and $\mathrm{Fe}$ (III) hydroxides (the last formed by the hydrolysis of nitroprusside), as well as of sodium uranates, is somewhat unexpected. These processes need a special investigation. One can only suppose that they proceed through disproportionation of plutonium(V) in heated alkaline solutions.

In conclusion it is necessary to note that the results obtained are still insufficient to recommend the best carriers and conditions to carry out coprecipitation to achieve high decontamination of alkaline solutions from TUE. Additional information is needed about the behavior of neptunium(IV), plutonium(IV), and americium(III) during formation of carrier precipitates. Information is also needed on the influence of waste component anions (e.g., carbonate, nitrate, nitrite), which possibly possess complexing or redox properties, on the capture by precipitates of TUE in different oxidation states. 


\subsection{ACKNOWLEDGEMENTS}

This work was supported by the U.S. Department of Energy, Office of Science and Technology, under the Office of Environmental Management. We thank in particular Dr. Teresa B. Fryberger, Program Manager, Efficient Separations and Processing Crosscutting Program, for her active interest in our research and for her vigorous support of our program at the Institute of Physical Chemistry, Russian Academy of Sciences. We especially thank Cal Delegard for useful discussions of the experimental results and for his help, with his colleagues at Hanford, to edit and prepare this document for publication. We also thank Dr. Jack Watson, Deputy Coordinator, for his advice and support. We acknowledge, with thanks, the organizational efforts of Dr. Thomas Albert in contract implementation. 
WHC-EP-0898

This page intentionally left blank. 


\subsection{REFERENCES}

Antoniu, N. K., A. M. Egorov, N. N. Sevryukov, and G. E. Ermolina, 1983, "Kinetics of the Reduction of Chromium(VI) to Chromium(III) by Metallic Aluminum in an Alkaline Medium," Zh. Neorg. Khim., 28, No. 1, pp. 125-128 (in Russian). Journal available in English translation as Russian Journal of Inorganic Chemistry (English Translation).

Barriga, C., A. Calero, J. Morales, and J. L. Tirado, 1989, "Preparation of Mixed Oxides in the Lithium-Cobalt-Oxygen and Lithium-Manganese-Oxygen Systems by Hydrolysis Reactions," Reactivity of Solids, 7 , No. 3, pp. 236-271.

Belyaev, V. P., N. I. Eremin, G. A. Romanov, and Yu. B. Solov'ev, 1975, "On the State of Trivalent Iron in Alkaline and Aluminate Solutions," Trudy VAMI, No. 91, pp. 16-21 (in Russian). Full journal title is Trudy - Vsesoyuznyi Naucho-Issledovatel'skii $i$ Proektnyi Institut Alyuminievoi, Magnievoi i Elektrodnoi Promyshlennosti translated as Transactions - All-Union Scientific Research and Planning Institute of the Aluminum, Magnesium and Electrode Industry. Not available in English translation. [Chem. Abstr., 85:149801z].

Brauer, G., ed., 1981, Handbuch der präparativen anorganischen Chemie, Vol. 3, Ferdinand Enke Verlag, Stuttgart, Germany (in German).

Cherniaev, I. I., ed., 1964, Kompleksnye Soedineniya Urana, Nauka Publ., Moscow, USSR, pp. 40-54 (in Russian). Available in English as Complex Compounds of Uranium, Israel Program for Scientific Translations, Jerusalem, Israel, 1966.

Datta, N. C., 1981, "Chemistry of Iron(III) Oxides and Oxyhydroxides," J. Sci. Indust. Res., 40, No. 9, pp. 571-583.

Delegard, C. H., T. D. Elcan, and B. E. Hey, 1994, Chemistry of Application of Calcination/Dissolution to the Hanford Tank Waste Inventory, WHC-EP-0766, Westinghouse Hanford Company, Richland, Washington, USA.

Egorov, Yu. V., V. V. Pushkarev, and E. V. Tkachenko, 1961, "On the Regularities of Strontium Coprecipitation with Iron Hydroxide and Active Manganese Dioxide from Water Solutions," Zh. Neorg. Khim., 6, No. 2, pp. 505-507 (in Russian). Journal available in English translation as Russian Journal of Inorganic Chemistry (English Translation).

El-Chandour, M. F. M., 1978, "Solubility of Cobaltous Oxide in Different Buffers and Sodium Hydroxide Solutions and Amphoteric Properties of Cobaltous Hydroxide," Indian J. Chem., Sect. A, 16A, No. 2, pp. 160 and 161. 
Ezhov, B. B., A. A. Kamnev, O. G. Malandin, and A. V. Vasev, 1987, "Electrochemical Behavior of Hydroxocomplexes of Iron(III)," Elektrokhimiya, 23, No. 7, pp. 997-1000 (in Russian). Journal available in English translation as Russian Journal of Electrochemistry.

Fox, R. K., D. F. Swinehart, and A. R. Garritt, 1941, "The Equilibria of Manganese Hydroxide, $\mathrm{Mn}(\mathrm{OH})_{2}$, in Solutions of Hydrochloric Acid and Sodium Hydroxide," J. Am. Chem. Soc., 63, No. 7, pp. 1779-1782.

Gershov, V. M., and N. T. Vanaga, 1977, "Characteristics of the Isolation of Cobalt Powder in the System Cobalt(III) Hydroxide - Hydroxyl Ion - Hydrazine," Latv. PSR Zinat. Akad. Vestis, Kim. Ser., No. 2, pp. 170-172 (in Russian). Not available in English translation. [Chem. Abstr. 87:26543a].

Giovanoli, R., E. Stähli, and W. Feitknecht, 1970, "Über Oxidhydroxide des vierwertigen Mangans mit Schichtengitter," Helv. Chim. Acta, 53, No. 3, pp. 453-464 (in German).

Glemser, O., G. Cattow, and H. Meisiek, 1961, "Darstellung und Eigenschaften von Braunsteinen. 1. (Die $\delta$-Gruppe der Braunsteine)," Z. anorg. allgem. Chem., $\underline{309}$, No. 1 and 2, pp. 1-19 (in German).

Gmelin, 1973a, Handbuch der anorganischen Chemie, 8 Auflage, "Mangan," Teil C1, Springer-Verlag, Berlin, Germany, New York, New York, pp. 126-364 (in German).

Gmelin, 1973b, Handbuch der anorganischen Chemie, 8 Auflage, "Mangan," Teil C2, Springer-Verlag, Berlin, Germany, New York, New York, pp. 64-85 (in German).

Gmelin, 1966, Handbuch der anorganischen Chemie, 8 Auflage, "Sauerstoff," Lief. 7, Springer-Verlag, Berlin, Germany, New York, New York, pp. 2364-2365 (in German).

Gmelin, 1964, Handbuch der anorganishen Chemie, 8 Auflage, "Cobalt," Teil D, Lief. 2, Kobalt(III)-Verbindungen, Springer-Verlag, Berlin, Germany, New York, New York (in German).

Gmelin, 1962a, Handbuch der anorganishen Chemie, 8 Auflage, "Chromium," Teil B, Springer-Verlag, Berlin, Germany, New York, New York, pp. 680-703 (in German).

Gmelin, 1962b, Handbuch der anorganishen Chemie, 8 Auflage, "Chromium," Teil B, Springer-Verlag, Berlin, Germany, New York, New York, pp. 59-79 (in German).

Gmelin, 1936, Handbuch der anorganischen Chemie, 8 Auflage, "Eisen," Teil B1, Springer-Verlag, Berlin, Germany, New York, New York, p. 124 (in German). 
Gurevich, A. M., and L. P. Polozhenskaja, 1961, "Investigation of the Solubility of Uranyl Peroxo Complex Ions $\mathrm{K}_{4}\left[\mathrm{UO}_{2}\left(\mathrm{O}_{2}\right)_{3}\right] \cdot 5 \mathrm{H}_{2} \mathrm{O}$ and $\mathrm{K}_{4}\left[\mathrm{UO}_{2}\left(\mathrm{O}_{2}\right)_{3}\right] \cdot 4 \mathrm{H}_{2} \mathrm{O}_{2} \cdot 4 \mathrm{H}_{2} \mathrm{O}$," Radiokhimiya, 3, No. 3, pp. 316-320 (in Russian). Journal available in English translation as Soviet Radiochemistry (Engl. Translation).

Harmon, H. D., 1994, "Trends in Actinide Processing at Hanford," J. Alloys and Compounds, 213/214, pp. 341-343.

Hlasivcová, N., and J. Novák, 1971, "Über die Reaktion des Permanganats mit Hydroxylamin," Collec. Czech. Chem. Comm., 36, No. 1, pp. 186-194 (in German).

Khain, V. S., V. F. Martynova, and A. A. Volkov, 1988, "Reduction of Chromium(VI) to Chromium(III) with Sodium Borohydride in an Alkaline Medium," Izv. Akad. Nauk SSSR Neorg. Mater., 24, No. 3, pp. $462-465$ (in Russian). Paper available in English translation as Inorganic Materials (English Translation), 24, No. 3, pp. 376-379 (1988).

Kobayashi, J., et al., 1982, "Structure of the Amorphous Oxyhydroxide of Trivalent Iron," Bosejoku Gizjuku, 31, No. 9, pp. 582-590 (in Japanese). Journal available in English translation as Corrosion Engineering. [Chem. Abstr. 99:43930q].

Kozawa, A., T. Kalnoki-Kis, and J. F. Yeager, 1966, "Solubilities of Mn(II) and Mn(III) Ions in Concentrated Alkaline Solutions," J. Electrochem. Soc., 113, No. 5, pp. $405-409$.

Krivoruchenko, J. P., B. P. Zolotovskii, R. A. Bujanov, V. I. Zankovskii, and G. B. Selima, 1977, "Study of the Dependence of Phase Composition and Morphology Structure of $\mathrm{Fe}^{3+}$ Hydrogel Aging Products from the Chemical Composition of the Primary Particles of Initial Precipitates," Kinetika $i$ Kataliz, 18, No. 1, pp. 207-211 (in Russian). Journal available in English translation as Kinetics and Catalysis.

Leont'eva, G. V., and V. V. Vol'khin, 1968, "Sorption Properties of Manganese Dioxide," Izv. Akad. Nauk SSSR Neorg. Mater., 4, No. 5, pp. $728-733$ (in Russian). Journal available in English translation as Inorganic Materials (English Translation). [Chem. Abstr. 69:70099n].

Musikas, C., 1974, "Sur les Peroxydes d'Éléments Transuraniens Pentavalents," J. Chim. Phys., 71, No. 2, pp. 197-202 (in French).

Musikas, C., 1971, "Peroxyde de Plutonium Pentavalent," Radiochem. Radioanal. Lett., 7, No. 6, pp. 375-379 (in French).

Musikas, C., 1970, "Peroxyde de Neptunium (V)," Radiochem. Radioanal. Lett., 4, No. 5-6, pp. $347-349$ (in French). 
Pechenjuk, S. I., and D. L. Rogachev, 1985, "The Oxyhydrates Obtained by the Fast Hydrolysis of Concentrated Solutions of Iron(III) Salts, " Zh. Neorg. Khim., 30 , No. 2, pp. 311-316 (in Russian). Joumal available in English translation as Russian Journal of Inorganic Chemistry (English Translation).

Rai, D., B. M. Sass, and D. A. Moore, 1987, "Chromium(III) Hydrolysis Constants and Solubility of Chromium(III) Hydroxide," Inorg. Chem., 26, No. 3, pp. 345-349.

Reiter, L. G., and V. A. Anan'evskii, 1978, "Study of Hydroxy Complexes of Iron(III) by Solubility," Vestn. Kiev Politekhn. In-ta. Khim. Mashinostr. i Tekhnol., No. 15, pp. 40-43 (in Russian). Journal title translated as Kiev Polytechnical Institute News: Chemical Engineering Industrial Technology. Not available in English translation. [Chem. Abstr. 20:128361u].

Ratner, A. P., A. M. Gurevich, L. D. Preobrazhenskaya, and N. P. Osicheva, 1958, "The Process of Thermal Decomposition and Hydrolysis of $\mathrm{Na}_{4} \mathrm{UO}_{8} \cdot 9 \mathrm{H}_{2} \mathrm{O}$ in Alkaline and Aqueous Solutions at 80 to $99^{\circ} \mathrm{C}$," Trudy Radievogo Inst. im. V. G. Khlopina, 8 , pp. 99-109 (in Russian). Journal title translated as Transactions of the Radium Institute, V. G. Khlopin; journal translation not available in English. [Chem. Abstr. 53:9793a].

Ratner, A. P., A. M. Gurevich, and L. P. Polozhenskaya, 1957, "Solubility of Sodium Peruranate in Water and in Solutions of Electrolytes," Zhur. Neorg. Khim., 2, pp. 2316-2322 (in Russian). Journal available in English translation as Russian Journal of Inorganic Chemistry (English Translation).

Regner, A., V. Ettel, and J. Veprek-Šiška, 1963, "Chemische Herstellung von aktivem Braunstein," Collec. Czech. Chem. Comm., 28, No. 11, pp. 2854-2863 (in German).

Ryabchikov, D. I., and M. M. Senyavin, eds., 1962, Analiticheskaya Khimiya Urana, USSR Academy of Sciences, Moscow, USSR, p. 134 (in Russian). Available in English as Analytical Chemistry of Uranium, 1963, Israel Program for Scientific Translations, Jerusalem, Israel, and Daniel Davey and Co., New York, New York.

Sazou, D., and G. Kokkinidis, 1989, "Electrocatalytic Reduction of Chromate(VI) Ions in Alkaline Media on Pt Modified by Underpotential Deposition of Heavy Metals," J. Electroanal. Chem. Interfac. Electrochem., 1989, 271, No. 1 and 2, pp. 221-231.

Scholder, R., and A. Kolb, 1951, "Über Mangan(II)-hydroxyd und Hydroxomanganat(II)," Z. anorg. allgem. Chem., 264, No. 1-6, pp. 209-216 (in German).

Schwarzenbach, G., and G. Flaschka, 1972, Complexometric Titration, Nauka Publ., Moscow, USSR, (Russian translation from German). Available in English as Complexometric Titrations, 1973, Methuen and Co. Ltd., London, UK. 
Sharlo, G., 1969, Analytical Chemistry Methods, Quantitative Analysis of Inorganic Compounds, Khimiya Publ., Moscow, USSR, p. 11 (in Russian).

Shilov, V., N. N. Krot, S. V. Kryutchkov, A. Yusov, N. Budantseva, A. Garnov, V. Perminov, and L. Astafurova, L. I. Belyaeva, 1996, Investigation of Some Redox Reactions of Neptunium, Plutonium, Americium, and Technetium in Alkaline Media, WHC-EP-0886, Westinghouse Hanford Company, Richland, Washington, USA.

Spicca, L., 1988, "Solubility of Chromium(III) Hydroxides," Inorg. Chem., 27, No. 2, pp. $432-434$.

Sterr, G., and A. Schmier, 1969, "Zur Kenntniss des ' $\gamma$ '-Mangandioxids," Z. anorg. allgem. Chem., 368 , No. 5 and 6, pp. 225-238 (in German).

Tananaev, I. G., 1990, "Forms of Np(V) and Am(V) in Basic Aqueous Media," Radiokhimiya, 32, No. 5, pp. 53-57 (in Russian). Journal available in English translation as Soviet Radiochemistry (Engl. Translation).

Tananaev, I. G., 1994, "Speciation of Neptunium(V) in Solutions of Tetraalkylammonium Hydroxides," Radiokhimiya, 36, No. 1, pp. 15-18 (in Russian). Journal available in English translation as Radiochemistry (Engl. Translation).

Visyascheva, V. A., Yu. F. Volkov, G. A. Simakin, and I. I. Kapshukov, 1984, "Some Hydroxo Complexes of Pentavalent Neptunium, Radiokhimiya, 26, No. 2, pp. 171-176 (in Russian). Journal available in English translation as Soviet Radiochemistry (Engl. Translation).

Walton, R. D., 1979, "Long-term Management of Defense High-level Radioactive Wastes Planes, Policies, and Programs," Am. Inst. Chem. Eng., Symp. Ser., 75, No. 191, pp. 88-92.

Yamamoto, N., M. Horibe, and S. Higashi, 1980, "Formation Diagram of $\delta$-Manganese Dioxide and Its Derivative in Alkaline Solution, in Ferrites, Proc. 3rd ICF, 1980, pp. 443-446 [Chem. Abst., 97, No. 22, 97:192195, (1988)].

Yoneda, H., 1958, "Stability of Cobalt(III) and Chromium(III) Ammine Complexes in a Strongly Alkaline Solution," Bull. Chem. Soc. Japan, 31, No. 1, pp. 74-79. 
WHC-EP-0898

This page intentionally left blank. 


\section{DISTRIBUTION}

Number of Copies

\section{OFFSITE}

7

1

1

3

\section{DOMESTIC}

Argonne National Laboratory

9700 S. Cass Ave.

Argonne, IL 60439

E. P. Horwitz

K. L. Nash

D. T. Reed

M. J. Steindler

D. M. Strachan

J. C. Sullivan

Technical Library

Florida State University

Department of Chemistry, B164

Tallahassee, FL 32306-1096

G. R. Choppin

Lawrence Berkeley National Laboratory

One Cyclotron Road

University of California

Berkeley, CA 94720

Technical Library

Lawrence Livermore National Laboratory

P. O. Box 808

Livermore, CA 94550

Z. Chiba

R. J. Silva

Technical Library 


\section{DISTRIBUTION}

Number of Copies

\section{OFFSITE}

4

7

7

2

4

\section{DOMESTIC}

Los Alamos National Laboratory

P. O. Box 1663

Los Alamos, NM 87545

N. C. Schroeder

MS J514

Z. V. Svitra

L. A. Worl

Technical Library

Oak Ridge National Laboratory

P. O. Box 2008

Oak Ridge, TN 37831

J. T. Bell

MS 6223

W. D. Bond

MS 6385

E. Z. Egan

MS 6223

C. P. McGinnis

L. M. Toth

MS 6268

J. S. Watson

Technical Library

Sandia National Laboratory

P. O. Box 1663

Los Alamos, NM 87545

S. F. Marsh

MS E501

Technical Library

Savannah River Technical Center

P. O. Box 616

Aiken, SC 29808

D. T. Hobbs

D. G. Karraker

M. C. Thompson

Technical Library
773-A

773-H 


\section{DISTRIBUTION}

Number of Copies

OFFSITE

1

1

1

1

\section{OFFSITE}

1

\section{DOMESTIC}

Thomas Albert and Associates. Inc. 34931 U.S. Highway 19 North

Suite 205

Palm Harbor, FL 34684

T. E. Albert

United States Department of Energy 12800 Middlebrook Road

Trevion II Building

Germantown, MD 20874

K. Gerdes

Technical Library

University of Tennessee

Department of Chemistry

Knoxville, TN 37996

J. R. Peterson

W. W. Schulz

720 Montgomery Boulevard

Albuquerque, NM 87109

J. L. Swanson

1318 Cottonwood Drive

Richland, WA 99352

INTERNATIONAL

Institut de Physique Nucléaire

B.P. $\mathbf{N}^{0} 1$

Orsay Cedex, France F-91406

F. David 


\section{DISTRIBUTION}

Number of Copies

\section{OFFSITE}

1

30

\section{INTERNATIONAL}

Forschungszentrum Rossendorf

Institut für Radiochemie

Postfach 510119

Dresden, Germany D-01314

H. Nitsche

Institute of Physical Chemistry

Russian Academy of Sciences

31 Leninsky Prospekt

Moscow, Russia 117915

L. Astafurova

V. I. Belyaeva

A. A. Bessonov

N. Budantseva

I. Charushnikova
A. Garnov
N. N. Krot (10)
S. V. Kryutchkov
V. F. Peretrukhin
V. Perminov
A. K. Pikaev
V. P. Shilov (5)
V. I. Silin
I. G. Tananaev
A. Yusov
E. M. Zakharova
Technical Library 


\section{DISTRIBUTION}

\section{Number of Copies}

ONSITE

1

21
Boeing Computer Services Richland

M. P. Curry

H6-31

Pacific Northwest National Laboratory

D. L. Blanchard

P7-25

G. N. Brown

P7-25

Y. Chen

K2-40

N. G. Colton

$\mathrm{K} 2-40$

S. K. Fadeff

P7-22

K. F. Feigner

B1-11

A. R. Felmy

K9-77

T. A. Fryberger

K2-20

T. E. Jones

K6-51

B. W. Killand

P7-75

W. L. Kuhn

K2-21

D. E. Kurath

P7-20

G. J. Lumetta

P7-25

T. C. Maiti

P7-07

D. Rai

K9-77

L. Rao

K9-77

B. M. Rapko

P7-25

J. L. Ryan

P7-25

D. W. Wester

K7-74

PNNL Technical Files

K1-11

Hanford Technical Library

P8-55

1

SAIC

D. J. Swanberg

$\mathrm{K} 8-50$ 


\section{DISTRIBUTION}

\section{Number of Copies}

\section{ONSITE}

7

United States Department of Energy

Richland Field Office

J. A. Frey

K8-50

J. P. Hanson

$\mathrm{K} 8-50$

J. E. Kinzer

S7-50

C.-K. Liu

A5-52

B. A. Mauss

K8-50

L. S. Waldorf

K5-51

Public Reading Room

Westinghouse Hanford Company

J. N. Appel

G3-21

H. Babad

S7-14

G. S. Barney

T5-12

D. B. Bechtold

T6-09

R. A. Bechtold

K7-22

M. A. Beck

T6-09

J. D. Berger

H6-34

G. T. Berlin

H6-34

T. M. Blaak

S5-13

A. L. Boldt

H5-49

K. D. Boomer

H5-61

S. A. Catlow

T6-30

T. D. Cooper

T5-12

C. H. Delegard (10)

T6-09

F. D. Fisher

T5-12

L. L. Fritts

T6-50

K. A. Gasper

G3-21

G. B. Griffin

T6-16

D. L. Herting

T6-09

B. E. Hey

T6-09

R. C. Hoyt

H5- 49

J. R. Jewett

T6-09

R. A. Kirkbride

H5-27 


\section{DISTRIBUTION}

Number of Copies

QNSITE

Westinghouse Hanford Company (Continued)

M. J. Klem

H5-27

M. J. Kupfer

H5-27

G. T. MacLean

H5-61

J. C. Person

T6-09

W. J. Powell

H5- 49

J. L. Slippern

T6-50

J. P. Sloughter

R2-54

D. J. Washenfelder

H5- 27

Document Processing Center

A3-94

Central Files

A3-88 
WHC-EP-0898

This page intentionally left blank. 